\title{
It Takes Two to Tango: Investigating the Relationship between Ghrelin and Endocannabinoids within the Ventral Tegmental Area with Regards to Feeding
}

\author{
Alexander Edwards \\ A thesis submitted to the Faculty of Graduate and Postdoctoral Affairs \\ in partial fulfillment of the requirements for the degree of \\ Master of Science in Neuroscience
}

Carleton University

Ottawa, ON,

Canada

Copyright@ 2014

Alexander Edwards 


\section{Abstract}

Ghrelin is a hormone that targets the brain to increase food intake and energy balance. Recent evidence suggests that ghrelin increases appetite in part by acting on growth hormone secretagogue receptors (GHSR) in the ventral tegmental area (VTA), a brain region associated with reward seeking behaviors. The ability of ghrelin to induce appetite is reminiscent of the appetite inducing effects of endogenous cannabinoids (CBs). Interestingly, ghrelin's ability to stimulate feeding within the hypothalamus is dependent on a functional CB system within this region. In the present thesis we hypothesized that ghrelin and CB systems work in tandem within the VTA to stimulate feeding. Here we showed that ghrelin significantly increased food intake $(p<.05)$ when directly microinjected into the VTA of rats. Furthermore, we demonstrated that this corresponding increase in food intake depended on a functional endocannabinoid system as peripheral pre-treatment with a selective CB-1 receptor (CB-1R) antagonist (i.e. rimonabant) completely attenuated this increase in food intake to control rat levels. Furthermore, we also demonstrated via reverse transcription quantitative polymerase chain reaction (RT-qPCR) experiments that CB-1R mRNA expression is significantly lower in the VTA but enhanced in the prefrontal cortex (PFC) of GHSR knock-out (GHSR KO) relative to wildtype (WT) rats $(p<.05)$. Together, these data provide evidence that ghrelin targets the VTA to increase food intake through a mechanism that requires a functional endocannabinoid system. 


\section{Acknowledgments}

I would first like to thank Alfonso Abizaid for accepting, teaching, guiding, supporting, and mentoring me while I conducted these experiments and wrote my Master's thesis. I also want to acknowledge the rest of my committee (Hymie Anisman, Owen Rowland, \& Mike Hildebrand) for reading, correcting, and providing advice that ameliorated the quality of this thesis. Likewise, I also want to thank the rest of the Abizaid lab, especially Zachary Patterson \& Harry Mackay, not only for their advice but also for teaching me many of the techniques that I needed to complete this thesis. Moreover, I want to acknowledge Stephanie Rosenbaum as her surgical skills, help, and friendship facilitated the completion of this thesis. I also want to acknowledge the financial support provided by both the Natural Sciences and Engineering Research Council (NSERC) and the Ontario Graduate Scholarship (OGS). Furthermore, I want to thank my friends and family, especially my parents, for all their love and support. Lastly, I want to thank the love of my life, Emilia, as she has shown unconditional support through the good and bad times and has never stopped reminding me that I possess what it takes to be successful. 


\section{Preface}

The following thesis will begin with an introduction briefly highlighting the merit and importance of feeding related neurocircuitry research in combating the "obesity epidemic". It will then transition into a review about what is currently known about the hunger hormone ghrelin, its receptor, and its signalling processes. Ghrelin's well understood role in the modulation of hypothalamic feeding and its recent implications in reward based feeding will also be discussed in detail. Subsequently, the endocannabinoid system's involvement in the modulation of both hypothalamic and mesolimbic dopamine feeding circuits will be investigated. Lastly, the notion that the interaction between ghrelin and endocannabinoid systems is imperative for controlling feeding within the hypothalamus, which led to our working hypothesis that an interaction between ghrelin and endocannabinoid systems is also essential for modulating food intake within the VTA, will both be presented here and supported by data here within. 


\section{List of Abbreviations}

$\Delta^{9}$-THC, $\Delta^{9}$ - tetrahydrocannabinol; 2-AG, 2-arachidonoylglycerol; $\boldsymbol{\alpha}$-MSH, alpha-melanocytestimulating hormone; ACC, acetyl-coenzymeA carboxylase; AEA, anandamide; AgRP, agoutirelated peptide; AMG, amygdala; AMP, adenosine monophosphate; AMPK, adenosine monophosphate activated protein kinase; ANOVA, analysis of variance; ATP, adenosine triphosphate; ARC, arcuate nucleus; $\boldsymbol{\beta}-\mathbf{M S H}$, beta -melanocyte-stimulating hormone; BAPTA, 1,2-bis(o-aminophenoxy) ethane-N, N, N', N'-tetraacetic acid; BMI, body mass index; BOLD, blood oxygen level dependent; CaMKII, $\mathrm{Ca}^{2+} /$ calmodulin-dependent protein kinase II; cAMP, cyclic adenosine monophosphate; CART, cocaine amphetamine regulated transcript; CDNA, complimentary deoxyribonucleic acid CB, cannabinoid; CB-1R, cannabinoid receptor 1; CB-1R KO, CB-1R knockout; CB-2R, cannabinoid receptor 2;CNS, central nervous system; CPP, conditioned place preference; CPT1 $\alpha$, carnitine-palmitoyl-transferase-1 $\alpha$; DEPC, diethylpyrocarbonate; DMH, dorsomedial nucleus; FAAH, fatty acid amid hydrolase; FAS, fatty acid synthase; GABA, gamma-aminobutyric acid; GAPDH, glyceraldehyde 3-phosphate dehydrogenase; GC, gas chromatography; GPCR, G-protein coupled receptors; GHSR, growth hormone secretagogue receptor; GHSR KO, growth hormone secretagogue receptor knockout; GOAT, ghrelin O-acyltransferase; HIP, hippocampus; HYP, hypothalamus; IP, intraperitoneal; LCFA-CoA, long chain fatty acid-coenzymeA; LHA, lateral hypothalamic area; MAGL, monoacylglycerol lipase; $\mathbf{M C}_{3}$, melanocortin-3 receptor; $\mathbf{M C}_{4}$, melanocortin-4 receptor; $\mathbf{m E P S C}$, miniature excitatory post synaptic current; mIPSC, miniature inhibitory post synaptic current; mRNA, messenger ribonucleic acid; NA, nucleus accumbens; NPY, neuropeptide Y; NTS, nucleus of the tractus solitaries; $\mathbf{O X}-\mathbf{1}$, orexin 1 receptor; PAMPK, phosphorylated adenosine monophosphate activated protein kinase; PFA, paraformaldehyde; PFC, prefrontal cortex; PKA, protein kinase A; PNS, peripheral nervous system; POMC, pro-opiomelanocortin; PPT, pedunculopontine nucleus; PVN, paraventricular nucleus; RT-qPCR, reverse transcription quantitative polymerase chain reaction; THL, tetrahydrolipstatin; VMN, ventromedial nucleus; VP, ventral pallidum; VTA, ventral tegmental area; WT, wild-type 


\section{Table of Contents}

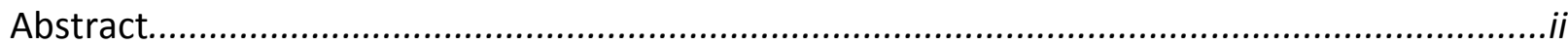

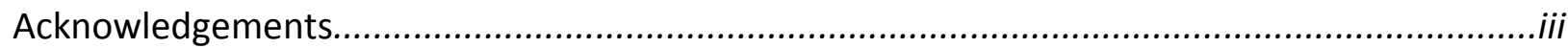

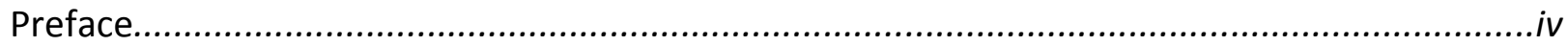

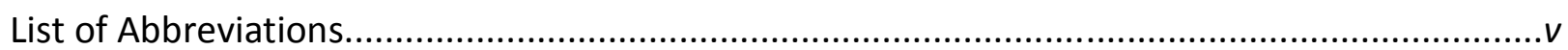

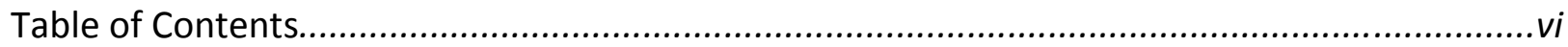

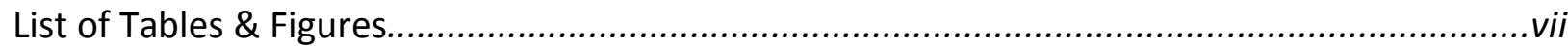

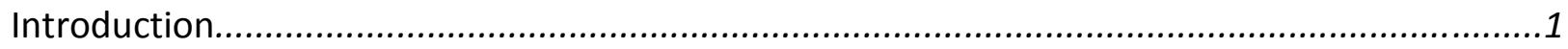

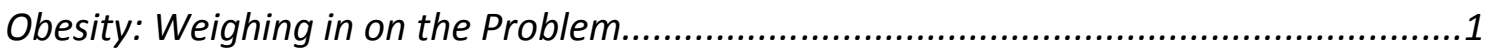

The Need for Tight Regulation of Feeding and Energy Balance.................................2

Ghrelin and its Receptor..............................................................................

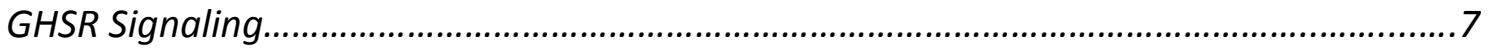

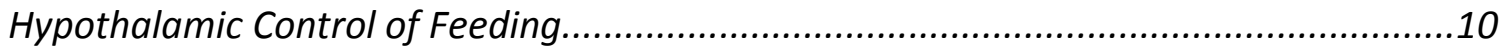

Ghrelin and Reward...............................................................................................13

The Discovery of the Endocannabinoid System .........................................................16

Endocannabinoids- The Retrograde Signalers.........................................................18

Suppression of Transmitter Release and CB-1 Receptor Signalling ..............................20

Endocannabinoids Stimulate Food Intake...........................................................21

Endocannabinoids Important in Food Reward...........................................................22

Interaction of Ghrelinergic and Cannabinoid Systems in the Hypothalamus...................26

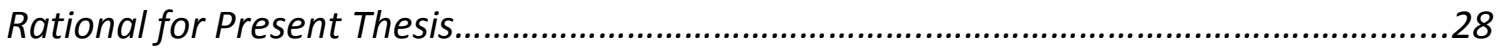

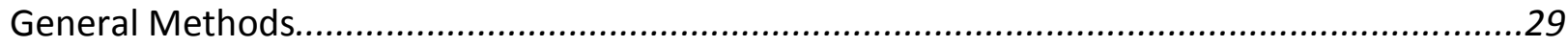

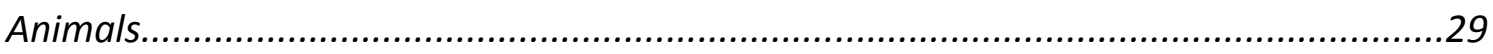

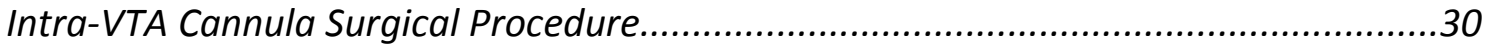

Histological Analysis and Cannula Placement Verification..............................................31

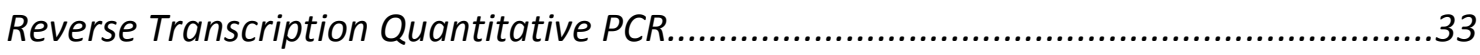

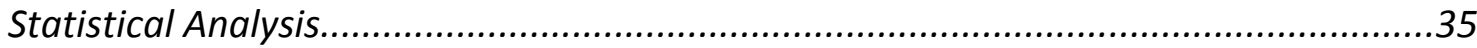

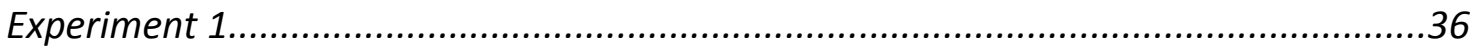

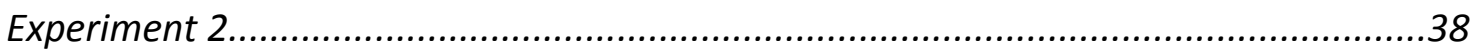

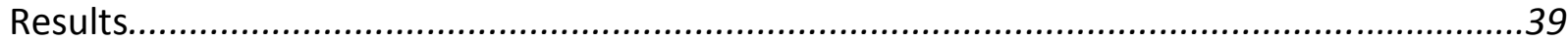

IP Rimonabant Attenuates the Orexigenic Effect of Ghrelin Infused into the VTA........39

Rimonabant's Effects on Food Intake are Independent of Locomotor Activity..............42

Differential CB-1R mRNA Expression in GHSR KO and WT Rats.................................44

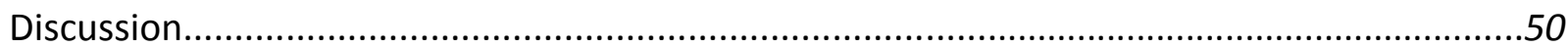

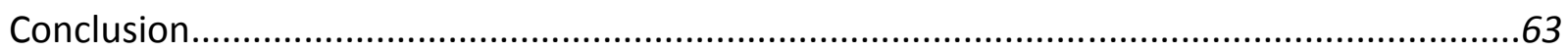

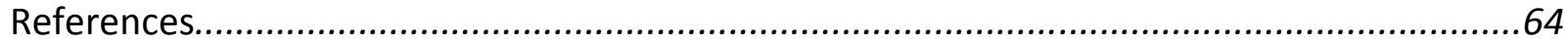




\section{List of Tables \& Figures}

Introduction \& Methods

Table 1: Summary of Well Known Gut Peptide Hormones Implicated in Feeding 3

Figure 1: Impact of Ghrelin, Leptin, \& Cannabinoids on Hypothalamic AMPK activity.....9

Figure 2: Mesolimbic Dopamine System.....................................................................13

Figure 3: Cannula Placement Summary for Experiment 1............................................32

Figure 4: Depiction of Experiment 1 Design............................................................

Experiment 1

Figure 5: Cumulative Food Intake Following IP and Intra-VTA Microinjections................41

Figure 6: Cumulative Ambulatory Activity Following IP and Intra-VTA Microinjections...43

Experiment 2

Figure 7: Relative VTA CB-1R mRNA Expression between GHSR KO \& WT rats...............45

Figure 8: Relative PFC CB-1R mRNA Expression between GHSR KO \& WT rats.................46

Figure 9: Relative HYP CB-1R mRNA Expression between GHSR KO \& WT rats................47

Figure 10: Relative NA CB-1R mRNA Expression between GHSR KO \& WT rats................48

Figure 11: Relative HIP CB-1R mRNA Expression between GHSR KO \& WT rats..............49 Discussion

Figure 12: Rimonabant's Hypothetical Action within the VTA....................................54 


\section{Introduction}

\section{Obesity: Weighing in on the Problem}

Obesity is a major health epidemic that is considered by many to be the leading preventable cause of death worldwide. Alarmingly, its prevalence in developed nations has increased substantially, with obesity rates rising almost 50 percent since the 1980 's. In 2008, almost 1.5 billion adults (over the age of 20 ) were categorized as overweight (i.e. body mass index (BMI) equal or greater than 25), with over 500 million of these adults, surpassing obese qualifications (i.e. BMI equal to or greater than 30). The increased frequency of obese and overweight individuals worldwide reflects a concomitant overindulgence in easily available high energy foods, which are often consumed independent of energy needs, as well as a shift to more sedentary lifestyles. While being overweight or obese has many negative consequences, some of the more distressing associated medical problems include increased incidence of type 2 diabetes, cardiovascular disease, atherosclerosis, hypertension, glucose intolerance, dyslipidemia, and cancer. (World Health Organization, 2013)

The negative repercussions of being overweight or obese are not limited to adverse health complications. These metabolic states also convey a significant financial burden. Estimating the financial costs associated with obesity is difficult as it is hard to delimit what constitutes an obesity or overweight related cost; however, studies conducted in 2008 estimate that obesity expenses in Canada range between $\$ 4.6-\$ 7.1$ billion depending on whether the amalgamated medical costs for 8 or 18 chronic diseases most consistently linked to obesity are used (Public Health Agency of Canada, 2011). Studies conducted in the United States, which base their estimates on direct costs (e.g. health services, laboratory test, medication) as well as 
indirect costs (e.g. lost work/productivity, insurance) have reported that an estimated 210 billion dollars (i.e. $20.6 \%$ of national health expenditures) is spent on obesity related illnesses annually (Cawley \& Meyerhoefer, 2012).

\section{The Need for Tight Regulation of Feeding and Energy Balance}

The complexity and redundancy in neural circuits responsible for the regulation of feeding behaviours and energy balance makes studying the mechanisms responsible for these processes difficult. However, through the identification of the important brain areas (i.e. nuclei), neurons, peptides, and other chemicals that contribute to these processes a comprehensive understanding of how the central nervous system (CNS) and peripheral nervous system (PNS) collaborate to control these processes is feasible. Historically, environmental changes in an organism's life were highly variable and unpredictable (e.g. food, weather, etc.) making the ability to modulate energy metabolism quickly and alter feeding behaviours so as to promote food procurement safely, essential for survival. To achieve this level of control and to ensure that energy demands to fuel cellular and vital homeostatic processes were satisfied, humans and other higher life forms developed an efficient means of communication between peripheral organs and the CNS. Peripheral hormone signals, which are released from many organs (e.g. fat, liver, pancreas, etc.), provide this necessary communication. Among these, gastrointestinal tract peptides have garnered much research interest due to the robust phenotypic and behavioural changes induced when these peptide systems are enhanced or dampened. There are over 20 different gastrointestinal tract peptides that are known to be involved in feeding responses and energy homeostasis (see Table 1 for examples); however, 
ghrelin, will be the predominant hormone discussed in detail in this thesis (please refer to many excellent reviews for detailed descriptions of other peripheral hormones) (Leibowitz \& Wortely, 2004; Patton \& Mistlberger, 2013; Koleva et al., 2013; Suzuki et al., 2012). In general, gastrointestinal hormones act on organs of the PNS as well as important brain areas responsible for modulating feeding and balancing energy demands and surpluses (Murphy \& Bloom, 2006). They are most often released from the gastrointestinal tract or adipose tissue to relay relevant information regarding internal energy states or shortly after food intake to update the brain of incoming nutrients. Once released, these hormones travel through the bloodstream and access their CNS targets via circumventricular organs (i.e. median eminence \& area postrema) that are characterized by extensive vasculature and weak blood brain barrier formation or through vagal afferent mechanisms (Sam et al., 2012). The arcuate nucleus (ARC) of the hypothalamus (HYP) and the nucleus of the tractus solitarius (NTS) (projects to HYP) are two well studied regions where peripheral hormones enter the CNS to elicit their intended responses (Sam et al., 2012).

Table 1: Summary of well known gut peptide hormones implicated in feeding

\begin{tabular}{|c|c|c|c|c|c|}
\hline $\begin{array}{c}\text { Gut Peptide/ } \\
\text { Hormone }\end{array}$ & $\begin{array}{c}\text { Reasons for } \\
\text { Secretion }\end{array}$ & $\begin{array}{c}\text { Major } \\
\text { Site(s) of } \\
\text { Secretion }\end{array}$ & $\begin{array}{c}\text { Main Regions } \\
\text { Involved in } \\
\text { Mediating } \\
\text { Feeding } \\
\text { Response }\end{array}$ & $\begin{array}{c}\text { Effect } \\
\text { on } \\
\text { Food } \\
\text { Intake }\end{array}$ & Other Effects \\
\hline Amylin & $\begin{array}{c}\text { Meal } \\
\text { ingestion }\end{array}$ & $\begin{array}{c}\text { Pancreatic } \\
\text { b cells }\end{array}$ & $\begin{array}{c}\text { Brain } \\
\text { (modulates } \\
\text { activity of the } \\
\text { serotonin, } \\
\text { histamine, \& } \\
\text { dopaminergic } \\
\text { systems) }\end{array}$ & $\downarrow$ & $\begin{array}{c}\downarrow \text { NPY release, } \downarrow \\
\text { adiposity }\end{array}$ \\
\hline Cholecystokinin & $\begin{array}{c}\text { Saturated } \\
\text { fats, long } \\
\text { chain fatty }\end{array}$ & $\begin{array}{c}\text { Small } \\
\text { intestine I } \\
\text { cells and }\end{array}$ & $\begin{array}{c}\text { Hypothalamus } \\
\text { (DMH), } \\
\text { brainstem (NTS }\end{array}$ & $\downarrow$ & $\begin{array}{c}\uparrow \text { PYY release, } \\
\downarrow \text { ghrelin, } \uparrow \\
\text { pancreatic }\end{array}$ \\
\hline
\end{tabular}




\begin{tabular}{|c|c|c|c|c|c|}
\hline & $\begin{array}{c}\text { acids, amino } \\
\text { acids }\end{array}$ & gut $L$ cells & $\begin{array}{c}\text { and } \mathrm{AP}) \text {, } \\
\text { cortex, vagal } \\
\text { afferents, } \\
\text { gastric mucosa }\end{array}$ & & $\begin{array}{l}\text { secretions and } \\
\text { gallbladder bile } \\
\text { salts }\end{array}$ \\
\hline Ghrelin & $\begin{array}{l}\text { Fasted } \\
\text { states }\end{array}$ & $\begin{array}{l}\text { X/A-like } \\
\text { cells of } \\
\text { gastric } \\
\text { oxyntic } \\
\text { mucosa } \\
\text { lining the } \\
\text { stomach }\end{array}$ & $\begin{array}{c}\text { Vagal } \\
\text { afferents, } \\
\text { hypothalamus, } \\
\text { brainstem (AP, } \\
\text { NTS), VTA }\end{array}$ & $\uparrow$ & $\begin{array}{c}\uparrow \text { gastric acid } \\
\text { and pancreatic } \\
\text { secretion, } \uparrow \\
\text { locomotor } \\
\text { activity, } \uparrow \\
\text { growth hormone } \\
\text { secretion }\end{array}$ \\
\hline Glucagon & $\begin{array}{l}\text { Fasted } \\
\text { states, } \\
\text { exercise, } \\
\text { stress }\end{array}$ & $\begin{array}{c}\text { Pancreatic } \\
\alpha \text { cells }\end{array}$ & $\begin{array}{l}\text { Liver, kidney, } \\
\text { adipocytes, } \\
\text { spleen, } \\
\text { pancreas, } \\
\text { heart, gut } \\
\text { adrenals }\end{array}$ & $\downarrow$ & $\begin{array}{c}\text { 个 stress } \\
\text { response, } \uparrow \\
\text { hepatic } \\
\text { glycogenolysis } \\
\text { and } \\
\text { gluconeogenesis, } \\
\uparrow \text { energy } \\
\text { expenditure }\end{array}$ \\
\hline $\begin{array}{c}\text { Glucagon-like } \\
\text { Peptide-1 }\end{array}$ & $\begin{array}{l}\text { Glucose } \\
\text { intake }\end{array}$ & Gut $L$ cells & $\begin{array}{l}\text { Hypothalamus, } \\
\text { brainstem }\end{array}$ & $\downarrow$ & $\begin{array}{c}\uparrow \text { insulin release, } \\
\downarrow \text { blood glucose, } \\
\text { delays gastric } \\
\text { emptying }\end{array}$ \\
\hline Oxyntomodulin & $\begin{array}{l}\text { Caloric } \\
\text { intake }\end{array}$ & Gut $L$ cells & $\begin{array}{l}\text { Hypothalamus } \\
\text { (ARC, PVN, } \\
\text { supraoptic } \\
\text { nucleus) }\end{array}$ & $\downarrow$ & $\begin{array}{c}\uparrow \text { increases } \\
\text { energy } \\
\text { expenditure, } \downarrow \\
\text { gastric secretion } \\
\& \text { delays gastric } \\
\text { emptying }\end{array}$ \\
\hline $\begin{array}{l}\text { Pancreatic } \\
\text { polypeptide }\end{array}$ & $\begin{array}{l}\text { Caloric } \\
\text { intake }\end{array}$ & $\begin{array}{l}\text { Pancreatic } \\
\text { islet PP } \\
\text { cells }\end{array}$ & $\begin{array}{c}\text { Hypothalamus } \\
\text { (ARC, VMH and } \\
\text { PVN) }\end{array}$ & $\downarrow$ & $\begin{array}{c}\text { 个 insulin release, } \\
\text { 个 blood glucose, } \\
\text { delays gastric } \\
\text { emptying, }\end{array}$ \\
\hline $\begin{array}{l}\text { Peptide tyrosine } \\
\text { tyrosine }\end{array}$ & $\begin{array}{l}\text { Caloric } \\
\text { intake } \\
\text { (especially } \\
\text { proteins) }\end{array}$ & Gut $L$ cells & $\begin{array}{c}\text { Hypothalamus } \\
\text { (ARC), } \\
\text { brainstem }\end{array}$ & $\downarrow$ & $\begin{array}{c}\downarrow \text { gastric } \\
\text { emptying, } \downarrow \text { of } \\
\text { jejunal \& colonic } \\
\text { motility, } \downarrow \\
\text { pancreatic } \\
\text { secretions }\end{array}$ \\
\hline
\end{tabular}

- Note that this is not an inclusive list of all gut peptides

- This table was developed with information reviewed in Suzuki et al., 2012 \& Sam et al., 2012 


\section{Ghrelin and its Receptor}

Of all of the peripheral hormones associated with food related behaviours and energy balance (e.g. appetite, feeding, substrate utilization), ghrelin is one of the most intensely studied. Ghrelin is a 28 amino-acid peptide that is secreted primarily by endocrine gastric X/Alike cells of the oxyntic mucosa lining of the stomach (Kojima et al., 1999; Dornonville de la Cour et al., 2001); however, expression has also been reported in the following organs: ovary (Caminos et al., 2003), placenta (Gualillo et al., 2001), testis (Tanaka et al., 2001), small intestine (Date et al., 2000), pancreas (Volante et al., 2002), kidney (Mori et al., 2000), lymphocytes (Hattori et al., 2001), pituitary (Korbonits et al., 2001), and the brain (Lu et al., 2002; Ferrini et al., 2009). Ghrelin is the endogenous ligand of the seven transmembrane Gprotein coupled type 1a growth hormone secretagogue receptor (GHSR) (Howard et al., 1996). This receptor shows constitutive activity and modulates its response to ghrelin by receptor internalization and by altering its transcript expression (Takaya et al., 2001; Camina et al., 2004; Schellekens et al., 2013). Interestingly, ghrelin requires a post-translation transacylation of a medium chain fatty acid (i.e. 6-12C), most commonly an $n$-octanoylation, on the hydroxy group of serine (position 3 of the peptide) for the peptide to be able to bind to GHSR (Bednarek et al., 2000; Gutierrez et al., 2008). The addition of n-octanoyl acid changes the conformation of the ghrelin peptide in such a way as to permit efficient binding of ghrelin to the active site (i.e. binding pocket) of the GHSR (Bednarek et al., 2000). Currently, the acylation of ghrelin is known to be mediated solely by a member of the membrane-bound O-acyltransferases called ghrelin O-acyltransferase (GOAT), as evidenced by the complete lack of acylated ghrelin in GOAT knock out (KO) mice (Gutierrez et al., 2008). Furthermore, because GOAT is the only known enzyme 
able to activate ghrelin, and that GOAT's expression varies with diet and nourishment, it is suggested that changes in GOAT expression may be one of the molecular switches that provides information about nutrient status (e.g. lipids levels) (Kirchner et al., 2009). Surprisingly, less than $20 \%$ of circulating ghrelin is acylated and thus able to bind to GHSRs to elicit ghrelin's known orexigenic effects (Hosoda et al., 2000). It remains a debate whether the rest, which circulates as des-acyl-ghrelin, is a degradation product or a precursor of the active form or whether it binds to a yet uncharacterised receptor to elicit effects (Hosoda et al., 2000, Ferrini et al., 2009). The GHSR is distributed in various locations within the periphery (i.e. adipose tissue, adrenals, gonads, lung, liver, kidney, pancreas, thyroid, arteries, myocardium, \& stomach) and CNS (i.e. HYP, ventral tegmental area (VTA), cerebral cortex, hippocampus (HIP), substantia nigra, raphe nuclei, nodose ganglion, \& dorsal vagal complex) (reviewed in, Ferrini et al., 2009). Not surprisingly, the vast distribution of ghrelin and its receptor allow ghrelin to modulate a variety of different processes such as insulin secretion (Broglio et al., 2003), glucose metabolism (Patel et al., 2006; Sun et al., 2007), anxiety (Asakawa et al., 2001; Schellekens et al., 2012), and reward (Abizaid et al., 2006, Schellekens et al., 2012), in addition to its known role in modulating feeding behaviour (Tschop et al., 2000). Ghrelin is known to stimulate both food intake and body weight gain upon systemic and central administration (Tschop et al., 2000; Wren et al., 2001a; Wren et al., 2001b). Although ghrelin has the capacity to enhance body weight and adiposity in an attempt to manage long term energy balance, a process that in part relies on decreasing lipid oxidation in the periphery, the present thesis focuses primarily on ghrelin's effects on feeding (Tschop et al., 2000; Theander-Carrillo et al., 2006). 


\section{GHSR Signaling}

Understanding the intracellular signaling pathways that are initiated or affected upon ghrelin binding to its receptor (i.e. GHSR), which elicit changes in feeding behavior and energy homeostasis, is of paramount importance, especially when attempting to comprehend the major players, pathways, and corresponding interactions (i.e. indirect or direct) that contribute to these physiological changes. Several signaling pathways have been shown to be activated upon ghrelin binding to its receptor; however, it is important to note that many of the studies that have contributed to the elucidation of these pathways have used a variety of unique cell types and/or tissues. These pathways include the phospholipase C signaling pathway (elucidated in rat pituitary cells) (Chen, 2000), the protein kinase A (PKA) pathway (discovered in neuropeptide Y (NPY) producing neurons of the arcuate nucleus) (Kohno et al., 2003), and the cyclic adenosine monophosphate (CAMP) element binding protein (CREB) pathway (revealed in transfected COS-7 \& human embryonic kidney 293 cells) (Holst et al., 2003); although, one of the best understood is the adenosine mono-phosphate activated protein kinase (AMPK) pathway (Andersson et al., 2004; Kola et al., 2005). This pathway has gained considerable support following several western blot and AMPK assay studies which methodically identified important enzymes involved in mediating ghrelin's orexigenic response within dissected hypothalami (refer to Figure 1) (Andersson et al., 2004; Kola et al., 2005; Kola et al., 2008). Interestingly, within the HYP, neurons use the quantity of cytoplasmic long chain fatty acid-coenzymeA (LCFA-CoA) molecules as an indicator of energy stores (Hardie \& Carling, 1997; Andersson et al., 2004; Kola et al., 2005; Lopez et al., 2008). An accumulation of these molecules within the cytoplasm represents a positive energy balance while low levels signify a 
negative energy balance (i.e. high AMP/ATP ratio) (Hardie \& Carling, 1997; Andersson et al., 2004). These LCFAs are quickly converted to LCFA-CoAs following entry into the cell by an enzyme called fatty acid synthase (FAS) before they are subsequently shuttled into the mitochondria by carnitine-palmitoyl-transferase-1 $\alpha($ CPT1 $\alpha)$ to aid in the generation of ATP through $\beta$-oxidation processes (Obici et al., 2002; Obici et al., 2003). The CPT1 $\alpha$ mitochondrial shuttling enzyme is allosterically inhibited by malonyl-Co-A, which is produced when a carboxyl group is transferred onto acetyl-CoA via acetyl-coenzymeA carboxylase (ACC) (Ha et al., 1998; McGarry et al., 1978). According to several reports, when ghrelin binds to its endogenous receptor within hypothalamic regions, AMPK is activated (Andersson et al., 2004; Kola et al., 2005; Kola et al., 2008; Lim et al., 2013). Although the exact mechanism in which ghrelin activates AMPK within the HYP is unknown, it is speculated that $\mathrm{Ca}^{2+} /$ calmodulin-dependent protein kinase II (CaMKII) may be activated by increased intracellular $\mathrm{Ca}^{2+}$ that accompanies GHSR activation (Kola, 2008). Once activated, CaMKII is thought to phosphorylate AMPK at its corresponding theronine activation site (Kola, 2008). Following AMPK phosphorylation, pAMPK (phosphorylated AMPK) initiates 2 separate processes that lower cytoplasmic LCFA-CoA, which ultimately result in the stimulation of food intake (Andersson et al., 2004; Kola et al., 2005; Kola et al., 2008; Lim et al., 2013). First, activated AMPK (pAMPK) phosphorylates and inhibits ACC, mitigating the conversion of acetyl-CoA to malonyl-CoA, effectively disinhibiting CPT1 $\alpha$ (Kola et al., 2005; Andersson et al., 2004). In response, this enzyme shuttles cytoplasmic LCFA-CoA molecules into the mitochondria for $\beta$-oxidation thus reducing the cytoplasmic levels of LCFACoA (Obici et al., 2003). This reduction in cytoplasmic levels of LCFA-CoA serves as a starved energy depleted signal consequently leading to the stimulation of food intake to replenish 
energy stores (Obici et al., 2002; Obici et al., 2003). Second, activated pAMPK also inhibits FAS, thereby preventing the transfer of CoA from malonyl-CoA to LCFA (Lopez et al., 2008). This further contributes to the promotion of food intake by preventing the replenishment of cytoplasmic LCFA-CoA levels (Lopez et al., 2008). In contrast, it is important to note that although it is highly supported that ghrelin's orexigenic effects are in part mediated by the activation of AMPK signaling cascades within the hypothalamus; this is not always the case. Increases in food intake caused by high ghrelin levels, enhanced endogenously (by fasting) and by external administration, have been observed in mice without increases in AMPK activity or phosphorylation of its downstream targets (Verhulst et al., 2012).

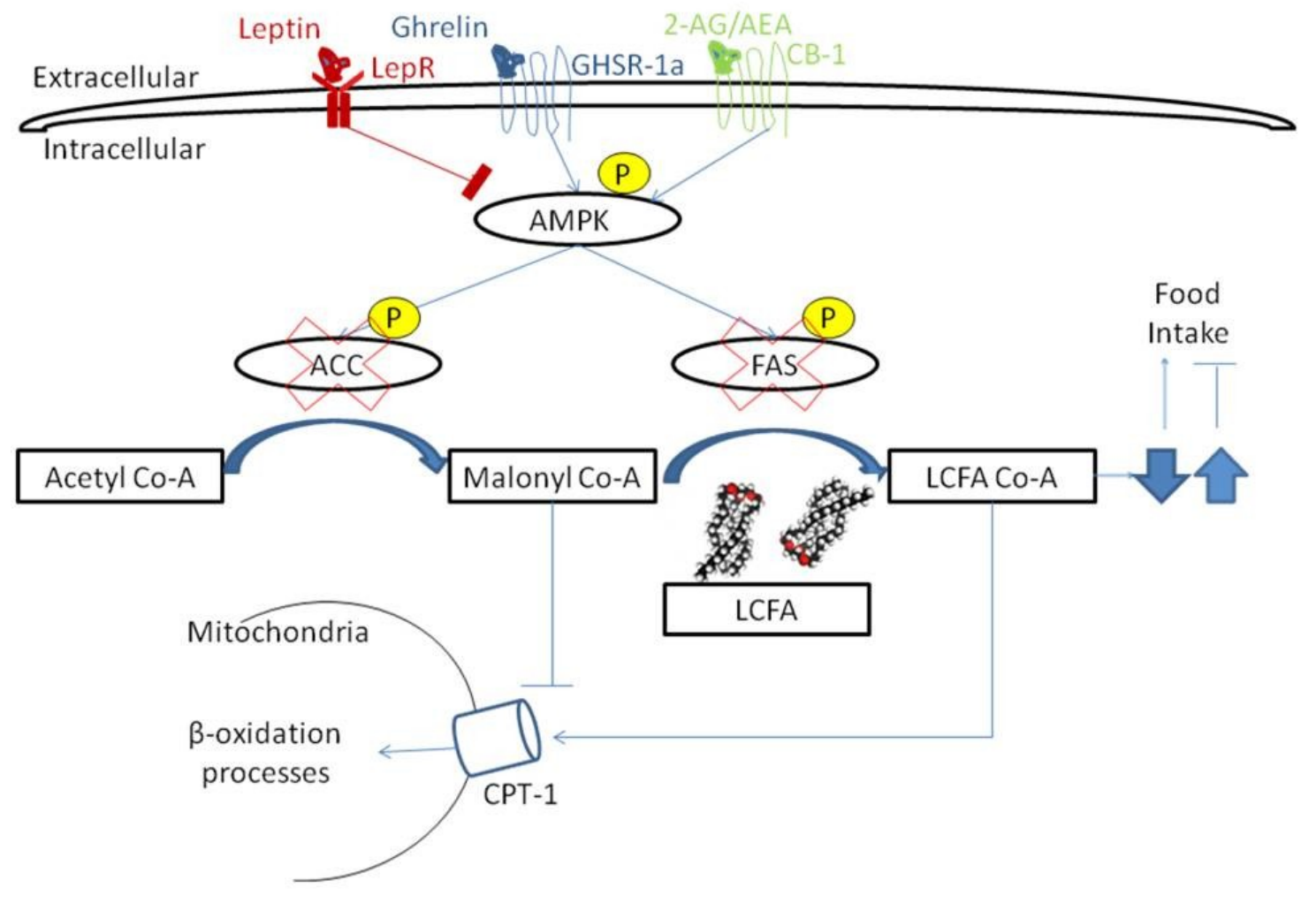

Figure 1: Hypothetical interactions of ghrelin, leptin, and cannabinoids on hypothalamic AMPK activity. Note that both GHSR-1a and CB-1 receptor activation, possibly by heterodimerization, leads to activation of AMPK and the overall stimulation of food intake; whereas, leptin inhibits AMPK activity to reduce food intake. 
In contrast, ghrelin is known to inhibit AMPK activity in peripheral tissues such as the liver, skeletal muscles and adipose tissue, leading to decreased glucose uptake and fatty acid oxidation and the promotion of fatty acid synthesis (Kola et al., 2005; Hardie \& Sakamoto, 2006). This is consistent with the observation that ghrelin promotes adiposity by promoting carbohydrate utilization over fat (Tshop et al., 2000). Ultimately, is seems as if the AMPK pathway is intimately involved in mediating energy homeostasis and feeding behaviors since fluctuations in AMPK activity and associated downstream enzymes reflect changes in energy status and are influenced by peripheral hormone levels such as ghrelin (Andersson et al., 2004, Minokoshi et al., 2002; Minokoshi et al., 2004).

\section{Hypothalamic Control of Feeding}

The HYP, which consists of distinct nuclei such as the paraventricular nucleus (PVN), lateral hypothalamic area (LHA), dorsomedial nucleus (DMH), ventromedial nucleus (VMN), and the ARC, is the most extensively studied and important brain region involved in coordinating the regulation of homeostatic food intake and maintenance of energy homeostasis. It integrates information, collected both centrally and from the periphery (e.g. peripheral hormones), regarding energy status and stores and initiates appropriate mechanisms and behaviours to restore homeostasis (i.e. feeding or substrate utilization) (reviewed in, Abizaid \& Horvath, 2008). This thesis' primary focus is to elucidate what drives non-hypothalamic feeding with an overall emphasis on how ghrelin and endocannabinoids interact to modulate feeding behaviours within the mesolimbic dopamine circuit. Although all regions of the HYP contribute to the regulation of homeostatic feeding and energy balance, as exemplified by the extreme 
changes in phenotype (PVN, VHM, DMH- hyperphagic \& obese; LHA- hypophagic \& lean) caused by lesion studies which target other hypothalamic nuclei, the contributions of ghrelin to promoting food intake in the ARC is only briefly outlined below (Brobeck et al., 1943; Hetherington \& Ranson, 1940; Hetherington, 1944; Anand \& Brobeck, 1951). Details concerning the identity and location of cell types, neuropeptides, innervations, projections, and behavioural studies associated with the aforementioned hypothalamic nuclei can be found in some excellent recent reviews (Abizaid \& Horvath, 2008; Leibowitz \& Wortely, 2004; Gao \& Horvath, 2007; Lenard \& Berthoud, 2008; Sanchez-Lasheras et al., 2010).

Within the ARC, two main opposing cell types modulate feeding behaviours in response to endogenous signalling, neuropeptide Y/agouti-related peptide/gamma-aminobutyric acid (NPY/AgRP/GABA) neurons, which promote appetite when activated, and proopiomelanocortin/cocaine amphetamine regulated transcript (POMC/CART) neurons, which encourage satiety when activated (Boston et al., 1997; Hahn et al., 1998; Ellacott \& Cone, 2004). Ghrelin`s orexigenic ability is driven in part by its capacity to increase the activity of NPY/AgRP/GABA neurons directly (Cowley et al., 2003) as well as indirectly by increasing the number of excitatory synapses that contact these neurons (Horvath, 2006). In contrast, ghrelin has the opposite effects on POMC neurons, encouraging decreased excitatory inputs onto them in addition to promoting the activity of GABA inhibitory synapses onto these satiety promoting neurons (Cowley et al., 2003; Horvath, 2006; Dietrich \& Horvath, 2013). During times of energy deficiency (i.e. fasted state) circulating ghrelin levels are elevated leading to the activation of NPY/AgRP/GABA neurons and the suppression of POMC/CART neurons (Abizaid \& Horvath, 2008). Once activated the NPY/AgRP/GABA neurons stimulate feeding through 
multiple mechanisms. First, NPY/AgRP/GABA neurons transcribe and release AgRP, which is known to antagonize the binding of alpha-melanocyte-stimulating hormone ( $\alpha-\mathrm{MSH})$ and $\beta$ $\mathrm{MSH}$ (produced by POMC/CART neurons) at melanocortin receptors $\left(\mathrm{MC}_{3} \& \mathrm{MC}_{4}\right)$ located in the PVN, LH, and DMH (dampens anorectic outputs from these regions) (Adan et al., 1994;

Mountjoy et al., 1994; Sahm et al.,1994; Ollmann et al., 1997; Biebermann et al., 2006; Aponte et al., 2011). Likewise, NPY/AgRP/GABA neuron activation results in the release of orexigenic NPY from projections that exist in multiple hypothalamic nuclei such as the PVN, VMH, and LH (Stanley \&Leibowitz, 1984; Mountjoy et al., 1994; Sahm et al., 1994; Baskin et al., 1999; Goa \& Horvath 2007; Abizaid \& Horvath, 2008). The release of NPY initiates behaviours favouring food procurement and feeding (Abizaid \& Horvath, 2008). Lastly, NPY/AgRP/GABA neurons project unidirectional GABA inhibitory synapses onto neighbouring POMC/CART neurons within the $A R C$ to reduce the activity of these neurons and effectively promote feeding responses (Cowley et al., 2001, Tong et al., 2008). These effects are reversed during a meal as nutrients and hormone satiety signals rise (Dietrich \& Horvath, 2013). Eventually this leads to POMC/CART neurons becoming less inhibited by GABA inhibitory synapses of NPY/AgRP/GABA neurons and their secreted anorectic peptides (i.e. $\alpha-\mathrm{MSH}$ and $\beta-\mathrm{MSH}$ ) are less inhibited by AgRP at melanocortin receptors in target regions (e.g. PVN, LH, DMH, etc.) (Abizaid \& Horvath, 2008). Ultimately, increased production of $\alpha-\mathrm{MSH}, \beta-\mathrm{MSH}$, and CART from POMC neurons and decreased NPY/AgRP/GABAergic tone results in an overall suppression of orexigenic pathways and the promotion of feelings of satiety (Abizaid \& Horvath, 2008). 


\section{Ghrelin and Reward:}

The ability of ghrelin to stimulate food intake is not solely driven by its action within the aforementioned hypothalamic nuclei. Recently, it has been demonstrated that ghrelin plays an important role in the hedonic aspect of feeding behaviours and contributes to the induction of motivational behaviours that stimulate food intake, especially that of palatable foods (reviewed in Abizaid, 2009; Perello \& Zigman, 2012; van Zessen et al., 2012). These studies, in addition to the location and high levels of GHSR-1a transcript highlighted throughout the mesolimbic dopamine system, which consist of dopaminergic neurons in the VTA and their corresponding neural projections to cortico-limbic structures such as the nucleus accumbens (NA), PFC, HIP, and the amygdala (AMG), have identified the mesolimbic dopamine system as a prime candidate for mediating ghrelin's extra-hypothalamic effects (see Figure 2) (Guan et al., 1997; Saper et al., 2002; Zigman et al., 2006; Field et al., 2007).

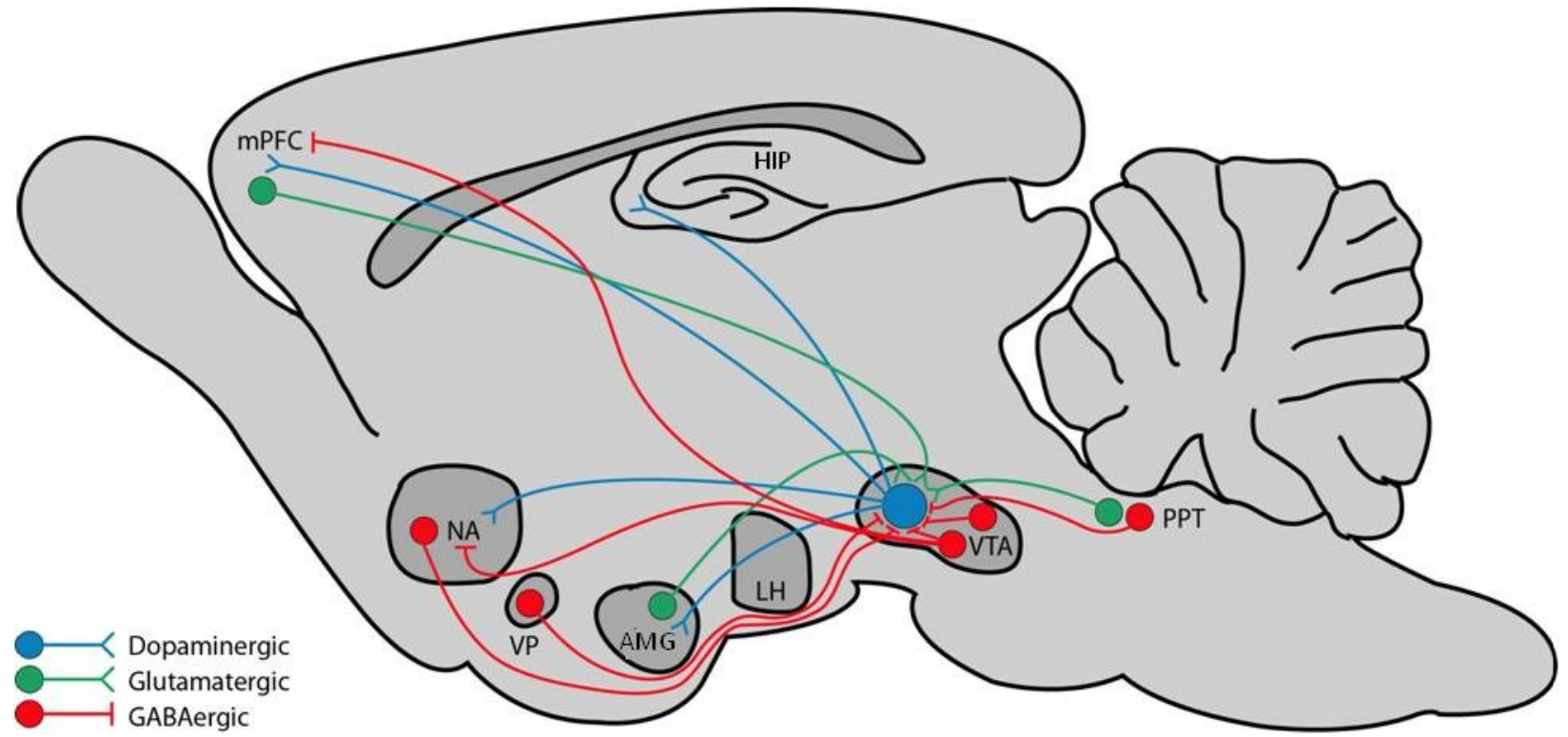

Figure 2: Over-simplified depiction of the mesolimbic dopamine system in a rat brain. Note that many connections are omitted for simplicity. AMG, amygdala; HIP, hippocampus; LH, lateral hypothalamus; mPFC, medial prefrontal cortex; NA, nucleus accumbens; PPT, pedunculopontine nucleus; VP, ventral pallidum; VTA, ventral tegmental area. 
Interestingly, ghrelin seems to modify food preference in rodents, as rats will choose a high-fat diet over a carbohydrate rich diet following intracerebroventricular injection of ghrelin; while, peripheral ghrelin causes a preferred selection of sweet sugar solution in wild-type (WT) but not GHSR KO mice (Shimbara et al., 2004; Disse et al., 2010). Furthermore, disruption of the ghrelinergic system (using GHSR-KO mice or ghrelin receptor antagonists) causes a significant decrease in the consumption of palatable foods but not necessarily regular chow compared to controls (Egecioglu et al., 2010; Landgren et al., 2011).

Moreover, the involvement of the ghrelin system in reward based feeding behavior is exemplified in conditioned place preference (CPP) and operant conditioning tests that use food rewards. The development of CPP for rewarding foods (high fat diet or chocolate) over less rewarding conditions (i.e. standard chow or no reward) has been observed with both the administration of ghrelin and stress induced endogenous increases of ghrelin (Perello et al., 2010; Chuang et al., 2011). Conversely, studies run using GHSR antagonists or GHSR KO rodents demonstrate the inability of rodents to acquire CPP for rewarding foods (Perello et al., 2010; Chuang et al., 2011). Additionally, rodents treated with peripheral ghrelin increase the number of times they will bar press for palatable rewards over vehicle treated animals, whereas, administration of a GHSR antagonist has the opposite effect (Perello et al., 2010; Finger et al., 2012).

Research focused on elucidating the neural circuits mediating ghrelin's influence on reward based feeding behaviours has primarily focused on the mesolimbic dopamine system, particularly the VTA. This is primarily due to the high expression of GHSR within the VTA and the fact that dopamine neurons that originate within this region are known to project to and 
modulate the activity of numerous cortico-limbic areas (refer to Figure 2) (Saper et al., 2002; Abizaid et al., 2006). Abizaid and colleagues demonstrated that ghrelin was able to activate dopaminergic neurons within the VTA by binding to GHSR located on these neurons and by enhancing the ratio of excitatory versus inhibitory synapses contacting these neurons (Abizaid et al., 2006). Consequently, this stimulated an increase in dopamine turnover within the NA (Abizaid et al., 2006). Moreover, they discovered that ghrelin increased the activity of these dopamine cells within WT but not GHSR KO mice (Abizaid et al., 2006). They complimented their molecular and electrophysiological data with behavioural studies showing that intra-VTA ghrelin infusions increased feeding (Abizaid et al., 2006). Furthermore, they showed that intraVTA infusion of a GHSR antagonist suppressed the appetite inducing ability of peripherally administered ghrelin as well as endogenously high ghrelin relative to controls (Abizaid et al., 2006).

Following the above study a series of behavioural experiments were conducted to examine the feeding effects of ghrelin within the VTA. King and colleagues found that chronic intra-VTA administration of ghrelin stimulates a sustained enhancement in food intake that increases dose dependently (King et al., 2012). Interestingly, they found that intra-VTA infusions of a GHSR antagonist selectively decreased the intake of a high fat diet but not the intake of protein or carbohydrate rich diets (i.e. when all diets were freely available) (King et al., 2012). Additionally, they reported that chronic administration of ghrelin within the VTA significantly increased while chronic infusions of GHSR antagonist reduced the amount of work non-fasted rats were willing to expend to earn a chocolate pellet (fixed-ratio paradigm) (King et al., 2012). Consistent with this, animals with VTA lesions eat less palatable food but not regular 
chow when ghrelin is administered peripherally (Egecioglu et al., 2010). Furthermore, these lesioned animals are less motivated to search for food when ghrelin is centrally administered than corresponding controls (Egecioglu et al., 2010). When a progressive ratio paradigm is used, where rats are required to press a lever more times with each given reward, intra-VTA ghrelin is shown to increase the breakpoint (number of presses within certain time frame); whereas, this effect is attenuated following VTA dopamine neuron specific lesions (Weinburg et al., 2011). Similarly, peripheral ghrelin injections in Cre-Lox transgenic mice, which only express normal levels of GHSR in dopamine neurons (i.e. TH-containing neurons), such as those found in the VTA, partially rescues the increase in food intake and development of CPP for a high fat diet that is seen when ghrelin is peripherally administered in WT mice (i.e. significantly higher than that seen in GHSR KO mice) (Chuang et al., 2011).

Interestingly, it has also been demonstrated that intravenously administered ghrelin activates these regions in humans, as evidenced by increased neuronal responses from mesolimbic areas, detected using functional magnetic resonance imaging, when volunteers are shown pictures of food (Malik et al., 2008).

Overall, these experiments lend evidence to the important role that the ghrelin system plays in hedonic feeding within the mesolimbic dopamine system.

\section{The Discovery of the Endocannabinoid System}

Cannabis sativa has been used medicinally for thousands of years to treat rheumatic and menstrual pain; however, its appetite inducing effects were only discovered a couple of centuries ago (Di Marzo, 2006). Interestingly, $\Delta^{9}$-tetrahydrocannabinol $\left(\Delta^{9}\right.$-THC), the chemical 
responsible for a majority of the psychoactive properties of marijuana, was discovered to be the component of Cannabis sativa that causes appetite stimulation (Gaoni \& Mechoulam, 1964). The first endogenous receptor for $\Delta^{9}$-THC (i.e. cannabinoid receptor 1 ) was discovered and cloned almost 30 years after $\Delta^{9}$-THC's chemical characterization using $\Delta^{9}$-THC labelled analogues (i.e. HU-210) and screening banks of orphan G-protein-coupled receptors (GCPRs) (Devane et al., 1988; Matsuda et al., 1990). Shortly after a second seven transmembrane G protein-coupled receptor was cloned (i.e. CB-2 receptor) that also bound to $\Delta^{9}$-THC and other endogenous compounds (Munro et al., 1993; Di Marzo et al., 1995). These endogenous compounds, which share an affinity for the CB receptors, are collectively termed endocannabinoids and are all derivatives (i.e. amides, ethers, \& esters) of long chain polyunsaturated fatty acids (Di Marzo et al., 2004). It is important to note that CB-1Rs, which are found predominantly in the CNS, are the most abundant known GPCR in the brain; whereas, CB-2Rs, are more commonly found in the periphery (e.g. spleen, thymus, tonsils, pancreas, etc.) and on immune cells (Herkenham et al., 1991; Howlett, 2002). Consistent with the widespread expression of CB receptors, the endocannabinoid system is associated with various physiological processes such as neural development, immune functioning, synaptic plasticity, learning, pain, emotional states, motivation, and reward (reviewed in Viveros et al., 2008). However, its role in feeding will be the focus in the present thesis following a brief introduction of the important aspects of the endocannabinoid system. 


\section{Endocannabinoids - The Retrograde Signalers}

The arachidonic acid derivatives anandamide ( $N$-arachidonoylethanolamine) (AEA) and 2-arachidonoylglycerol (2-AG) were the first two endocannabinoids discovered and remain the two most widely studied (Devane et al., 1992; Sugiura et al., 1995). Within the CNS, these two endocannabinoids are reported to be synthesized on demand from lipids of the post-synaptic neuronal membrane in response to intracellular increases in $\mathrm{Ca}^{2+}$ (Di Marzo et al., 2004). Concomitant increases in cyclic AMP and intracellular $\mathrm{Ca}^{2+}$ that occur as a result of neuronal activation stimulate the enzymes necessary for the "de novo" synthesis of AEA and 2-AG (Di Marzo et al., 2004). Generally, these endocannabinoids are thought to diffuse across the synaptic cleft from the activated post-synaptic neuron where they are synthesized to the presynaptic neuron where they bind membrane bound CB-1Rs to suppress neurotransmitter release (Alger, 2002). This model of cannabinoid action is supported by substantial electrophysiological and biochemical studies that were conducted with both acute brain slices and cultured neurons. First, CB-1Rs are predominantly localized to pre-synaptic terminals; whereas, the enzymes that are required for the formation of 2-AG and AEA are located primarily in post-synaptic neurons (Kano et al., 2009). Second, following post-synaptic neuron stimulation, neurotransmitter release from pre-synaptic cells is reduced when cannabinoid agonists (e.g. WIN55, 212-2) bath the slices; whereas, pre-treatment with synthetic cannabinoid antagonists (e.g. SR141716A) prevent inhibition of neurotransmitter release from pre-synaptic terminals (Ohno-Shosaku et al., 2001). Third, Wilson and Nicole demonstrated that liberating calcium stores within a post-synaptic cell via photolysis is sufficient to induce endocannabinoid signalling and prevent neurotransmitter release from pre-synaptic neurons; whereas, inhibiting 
calcium release blocks this inhibition (Wilson \& Nicole, 2001). Lastly, the lipophilic nature of endocannabinoids and the inability of botulinum toxin to block endocannabinoid inhibition of neurotransmitter release support a role for a vesicle independent diffusion of endocannabinoids across the synaptic cleft to elicit their effects (Wilson \& Nicole, 2001).

Mechanisms exist to clear (transport) and recycle (degrade) left over endocannabinoids from the extracellular space following their retrograde release and stimulation of pre-synaptic CB-1Rs. Although this process is not extremely well understood, it is thought AEA does one of three things to get into post-synaptic neurons where the degradative enzyme that can break it down mostly reside (Di Marzo et al., 2004). Research suggests that AEA's transport across the cell membrane is either mediated via a carrier protein (Fegley et al., 2004), through endocytotic mechanisms (McFarland et al., 2004) or by passive diffusion (Glaser et al., 2003). Less is known about how 2-AG is cleared from the extracellular space but some hypothesize that it may share the same system or mechanism that AEA uses (Beltramo \& Piomelli, 2000; Beltramo et al., 1997). In contrast, there is also evidence supporting that 2-AG must have its own transporter or passively diffuse across the neuronal membrane as monoacylglycerol (MAGL), the enzyme that is mostly responsible for its degradation, is found predominantly in the pre-synaptic neuron (Gulyas et al., 2004). Proceeding entry into the cell these endocannabinoids are broken down by both hydrolysis and oxidation processes (Vandevoorde \& Lambert, 2007). AEA is hydrolyzed by an enzyme called fatty acid amid hydrolase (FAAH), whereas, 2-AG is hydrolyzed by MAGL (Vandevoorde \& Lambert, 2007). Furthermore, cyclooxygenase and lipoxygenase enzymes facilitate the oxidization of 2-AG and AEA at their corresponding arachidonic acid groups (Vandevoorde \& Lambert, 2007). 


\section{Suppression of Transmitter Release and CB-1R Signalling}

Activation of CB-1Rs has been reported to cause a multitude of intracellular changes that contribute to the known neurotransmitter release inhibition seen in glutamate, GABA, dopamine, serotonin, acetylcholine, norepinephrine, glycine, and cholecystokinin neurons (reviewed in, Kano et al., 2009). Most of these processes rely on CB-1R associated $G_{i / o}$ family of G proteins as supported by studies that show disinhibition of neurotransmitter release when CB-1Rs are activated by CB-1R agonists in the presence of pertussis toxin (i.e. inactivates $\mathrm{G}_{i}$ and $G_{o} G$ - proteins) (Pertwee, 1997). However, its interaction with $G_{s}$ has also been observed in pertussis toxin treated conditions (Pertwee, 1997). Traditionally, one of the most frequently reported intracellular events initiated upon CB-1R activation is the inhibition of adenylyl cyclase (Demuth \& Molleman, 2006). This inhibition leads to a corresponding drop in cAMP levels and a consequential decrease in PKA activity; however, recent studies show that CB-1R activation can lead to the inhibition or activation of adenylyl cyclase depending on which of the 6 isoforms is present in the tissue or cell culture studied (Demuth \& Molleman, 2006). In general, CB-1R stimulation leads to the activation of A-type and inwardly rectifying potassium channels while inhibiting N- , L-, and P/Q type calcium channels (Kano et al., 2009). Interestingly, there is also evidence that more direct effects on vesicle release machinery may contribute to the inhibition of neurotransmitter release as tetrodotoxin (i.e. blocks voltage gated Na channels) studies have reported lower frequencies of miniature excitatory post synaptic currents (mEPSC) and miniature inhibitory post synaptic currents (mIPSC) when CB-1 agonists are applied to neuronal slices (Schllcker \& Kathmann, 2001). In addition, CB-1R activation leads to the initiation of many pathways such as mitogen-activated protein kinase (MAPK) and phosphatidylinositol 3- 
kinase (PI3K) signalling cascades (Kano et al., 2009). Moreover, CB-1R activation is known to increase AMPK activity in the HYP but decrease its activity in fat tissue and liver as seen with GHSR activation (see Figure 1) (Lim et al., 2013). There have been a vast amount of studies that have been conducted on diverse tissues and cultures in an attempt to identify what pathway is responsible for inhibiting neurotransmitter release; however, it seems that a combination of pathways contribute to endocannabinoid inhibition of neurotransmitter release and that this inhibition may be achieved through different mechanisms depending on the cell types and conditions used (Demuth \& Molleman, 2006).

\section{Endocannabinoids Stimulate Food Intake}

Although significant anecdotal evidence on the appetite inducing effects of marijuana had accumulated by the late 1900 's, it was the discovery that $\Delta^{9}$-THC and other endogenously found compounds bound to the same CB-1Rs to induce these hyperphagic behaviours that led to an explosion in empirical cannabinoid research (Gaoni \& Mechoulam, 1964; Devane et al., 1988; Matsuda et al., 1990; Munro et al., 1993; Di Marzo et al., 1995). Interestingly, synthetic compounds that bind to CB-1Rs are still taken advantage of in modern medicine to attenuate feelings of nausea, stimulate food intake, and mitigate weight loss in cancer and AIDS patients (Di Marzo, \& Matias, 2005). A plethora of reputable biochemical, genetic, and behavioural studies investigating feeding behaviours lend support to the important role that the endocannabinoid system plays in modulating feeding. First, the peripheral administration of $\Delta^{9}$ THC, 2-AG, and AEA are known to stimulate food intake and enhance feeding behaviours in rodents (Di Marzo et al., 1998; Williams \& Kirkham, 1999; Williams \& Kirkham, 2002a; Kirkham 
et al., 2002; Hao et al., 2000). Second, administration of endocannabinoids or synthetic agonists of the CB-1R within important feeding centers (e.g. HYP, NA) similarly encourages an increase in food intake (Jamshidi \& Taylor, 2001; Kirkham et al., 2002; Miller et al., 2004). In contrast, pretreatment of rodents with a CB-1R antagonist (e.g. rimonabant) blocks both the systemic and central appetite stimulating effects of CB-1R agonists thus confirming that the increases in food intake observed are mediated specifically through CB-1Rs (Rinaldi-Carmona et al., 1994; Williams \& Kirkham, 1999; Williams \& Kirkham, 2002b). Moreover, peripheral injections of rimonabant can also independently cause a marked reduction in sucrose intake in rats (Arnone et al., 1997). Third, mice lacking functional CB-1Rs are known to have reduced re-feeding following a 24 hour fast compared to controls (Di Marzo et al., 2001). Likewise, CB-1R deficient mice do not decrease their food intake when rimonabant is administered intraperitoneally; whereas, controls demonstrate significantly decreased food intake (Di Marzo et al., 2001).

\section{Endocannabinoids Important in Food Reward}

Early studies report that CB-1R antagonists preferentially reduce the intake of palatable foods over regular chow in WT rodents, while cannabinoid receptor deficient mice also demonstrate decreased consumption of palatable foods relative to controls (Arnone et al., 1997; Simiand et al., 1998; Poncelet et al., 2003). In rats, it has been shown that central administration of CB-1R agonists (2-AG, AEA, $\Delta^{9}-\mathrm{THC}$ ) increases the number of licks for a $10 \%$ sucrose solution; whereas, rimonabant decreases the number of licks compared to controls (i.e. water) (Higgs et al., 2003). A more in depth analysis of the licking microstructure suggests that the licks of the CB-1R agonist treated animals' mimic licks observed when more palatable 
solutions are consumed; whereas, those treated with rimonabant licked as if the solution was less palatable (Higgs et al., 2003). Studies looking at hedonic responses, scored by monitoring innate ingestive responses to aversive (quinine) and rewarding foods (sucrose pellets) found that $C B-1 R$ agonists decreased the rejection of aversive solutions and increased positive ingestive liking responses of rewarding foods in rats (Jarret et al., 2005; Jarret et al., 2007). This effect was attenuated in rimonabant treated animals (Jarret et al., 2005; Jarret et al., 2007). Furthermore, when CB-1R antagonists were administered alone they diminished hedonic reactions to sucrose and increased dislike of quinine (Jarret et al., 2005; Jarret et al., 2007). Together these experiments support a role for the endocannabinoid system in contributing to the hedonic aspects of food reward.

Many studies have used operant conditioning paradigms to investigate the role that endocannabinoids play in the motivational aspect of feeding behaviour. Two of the most common are the progressive ratio paradigm, in which rats are required to bar press a greater number of times following each reward to get the subsequent treat, and the fixed ratio paradigm, in which rats only receive a reward every predetermined number of lever presses. In the former paradigm it is found that CB-1R agonists dose dependently increase the amount of work rats are willing to expend to receive food rewards while CB-1R antagonists demonstrate a dose dependent decrease (Solinas \& Goldberg, 2005). This effect is also mimicked in mice as CB-1R knockout (CB-1R KO) mice decrease their break-point (i.e. point at which animals stop responding) relative to WT mice (Sanchis-Segura et al., 2004). Furthermore, rimonabant treated animals demonstrate a reduced fixed ratio operant responding efficiency when responding for palatable and standard chow rewards (Perio et al., 2001). Interestingly, it has been shown that 
administration of CB-1R agonists can induce feeding when animals are not motivated to eat (i.e. completely satiated) (Kirkham, 2009). Consequently, these agonists are reliably observed to reduce the duration of time between meals (Kirkham, 2009). Similarly, humans report higher subjective feelings of hunger with endocannabinoid system stimulation and significantly reduced feelings of hunger and desire to eat following rimonabant treatment (Kirkham, 2009). These experiments support a role for endocannabinoids in enhancing the incentive salience of food.

In agreement with the involvement of endocannabinoids in food motivation and reward, $\mathrm{CB}-1 \mathrm{Rs}, \mathrm{CBs}$, and degradative enzymes are expressed in brain regions traditionally associated with mediating these processes such as those belonging to the mesolimbic dopamine system (see Figure 2) (NA, VTA, HIP, etc.) (Herkenham et al., 1991; Matsuda et al., 1993; Romero et al., 2002; Kirkham et al., 2002). In support of this, CB-1Rs show similar distribution to D1 and D2 receptors within the mesolimbic dopamine system (Hermann et al., 2002). Interestingly, studies demonstrate that intravenous administration of $C B-1 R$ agonists cause a robust hyperphagic effect and an increase in dopamine levels (i.e. similar to those observed with drugs of abuse) within the shell of the NA of freely moving rats (Solinas et al., 2006; Kirkham et al., 2002). Furthermore, natural enhancement of dopamine levels within the NA that accompany the presentation of palatable foods is completely attenuated by the administration of rimonabant (Melis et al., 2007).

Although ghrelin's ability to stimulate feeding once targeted to the VTA is fairly well recognized, the role of the endocannabinoid system in modulating VTA driven feeding effects remains poorly understood. Interestingly, the presence of CB-1Rs within the VTA, behavioural \& 
pharmacological manipulations, and accumulating electrophysiological data advocate that the endocannabinoid system is likewise intimately involved in controlling the activation of VTA dopamine neurons (Szabo et al., 2002; Melis et al., 2004; Oleson et al., 2012; Labouèbe et al., 2013). In support of this, intra-tegmental rimonabant (i.e. $200 \mathrm{ng}$ ) decreases while JZL 184, a drug which inhibits MAGL (i.e. 2-AG degradative enzyme) to increase 2-AG levels, increases dopamine neurotransmission in the NA core (Oleson et al., 2012). Moreover, intra-VTA rimonabant treatments consequently reduce whereas intra-VTA JZL 184 treatments increase reward seeking behaviours in intra-cranial self-stimulation and food self-administration tasks (Oleson et al., 2012). Furthermore, intravenous administrations of CB-1 agonists enhance VTA dopamine neuron activity (French et al., 1997; Gessa et al., 1998).

Two different studies support a role for endocannabinoids in modifying pre-synaptic release onto VTA dopamine neurons. Szabo and colleagues highlighted that CB-1R agonists caused inhibition of IPSC in VTA neurons (>75\% are dopaminergic), an effect reversed when rimonabant was added to the bath (Szabo et al., 2002). Conversely, Melis and colleagues demonstrated the ability of CB-1R agonists to decrease EPSC onto VTA dopamine neurons by preventing glutamate release onto these neurons, an effect that was also abolished by pretreatment with rimonabant (Melis et al., 2004). These electrophysiology experiments have confirmed that endocannabinoids are released from VTA dopamine neurons, in response to enhanced intracellular $\mathrm{Ca}^{2+}$ (within these VTA dopamine neurons), and travel in a retrograde manner where they bind to CB-1Rs located on both glutamatergic and GABAergic VTA inputs (Wilson \& Nicoll, 2001; Szabo et al., 2002; Melis et al., 2004; Lupica \& Riegel, 2005). Once bound, they mitigate neurotransmitter release from these neurons, resulting in an overall 
activation or suppression of VTA dopamine neurons depending on the ratio of excitatory to inhibitory synapses contacting them (Szabo et al., 2002; Melis et al., 2004; Labouèbe et al., 2013).

Taken together, these studies demonstrate that endocannabinoids may act at many locations within the mesolimbic dopamine system to modulate food reward; however, it is clear that modulation of the endocannabinoid system within the VTA significantly alters the activity of VTA dopamine neurons and hedonic feeding through the manipulation of dopamine release in target regions (e.g. NA) (Oleson et al., 2012). More specifically they suggest that blockage of CB-1Rs within the VTA decreases the activation of VTA dopamine neurons and hence dampens dopamine turnover in target areas to reduce motivation for rewards.

\section{Interaction of Ghrelinergic and Cannabinoid Systems in the Hypothalamus}

Endocannabinoid levels in the rat limbic forebrain and HYP are highly correlated with feeding status. Endocannabinoid levels peak in the fasted state and decline shortly after feeding as satiation is approached (Kirkham et al., 2002). Moreover, endocannabinoid levels steadily rise as the duration between meals increases (Kirkham et al., 2002). The fact that endocannabinoid levels mimics ghrelin's expression levels, and that cannabinoid and ghrelin receptors are found in many important brain regions associated with the regulation of food intake and motivated behaviours (e.g. HYP, VTA), suggests that these two systems interact to modulate feeding (Herkenham et al., 1991; Guan et al., 1997). Tucci and colleagues provided the first substantial evidence that this relationship existed when they demonstrated that pretreatment with a sub-anorectic dose of rimonabant could completely attenuate the increase in 
food intake that is observed with intra-PVN injections of ghrelin (Tucci et al., 2004). It was proposed that one of the mechanisms by which ghrelin and endocannabinoids stimulate food intake was by activating AMPK signalling cascades (Kola et al., 2005). This was hypothesized as both ghrelin and cannabinoids (2-AG, AEA, \& $\Delta^{9}-\mathrm{THC}$ ) administered separately enhance AMPK activity and the phosphorylation of its downstream targets (i.e. ACC) (Kola et al., 2005). Furthermore, it was demonstrated that in the absence of functional CB-1Rs, using CB-1R deficient mice, that ghrelin is unable to induce its characteristic appetite stimulating effects following its central administration (Kola et al., 2008). Although intraperitoneal (IP) ghrelin was able to significantly elevate hypothalamic AMPK activity in WT animals, AMPK levels in both rimonabant treated and CB-1R KO mice were similar to controls (Kola et al., 2008). Interestingly, peripheral administration of ghrelin increases 2-AG levels in HYP (i.e. whole hypothalami) of WT but not CB-1R KO mice (Kola et al., 2008). Likewise, peripheral coadministration of rimonabant and ghrelin is sufficient to mitigate ghrelin's ability to increase 2AG content within the HYP (Kola et al., 2008). Using electrophysiological experiments it was discovered that ghrelin treatment inhibits mEPSC onto PVN parvocellular neurons (i.e. whole cell patch recordings), which when activated are known to have an inhibitory effect on feeding (Kola et al., 2008). Intriguingly, this inhibition is lost by administration of compounds known to inhibit endocannabinoid signalling such as rimonabant, BAPTA (calcium chelator), and tetrahydrolipstatin (inhibits 2-AG synthesis) (Gao \& Horvath, 2007; Kola et al., 2008). The above experiments advocate that within the HYP ghrelin's ability to increase 2-AG content, AMPK activation and food intake is reliant on a functional cannabinoid system. Conversely, Lim and colleagues demonstrated that both ghrelin and CB-1R agonist (HU210) enhance hypothalamic 
AMPK activity in WT mice but that this activity is completely attenuated in GHSR KO mice (Lim et al., 2013). This confirms that a working ghrelinergic system is also required to elicit cannabinoid induced increases in hypothalamic AMPK (Lim et al., 2013). The aforementioned experiments confirm a corroborative interaction, which in part relies on shared activation of AMPK signalling cascades, between cannabinoid and ghrelin pathways in stimulating feeding within the HYP.

\section{Rational for Present Thesis}

There are several pieces of evidence that lead to the formulation of our hypothesis that ghrelin and endocannabinoid systems likely interact within the VTA to drive feeding and more specifically that ghrelin's orexigenic effects within this region depend on a functional endocannabinoid system. First, there is evidence that these two systems interact within the HYP to promote feeding, as genetic and pharmacological blockage of either endocannabinoid or ghrelin signalling is sufficient to attenuate increases in food intake seen when either CB-1R or GHSR agonists are administered within the HYP of WT animals (Tucci et al., 2004; Kola et al., 2005; Kola et al., 2008; Lim et al., 2013). Second, GHSRs and CB-1Rs are found within brain regions of the mesolimbic dopamine system including the VTA (Herkenham et al., 1991; Guan et al., 1997). Lastly, both ghrelinergic and endocannabinoid systems are known to stimulate non-homeostatic feeding primarily by activating neurons within the mesolimbic dopamine system (e.g. VTA) (Abizaid et al., 2006; Kirkham et al., 2002; Szazbo et al., 2002; Melis et al., 2004). 
In order to test if a functional endocannabinoid system is required to mediate ghrelin's orexigenic effects within the VTA we pre-treated rats with peripheral rimonabant and monitored food intake after administering ghrelin into the VTA (30 minutes after IP rimonabant). We predicted that by pre-treating rats with peripheral rimonabant we would be able to attenuate increases in food intake traditionally seen when ghrelin is microinjected into the VTA (Abizaid et al., 2006). Furthermore, we proposed that if the interaction of these two systems is essential to the modulation of feeding in the VTA, as it is in the HYP, then the disruption of the ghrelin system should induce changes in the endocannabinoid system (i.e. changes in CB-1R expression) within this region as well as other important feeding related brain regions (i.e. HIP, NA, PFC, and HYP). To address this hypothesis we examined CB-1R mRNA expression levels, within the aforementioned regions, of ghrelin receptor knockout (GHSR KO) relative to wild-type rats via RT qPCR experiments.

\section{General Methods}

\section{Animals}

The male Long-Evans rats (300-500 grams) that were used in the food intake study were purchase from Charles River (St. Constant, Quebec, Canada). The Fawn-hooded hypertensive GHSR KO and WT rats used for RT qPCR were bred at the Carleton University animal care facility but were originally purchased from Transposagen Biopharmaceuticals Incorporated (Lexington, KY, USA). Upon delivery, rats from the food intake study were housed individually; whereas, those used in the RT-qPCR study were housed in pairs following weaning. In both cases rats were housed in plexiglass cages $(48 \mathrm{~cm} \times 26 \mathrm{~cm} \times 20 \mathrm{~cm}$ ) with access to ad libitum chow (Harlan 
Diets; 3.3 kcal.g ${ }^{-1} ; 4 \%$ fat; $48 \%$ carbohydrates; $14.3 \%$ protein) and water. Delivered rats were given 1 week to habituate to Carleton University animal care facilities, which are temperature $\left(22^{\circ} \mathrm{C}\right)$ and humidity $(45-55 \%)$ controlled. The animals were handled regularly throughout this period to minimize stress during experimental manipulations. All procedures followed Carleton University Animal Care Committee guidelines of the Canadian Council on Animal Care (CCAC) under p13-04 \& p10-39 protocols.

\section{Intra-VTA Cannula Surgical Procedures}

Rats were subjected to an isoflurane:oxygen (5:2) mixture to induce anesthesia; however, they were switched to a 2.5:2 mix throughout the procedure to maintain anesthesia. Likewise, the rats were given a $1 \mathrm{mg} / \mathrm{kg}$ dose of Metacam $(5 \mathrm{mg} / \mathrm{ml}$ ) IP on the day of surgery to provide additional operative analgesia. Similarly, the rats received Metacam $(5 \mathrm{mg} / \mathrm{ml})$ at a dose of $0.5 \mathrm{mg} / \mathrm{kg}$ for at least 2 days following surgery to maintain post-operative analgesia. The rats head's were shaved prior to placement into the stereotaxic apparatus (Kopf Instruments, Tujunga, CA). Tear gel was administered to mitigate dehydration of the rats' eyes. Their scalp was cleaned with germistat, alcohol, and proviodine to ensure that surfaces surrounding the incision site would remain aseptic. An incision was made along the midline, from just anterior to bregma to just posterior of lambda, and the skin was pinned back using hemostats to provide ample room to measure and mark out the anterior to posterior $(\mathrm{AP}=-5.3$ $\mathrm{mm}$ ) and medial to lateral $(\mathrm{ML}=+2.0 \mathrm{~mm}$ ) coordinates of the VTA (from bregma). A mechanical surgical drill was used to remove the skull in the location that the unilateral guide cannula was later inserted. Likewise, the drill was exploited to make three other holes that were used to 
implant screws that were later used to anchor the cannula. The cannula was inserted to the appropriate depth ( $D V=-7.6 \mathrm{~mm}$ ) on an $8^{\circ}$ tilt to avoid hitting the aqueduct. Using the three jeweller's screws and dental cement the cannula was secured to the skull. To prevent clogging of the guide cannula, a dummy cannula of the same length as the guide cannula was inserted into the stabilized guide. The incision was then sutured shut with PROLENE monofilament sutures and the rats were taken off of the anesthetic and placed in freshly clean cages. The rats' behavior and wounds were monitored closely for at least 1 hour post surgery for signs of complications. Post surgery rats were checked at minimum 3 times daily for a week following surgery to ensure optimal recovery before they were allowed to take part in experiment 1.

\section{Histological Analysis and Cannula Placement Verification}

Following the food intake study, rats were quickly decapitated, and their brains were collected and post-fixed in 4\% paraformaldehyde (PFA) for 72 hours. Following this 72 hour period, the 4\% PFA was removed and replaced with a $30 \%$ sucrose solution dissolved in $0.1 \mathrm{M}$ phosphate buffer. The brains were stored at $4^{\circ} \mathrm{C}$ for approximately 48 hours or until the brains had sunk to the bottom of the vial. The brains were removed from the $30 \%$ sucrose solution and placed onto a metal cutting plate where the anterior part of the brain was cleaved off to facilitate preparation of the mid-posterior brain fragment, containing the VTA, for cannula verification placements. These midbrain sections were sliced on a LEICA CM1900 cryostat into $50 \mu \mathrm{m}$ thick coronal sections. The location of the tip of the cannula in each rat brain was scored and recorded, with tracks not within the vicinity of the VTA being excluded from further analysis (see Figure 3). The anterior portion of the brain was kept for future NA c-FOS studies. 

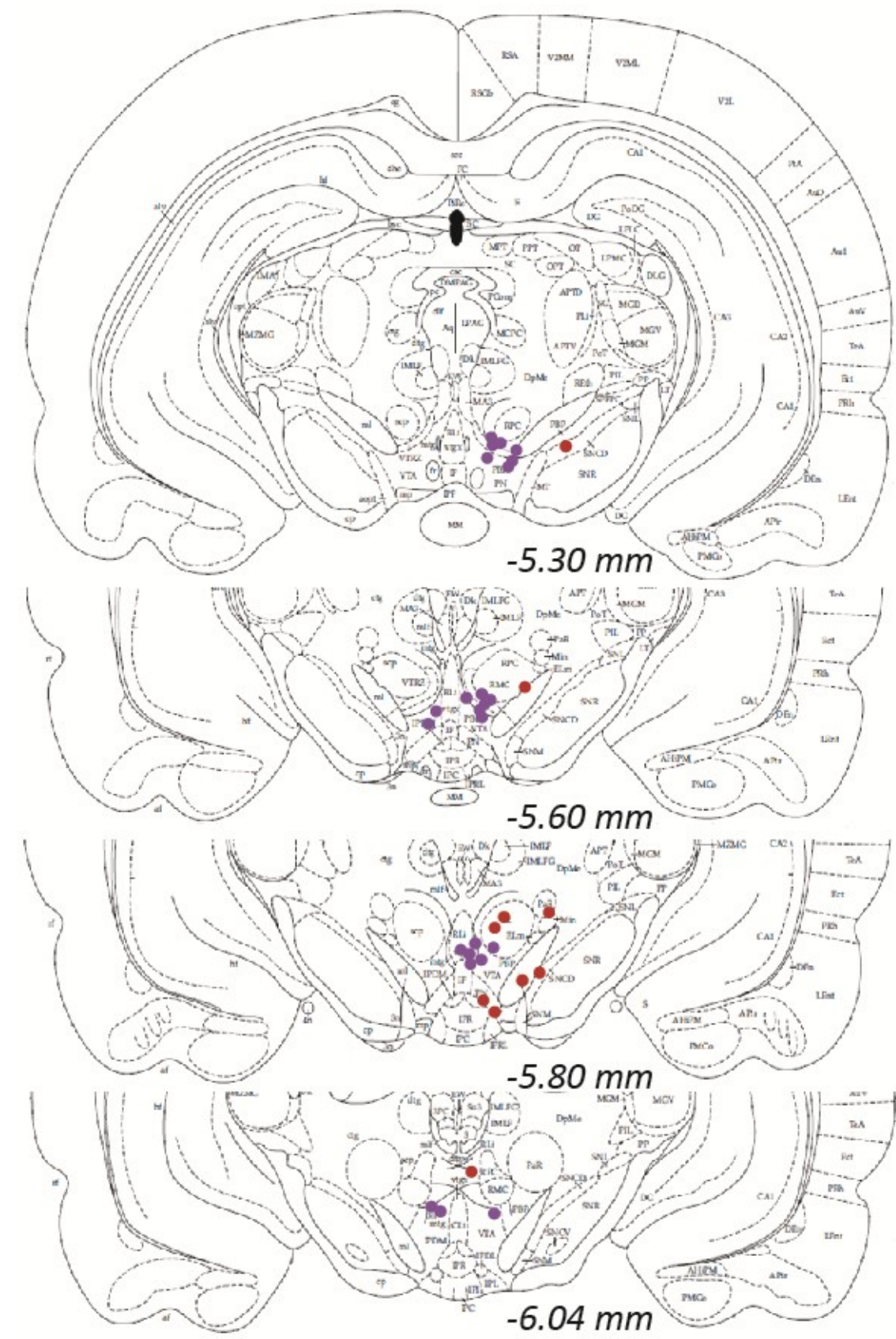

Figure 3: Summary of cannula placements for experiment 1. The purple dots represent those placements that were deemed to fall in an appropriate location within or just above the VTA and therefore were included in the statistical analysis. The red dots represent cannula which did not fall within the vicinity of the VTA and were therefore excluded from analysis. 


\section{Reverse Transcription Quantitative PCR}

Rats were quickly decapitated, their brains were extracted, and the desired brain regions were punched (i.e. VTA, HIP, NA, PFC, and HYP) into $500 \mu$ ls of TriZol (Invitrogen) and stored at $-80^{\circ} \mathrm{C}$ until the day of RNA extraction. On the day of RNA extraction the punches were homogenized \& were then left to incubate for 5 minutes at $15-30^{\circ} \mathrm{C}$ to ensure all nucleoprotein complexes had time to dissociate prior to the addition of chloroform $(0.1 \mathrm{ml})$. The samples were agitated for 15 seconds and incubated at $15-30^{\circ} \mathrm{C}$ for a further $2-3$ minutes before the samples were spun at $12000 \times \mathrm{g}$ for 15 minutes at $2-8^{\circ} \mathrm{C}$ to separate the desired aqueous phase. The RNA was precipitated from the aqueous phase by mixing it with $0.25 \mathrm{mls}$ of isopropyl alcohol and $6.5 \mu \mathrm{ls}$ of linear acrylamide (co-precipitate) for 10 minutes $\left(15-30^{\circ} \mathrm{C}\right)$. The samples were then subjected to a $12000 \times$ g centrifugation at $2-8^{\circ} \mathrm{C}$. The RNA pellets were washed twice with $75 \%$ ethanol, spun down at $7500 \times \mathrm{g}$, and were dissolved in $15 \mu \mathrm{ls}$ of RNAase free water. The quality of the extracted RNA was assessed using a Thermo Scientific Nanodrop 100 spectrophotometer by comparing the ratio of the absorbancies at $260 \mathrm{~nm}$ over $280 \mathrm{~nm}$ (ratio close to 2 was considered ideal). Likewise, the concentration of the RNA was also determined using the Nanodrop spectrophotometer. The extracted RNA was reversed transcribed into cDNA by first adding $1 \mu \mathrm{L}$ of oligo (dT) primer (Invitrogen) to $9 \mu \mathrm{ls}$ of a RNA and diethylpyrocarbonate (DEPC) water solution (ensuring 5000 ng of RNA from each sample was present in the reaction) and heating it for 5 minutes at $70^{\circ} \mathrm{C}$. A master mix containing the following components per sample was made: $4 \mu \mathrm{Ls}$ of $5 \mathrm{X}$ first strand buffer (Invitrogen), $2 \mu \mathrm{Ls}$ of $0.1 \mathrm{M}$ dithiothreitol (Invitrogen), $1 \mu \mathrm{L}$ of RNase inhibitor (Promega), $1 \mu \mathrm{L}$ of $10 \mathrm{mM}$ deoxynucleotide triphosphate (Invitrogen), $1 \mu \mathrm{L}$ of DEPC water and $1 \mu \mathrm{L}$ of SSII RT (Invitrogen). 
$10 \mu \mathrm{ls}$ of this master mix was added to each of the samples. The samples were run on a PTC-200 Thermal Cycler (MJ Research) at $42^{\circ} \mathrm{C}$ for 1.5 hours followed by a ten minute $90^{\circ} \mathrm{C}$ incubation. The cDNA was diluted to a final concentration of $0.75 \mathrm{ng} / \mu \mathrm{l}$ and was stored at $-20^{\circ} \mathrm{C}$ until RTqPCR experiments commenced. The sequences of the primers used for the amplification of the CB-1R, and housekeeping genes $\beta$-actin \& glyceraldehyde 3-phosphate dehydrogenase (GAPDH) were as follows: CB-1R forward-5'-CTGGTTCTGATCCTGGTGGT-3 (Lundanyi et al., 2008); CB-1R reverse- 5- TGTCTCAGGTCCTTGCT CCT-3 (Lundanyi et al., 2008); $\beta$-actin forward: 5'-TCATGAAG TGTGACGTTGACATCCG-3'; $\beta$-actin reverse: 5'-CCTAGAAGCATTTGCGGTGCACGATG-3'; GAPDH forward: 5'-AAGATGGTGAAGGTCGG TGT-3'; GAPDH reverse: 5'-CTTGCCGTGGTAGAGTCAT-3'. In short, $5 \mu \mathrm{ls}$ of each cDNA sample was added to each well of the PCR plate before $2 \mu \mathrm{Ls}$ of working primer solution $(2 \mu \mathrm{M}), 3 \mu \mathrm{ls}$ of MilliQ $\mathrm{H}_{2} \mathrm{O}$, and $10 \mu \mathrm{Ls}$ of iQ SYBR Green Super Mix combined with fluorescein (BioRad) were added. All samples along with non-template controls were run in duplicate using primers for the CB-1R and housekeeping genes GAPDH and $\beta$-actin. The PCR plate was run on a MylQ Single Color RT-qPCR Detection System (Bio-Rad). The program used was as follows: 30 second $95^{\circ} \mathrm{C}$ setting followed by 45 cycles of denaturing (10 seconds at $95^{\circ} \mathrm{C}$ ), annealing $\left(30\right.$ seconds at $\left.55^{\circ} \mathrm{C}\right)$, and extension phases $\left(20\right.$ seconds at $72^{\circ} \mathrm{C}$ ). The program concluded with a 1 minute $95^{\circ} \mathrm{C}$ step proceeded by a 1 minute $55^{\circ} \mathrm{C}$ step. The primers used to investigate CB-1R and housekeeping gene expression were tested for their amplifications efficiencies using a standard curve method. Only those primers which fell between $90-110 \%$ efficient were kept for RT-qPCR experiments. The RT-qPCR data was analyzed using the $2^{-\Delta \Delta C t}$ method (previously described in Schmittgen \& Livak, 2008). This method is a comparative method to present gene expression of a treatment condition or genotype (i.e. 
GHSR KO) relative to controls (i.e. WT). This method also normalizes the data to appropriate control housekeeping genes to ensure that changes in target gene expression are reflective of actual alterations in expression levels between two different groups and are not reflective of discrepancies in quality or concentration inherent in the cDNA samples. The housekeeping genes, GAPDH and $\beta$-actin, were used to express the relative CB-1R mRNA levels in accordance with the $2^{-\Delta \Delta C t}$ method.

\section{Statistical Analysis}

Food intake and locomotor activity data from experiment 1 were each analyzed using mixed repeated measure analysis of variance (ANOVA) where the within subjects factor was time and the between subject factor was the treatment (IP saline/intra-VTA saline, IP saline/intra-VTA ghrelin, IP rimonabant/intra-VTA saline, and IP rimonabant/intra-VTA ghrelin). In both instances, Mauchly's test of sphericity was violated and thus the Greenhouse-Geisser correction was used to adjust the degree's of freedom and compensate for these violations (all $\mathrm{p}$ values reflect this correction). Analyses of the mean cumulative food intake and locomotor activity between groups at each time point was also analyzed via univariate ANOVAs. LSD post hoc tests were performed when significant main effects were found. The $2^{-\Delta \Delta C t}$ values computed following RT-qPCR experiments were analyzed using independent samples t-tests where the grouping variable was the genotype (GHSR KO vs WT) and the test variable was the $2^{-\Delta \Delta C t}$ value. 


\section{Experiment 1: Rimonabant Peripheral Injections Attenuate the Orexigenic Effect of Ghrelin}

\section{Infused into the VTA}

\section{Method}

This study was designed to test whether a functional endocannabinoid system is important for modulating ghrelin's orexigenic effects within the VTA. We were interested if pharmacological blockage of CB-1R, via peripheral injections of rimonabant, could dampen or eliminate the traditional increase in food intake seen with ghrelin infusions within the VTA.

To this end, forty Long-Evans rats were given ad libitum access to normal chow and water for 1 week before surgery to establish a pre-surgery baseline. The animals were then subjected to the VTA cannula surgical procedure and were given 1 week to recover. On post surgery day 7 , half the rats received IP injections of rimonabant $(1.0 \mathrm{mg} / \mathrm{kg})$ while the other half received $0.9 \%$ saline. Thirty minutes following the IP injection, half the rats were given intraVTA infusions (i.e. microinjections) of ghrelin ( $1 \mu \mathrm{g}$ in $0.5 \mu$ l over 1 minute); while, the other half received saline infusions (refer to Figure 4). Injections were completed on or around noon therefore rats were not in there active feeding period nor were they in a fasted state. All microinjections were completed using a GenieTouch ${ }^{\text {TM }}$ dual syringe pump (Kent Scientific Corporation). This design yielded 10 rats per group for the following four treatments: IP saline/intra-VTA saline, IP saline/intra-VTA ghrelin, IP rimonabant/intra-VTA saline, and IP rimonabant/intra-VTA ghrelin. Food intake was monitored 1, 2, 4, \& 6 hours post microinfusions. Additionally, locomotor activity was also monitored for the first four hours postmicroinjection to ensure that any differences in food intake were not a result of changes in locomotor activity. A week later these injections were repeated, albeit in a counter-balanced 
fashion. However, this time the rats' food intake and locomotor activity were not measured and the rats were sacrificed 1 hour after receiving their microinjection. The animals were rapidly decapitated and their brains were post-fixed for cannula verifications and future NA c-FOS experiments.

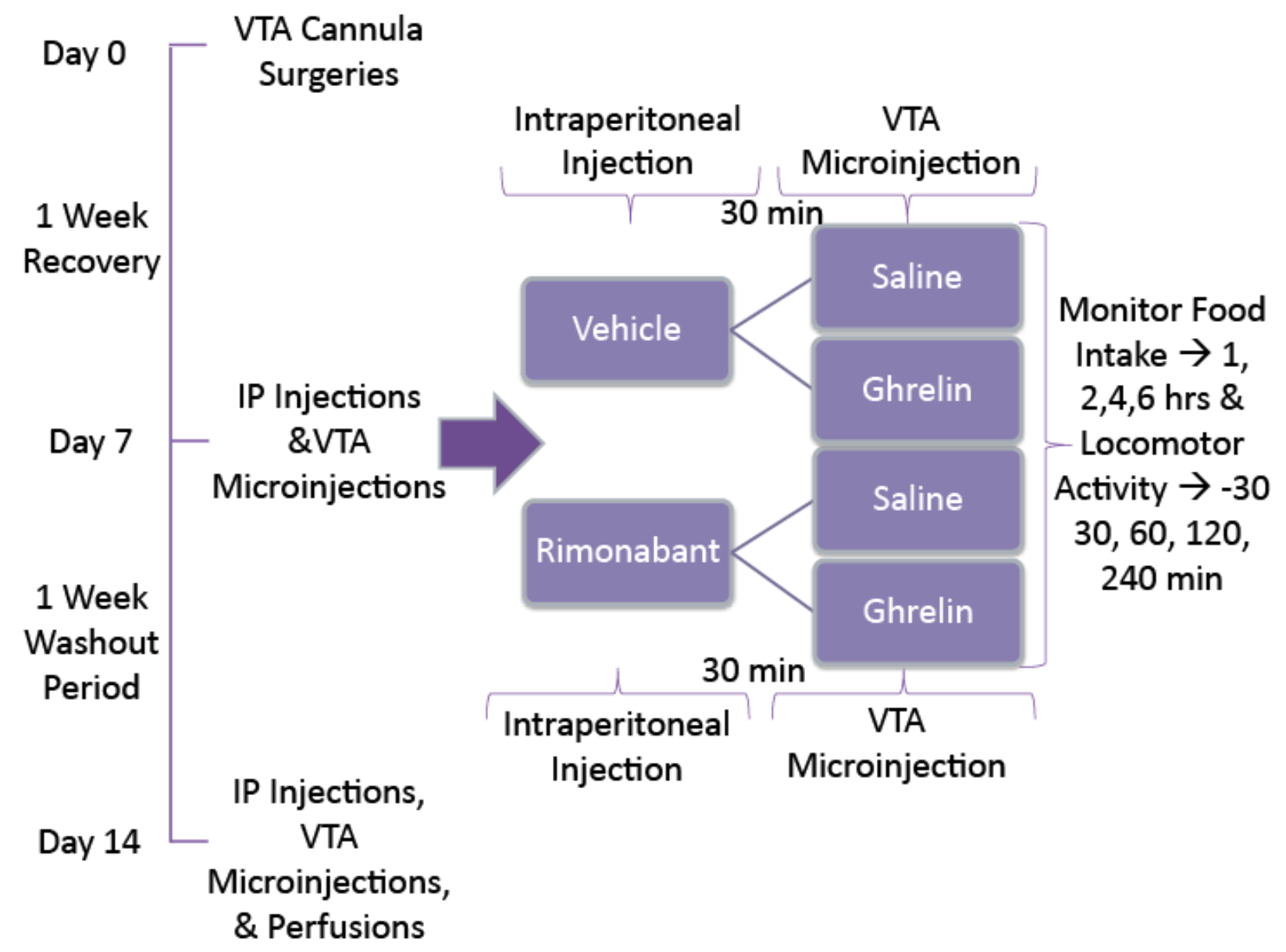

Figure 4: Depiction of experiment 1 design. This study included the following 4 treatment groups: IP vehicle/intra-VTA saline, IP vehicle/intra-VTA ghrelin, IP rimonabant/intra-VTA saline, and IP rimonabant/intra-VTA ghrelin. Note that rimonabant $(1.0 \mathrm{mg} / \mathrm{kg})$ or vehicle was given intraperitoneal 30 minutes before ghrelin $(1 \mu \mathrm{g})$ or saline was infused ( $1 \mu$ l over 1 minute) into the VTA via microinjection. Injections were given on both day 7 and day 14 albeit in a counter balanced fashion. 
Experiment 2: Comparing CB-1R mRNA Expression within Important Feeding Nuclei of GHSR KO and WT Rats

\section{Method}

In this study, we investigated relative levels of CB-1R mRNA in GHSR KO and WT rats in different feeding related brain regions (i.e. VTA, HIP, NA, PFC, and HYP). The rationale behind this experiment was to see if disrupting ghrelin signalling induces alterations in the endocannabinoid system, particularly with respect to the expression of CB-1Rs in these brain regions. 12 GHSR KO rats and 8 WT rats were sacrificed, their brains were removed and punches of the feeding related regions were processed according to the RT-qPCR methods section. 


\section{Results}

\section{IP Rimonabant Attenuates the Orexigenic Effect of Ghrelin Infused into the VTA}

To investigate if a functional endocannabinoid system is required to mediate ghrelin's orexigenic effects within the VTA the following treatments were administered: IP vehicle/intraVTA saline, IP vehicle/intra-VTA ghrelin, IP rimonabant/intra-VTA saline, IP rimonabant/intraVTA ghrelin and food intake was subsequently measured at several time points $(1,2,4, \& 6 \mathrm{hrs})$. For these treatments, rimonabant was administered IP at a dose of $1.0 \mathrm{mg} / \mathrm{kg}$; whereas, $1 \mu \mathrm{g}$ of ghrelin was dissolved in $0.5 \mu \mathrm{l}$ of saline and infused into the VTA over a 1 minute time period for the intra-VTA ghrelin microinjections.

Figure 5 illustrates the mean cumulative food intake of each of the four groups measured 1, 2, 4, and 6 hours after their corresponding microinjections. A repeated measures ANOVA revealed that all of the treatment groups ate significantly more over the 6 hour time period (main effect for time, $\left.F_{(1.879,37.589)}=18.668, p<.05\right)$. Likewise, the mean cumulative food intake between the treatment groups changed differentially over time (i.e. significant time and treatment interaction) as assessed by testing within subject effects using a repeated measures ANOVA $\left(F_{(5.63,37.589)}=2.502, p<.05\right)$. LSD post hoc tests showed that those animals that were not pretreated with rimonabant but did receive intra-VTA ghrelin (i.e. IP vehicle/intra VTA ghrelin) ate significantly more than the other 3 groups $(p<.05)$. Moreover, the increased food intake effect observed following intra-VTA ghrelin infusion was completely attenuated in rats that were pre-treated with rimonabant (i.e. IP rimonabant/intra-VTA ghrelin); however, rimonabant alone (i.e. IP rimonabant/intra-VTA saline) did not significantly reduce feeding as none of the three aforementioned groups (i.e. IP vehicle/intra-VTA saline, IP rimonabant/intra- 
VTA saline, \& IP rimonabant/intra-VTA ghrelin) differed from each other in terms of their mean cumulative food take (collapsed across time) $(p>.05)$.

Analyses of the mean cumulative food intake between groups at each time point (i.e. 1, 2, 4, 6 hours) were compared via univariate ANOVAs. An ANOVA on the mean cumulative food intake 1 hour after microinjection detected no significant between subject effects $\left(F_{(3,20)}=\right.$ 2.064, $p>.05)$. Rats that were administered IP vehicle/intra-VTA ghrelin had the highest food intake at this time point; however, the effect did not attain significance.

Univariate ANOVA on the mean cumulative food intake 2 hours after microinjection revealed significant between treatment effects $\left(F_{(3,20)}=4.454, p<.05\right)$. Additional LSD post hoc tests demonstrated that rats within the IP vehicle/intra-VTA ghrelin group consumed significantly more standard chow on average than the other three groups $(p<.05)$

Similarly, the mean cumulative food intake between the treatment groups significantly differed 4 hours after microinjection $\left(\mathrm{F}_{(3,20)}=3.057, p=.052\right)$. LSD post hoc tests highlighted that the IP vehicle/intra-VTA ghrelin group ate significantly more than IP vehicle/intra-VTA saline $(p<.05)$ \& IP rimonabant/intra-VTA ghrelin $(p<.05)$ groups but not more than those rats which received the IP rimonabant/intra-VTA saline treatment $(p>.05)$.

Lastly, significant between treatment effects remained 6 hours post microinjection $\left(F_{(3,}\right.$ 20) $=3.668, p<.05)$. The rats that received ghrelin into the VTA but were not treated with rimonabant (i.e. IP vehicle/intra-VTA ghrelin) continued to have significantly higher mean cumulative food intake compared to the saline control (i.e. IP vehicle/intra-VTA saline) $(p<.05)$ and those pretreated with rimonabant (i.e. IP rimonabant/intra-VTA ghrelin, IP rimonabant/intra-VTA saline) $(p=.05)$. 


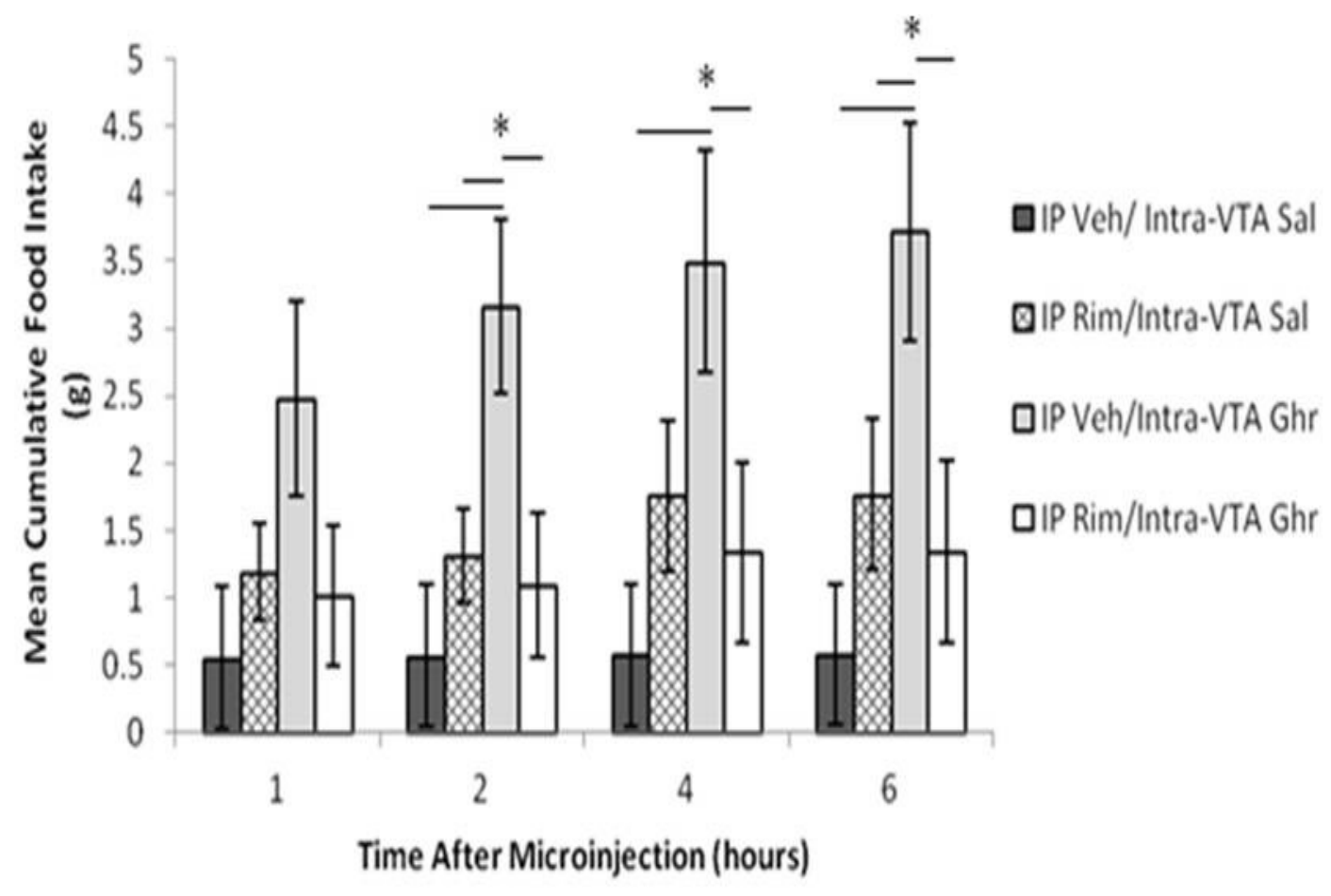

Figure 5: Mean cumulative food intake ( \pm S.E.M) of non-fasted male rats during their light cycle receiving one of the following four treatments: IP vehicle (Veh)/ Intra-VTA saline $(S a l)(n=4)$, IP rimonabant (Rim)/Intra-VTA Sal $(n=7)$, IP Veh/Intra-VTA ghrelin (Ghr) $(n=7)$, or IP Rim/IntraVTA Ghr $(n=6)$. Food intake was measured $1,2,4, \& 6$ hours after each rat's microinjection. IP injections were given 30 minutes before microinjections. Note that rimonabant and ghrelin were administered at $1.0 \mathrm{mg} / \mathrm{kg}$ and $1 \mu \mathrm{g} / \mu \mathrm{r}$ respectfully. ${ }^{*} p<.05$. 
The Ability of Rimonabant to Attenuate the Orexigenic Effects of Ghrelin in the VTA is Independent of Locomotor Activity

To ensure that the changes in food intake observed were due to the corresponding treatments and not due to increased or decreased locomotor activity, the rats' ambulatory activity, measured by total number of beam breaks, was measured in the time between their IP injections and microinjections (i.e. -30 minutes) as well as $30,60,120, \& 240$ minutes proceeding their microinjections (see Figure 6). A repeated measures ANOVA determined that there was no significant difference in locomotor activity between the four treatment groups across time (i.e. no time and treatment interaction) $\left(\mathrm{F}_{(3.658,24.386)}=2.01, p>.05\right)$. Furthermore, separate analyses of the mean horizontal activity count between groups at each time point were compared via univariate ANOVAs. Again no significant differences in locomotor activity were revealed between the four treatment groups in between the two injections (i.e.-30 $\mathrm{min}$ ) $\left(F_{(3,20)}=0.073, p>.05\right)$ or at $30\left(F_{(3,20)}=1.377, p>.05\right), 60\left(F_{(3,20)}=1.395, p>.05\right), 120\left(F_{(3,20)}\right.$ $=1.860, p>.05)$, and $240\left(\left(\mathrm{~F}_{(3,20)}=1.999, p>.05\right)\right.$ minutes post microinjection. 


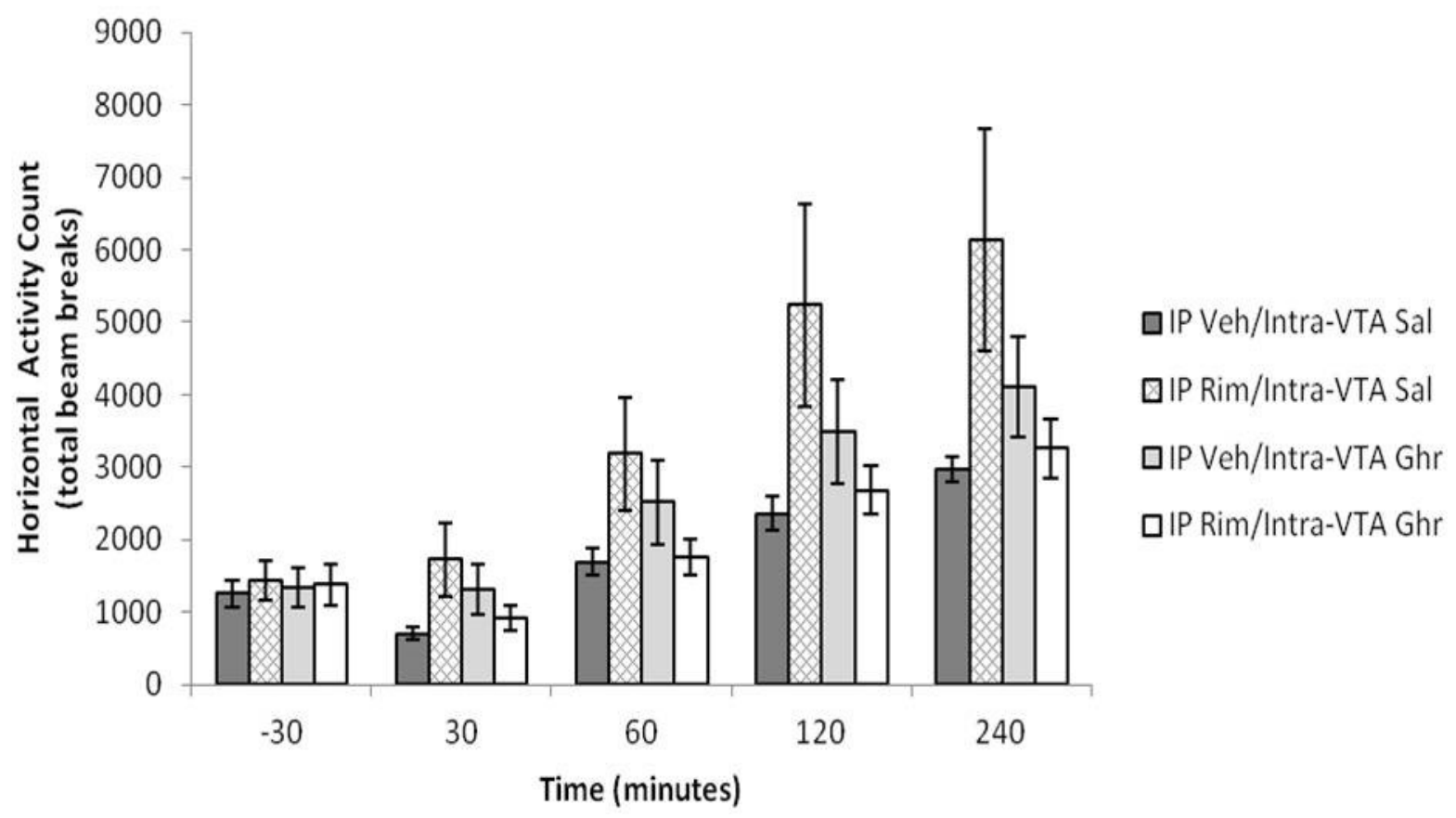

Figure 6: Mean horizontal activity count ( \pm S.E.M) of non-fasted male rats during their light cycle receiving one of the following four treatments: IP Veh/Intra-VTA Sal $(n=4)$, IP Rim/IntraVTA Sal ( $n=7)$, IP Veh/Intra-VTA Ghr $(n=7)$, or IP Rim/Intra-VTA Ghr ( $=6)$. IP injections were given 30 minutes before microinjections. Note that rimonabant and ghrelin were administered at $1.0 \mathrm{mg} / \mathrm{kg}$ and $1 \mu \mathrm{g} / \mu \mathrm{l}$ respectfully. There was no significant $(p>.05)$ difference in locomotor activity between any of the treatment groups at any of the time points. 
GHSR KO Rats Have Significantly Lower VTA but Higher PFC CB-1R mRNA Expression than WT Rats

In experiment 2, RT-qPCR was used to investigate the relative expression of CB-1R mRNA within GHSR KO relative to WT rats in the following five feeding associated brain regions: VTA, HIP, HYP, NA, \& PFC. Independent-samples t-tests were conducted to compare the expression of CB-1R mRNA, reflected by $2^{-\Delta \Delta C T}$ values, in GHSR KO versus WT rats.

GHSR KO rats $(M=0.59, \mathrm{SEM} \pm 0.11)$ had significantly $(\mathrm{t}(18)=2.48, p=.014)$ lower VTA CB-1R mRNA expression than corresponding $W T$ rats $(M=1.06, S E M \pm 0.20)$ (see Figure 7$)$. In contrast, GHSR KO rats $(\mathrm{M}=1.65, \mathrm{SEM} \pm 0.23)$ had significantly $(\mathrm{t}(17)=-2.03, p=.059)$ higher PFC CB-1R mRNA expression compared to $W T$ rats $(M=1.05, S E M \pm 0.13)$ (see Figure 8$)$. There was no significant difference $(\mathrm{t}(14)=0.63, p=.950)$ in CB1-R mRNA expression between GHSR KO $(M=1.98, S E M \pm 0.27)$ and $W T(M=2.03, S E M \pm 1.00)$ rats with respect to the HYP (see Figure 9). Likewise, no significant difference $(\mathrm{t}(15)=-.560, p=0.584)$ within the NA was found between GHSR KOs (M=1.37, SEM \pm 0.19$)$ and WTs $(M=1.18, \mathrm{SEM} \pm 0.32)$ (see Figure 10). Lastly, there was also no significant difference $(\mathrm{t}(16)=-1.03, p=.319)$ in $\mathrm{CB}-1 \mathrm{R}$ mRNA expression between GHSR KO (M = 1.41, SEM \pm 0.12$)$ and $W T(M=1.14, S E M \pm 0.25)$ rats within the HIP (see Figure 11). 


\section{Ventral tegmental area}

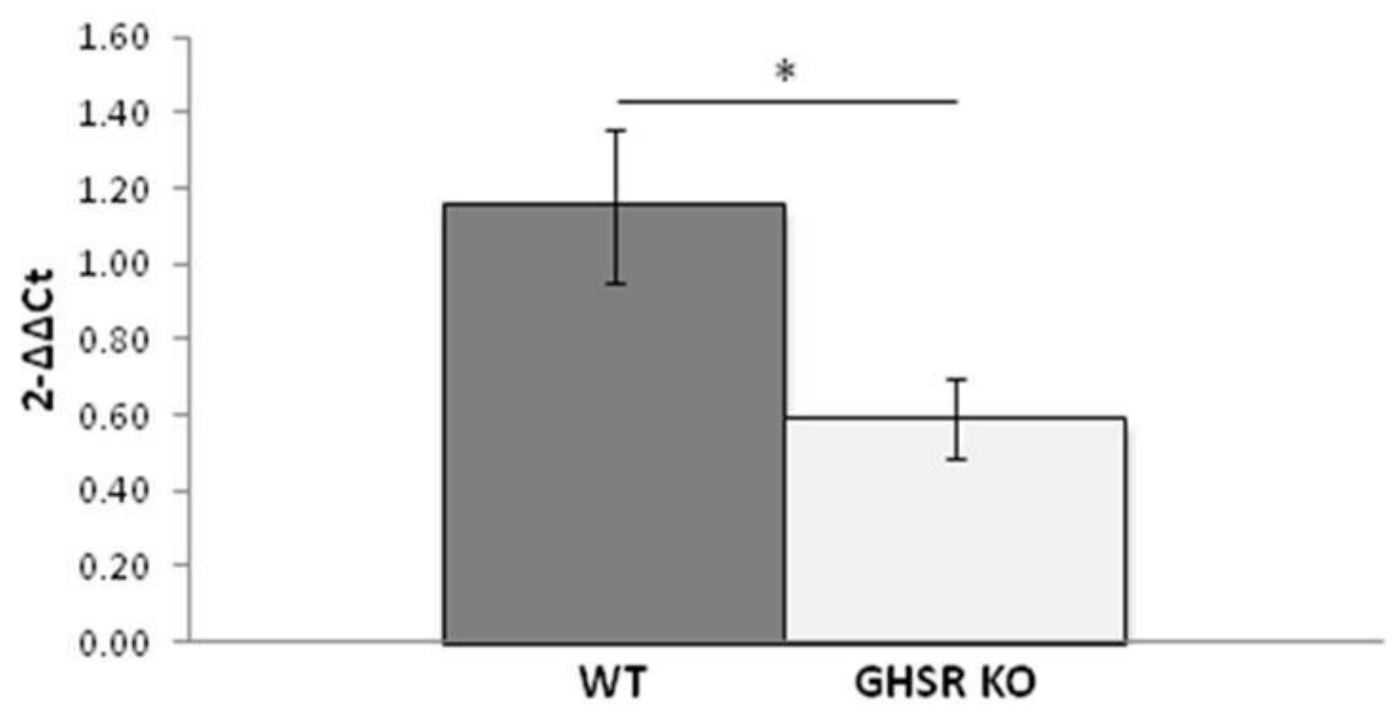

Figure 7: Relative CB-1R mRNA expression ( \pm S.E.M) within the VTA of WT $(n=8)$ and GHSR KO $(n=12)$ rats analyzed using $2^{-\Delta \Delta c t}$ method (previously described in, (Schmittgen \& Livak, 2008)). GHSR KOs had significantly lower mean VTA CB-1R mRNA expression than corresponding WT rats $(p=.014)$. 


\section{Prefrontal cortex}

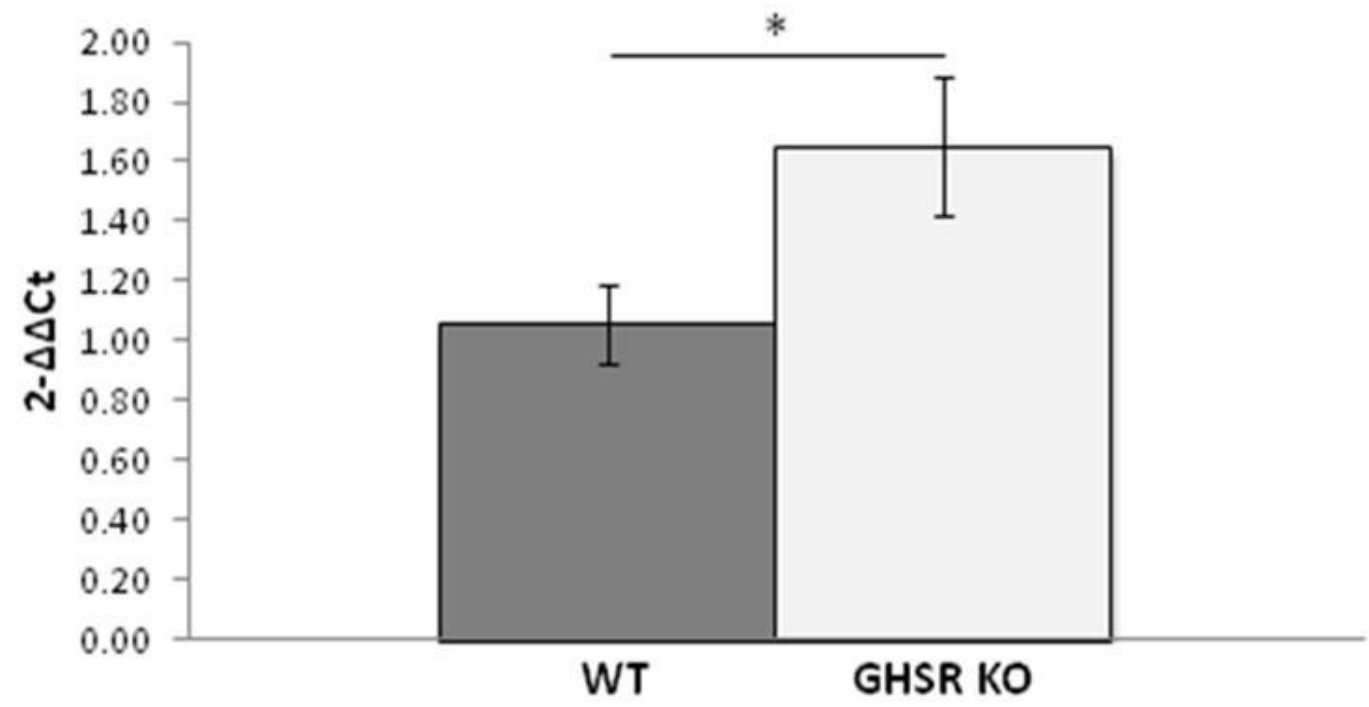

Figure 8: Relative CB-1R mRNA expression ( \pm S.E.M) within the PFC of WT $(n=8)$ and GHSR KO $(n=11)$ rats analyzed using $2^{-\Delta \Delta c t}$ method (previously described in, (Schmittgen \& Livak, 2008)). GHSR KOs had significantly higher mean PFC CB-1R mRNA expression than corresponding WT rats $(p=.059)$. 


\section{Hypothalamus}

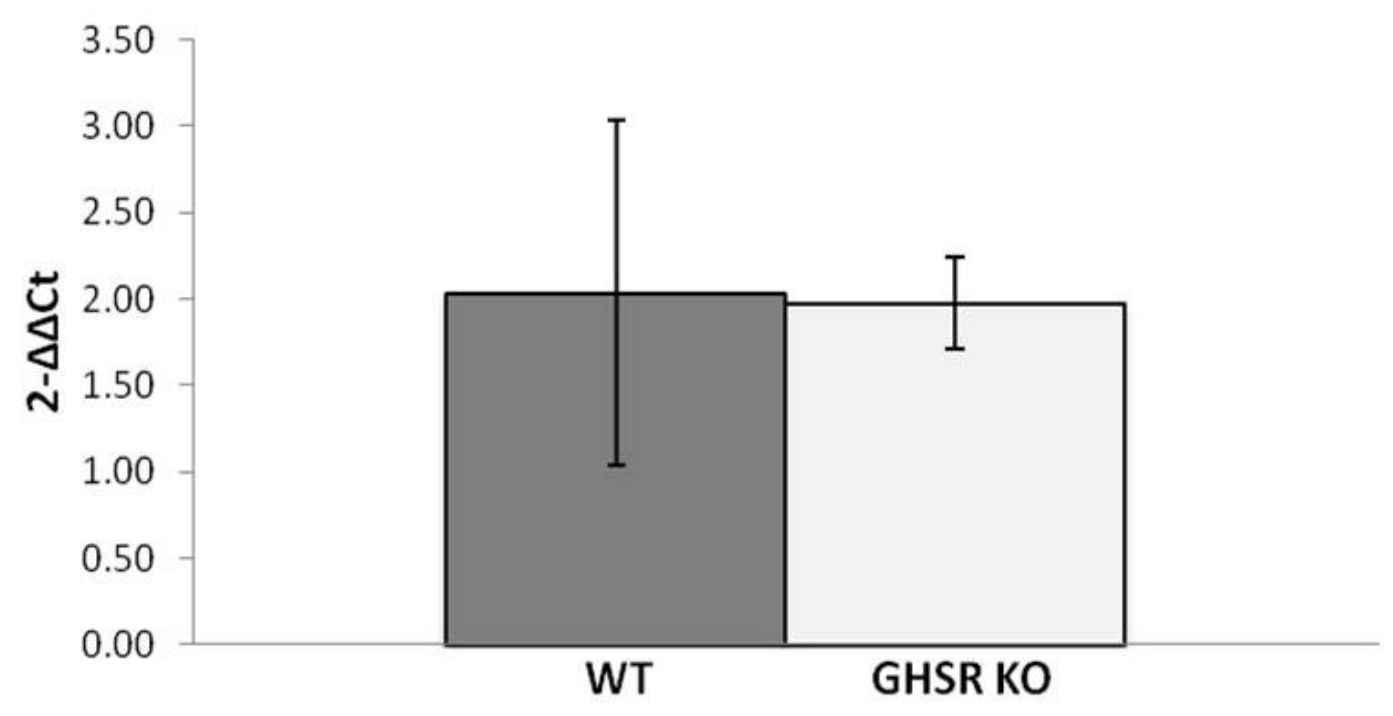

Figure 9: Relative CB-1R mRNA expression ( \pm S.E.M) within the hypothalamus of WT $(n=6)$ and GHSR KO $(n=10)$ rats analyzed using $2^{-\Delta \Delta c t}$ method (previously described in, (Schmittgen \& Livak, 2008)). There was no significant difference between WT and GHSR KO rats ( $p>.05)$. 
Nucleus accumbens

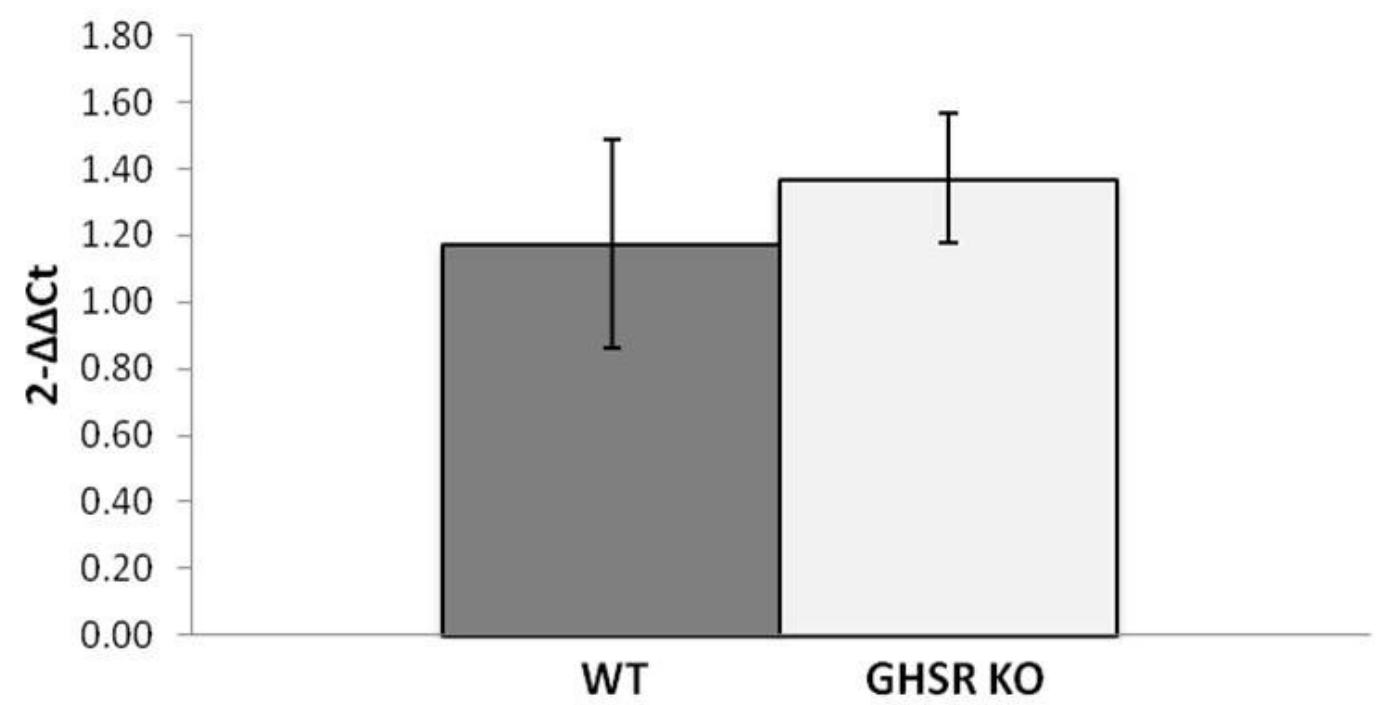

Figure 10: Relative CB-1R mRNA expression ( \pm SEM) within the nucleus accumbens of WT $(n=7)$ and GHSR KO $(n=10)$ rats analyzed using $2^{-\Delta \Delta c t}$ method (previously described in, (Schmittgen \& Livak, 2008)). There was no significant difference between WT and GHSR KO rats $(p>.05)$. 


\section{Hippocampus}

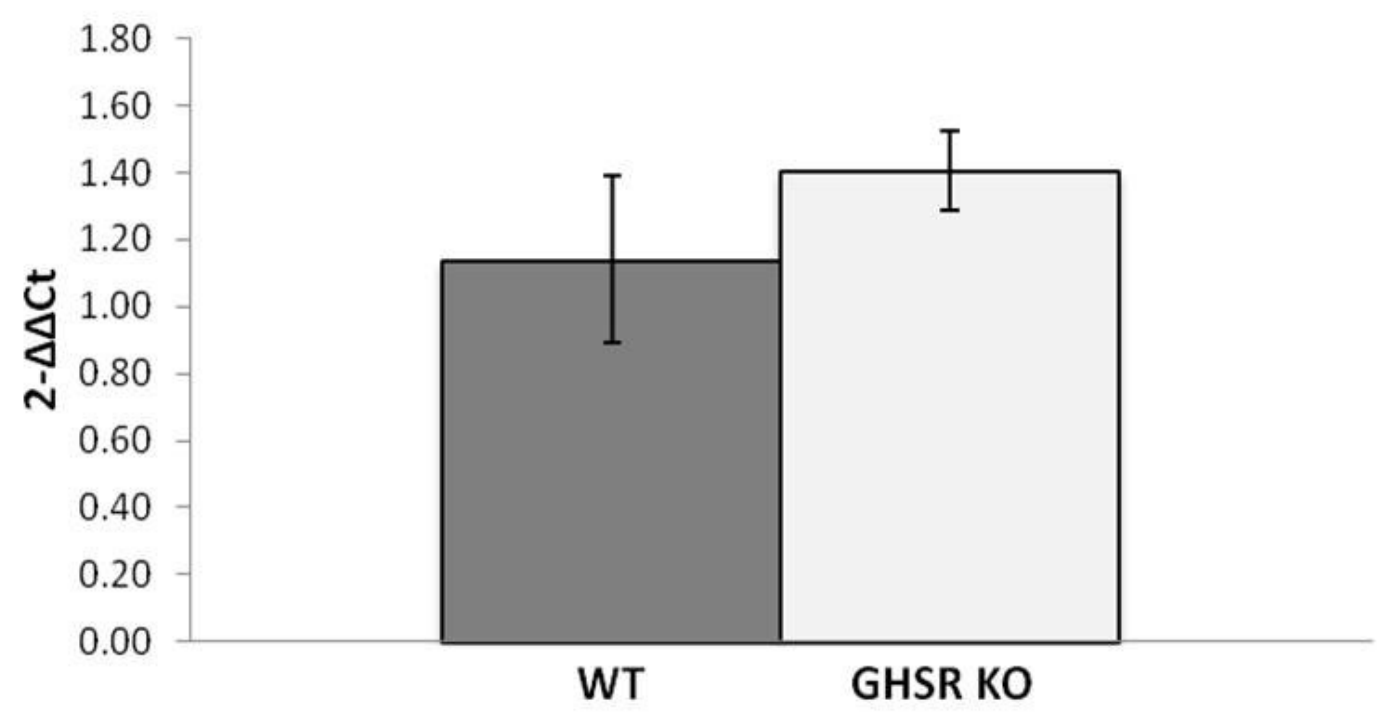

Figure 11: Relative CB-1R mRNA expression ( \pm SEM) within the hippocampus of WT $(n=8)$ and GHSR KO $(n=10)$ rats analyzed using $2^{-\Delta \Delta c t}$ method (previously described in, (Schmittgen \& Livak, 2008)). There was no significant difference between WT and GHSR KO rats ( $p>.05)$. 


\section{Discussion}

This current thesis aimed to test the hypothesis that the orexigenic effects of ghrelin in the VTA depend on a functional endocannabinoid system. Several findings led to the development of the above hypothesis. First, studies have shown that both ghrelin and endocannabinoid systems are important for modulating homeostatic feeding within the hypothalamus (Tucci et al., 2004; Kola et al., 2008). Second, hypothalamic disruption of either one of these systems (i.e. genetic or pharmacological) has been shown to attenuate or completely eliminate the orexigenic effects of the other system's appetite stimulating compound (i.e. ghrelin or endocannabinoids) (Tucci et al., 2004; Kola et al., 2005; Kola et al., 2008; Lim et al., 2013). Third, GHSRs and CB-1Rs are both known to be expressed within the VTA (Herkenham et al., 1991; Guan et al., 1997). Lastly, several autonomous research groups have demonstrated that stimulation of either ghrelinergic or endocannabinoid systems within the VTA increases food intake primarily through the activation (direct and indirect) of dopamine neurons that originate in this area (Abizaid et al., 2006, Kirkham et al., 2002; Szazbo et al., 2002; Melis et al., 2004; Sinnayah, 2008).

Data from experiment 1 show that, as expected, rats given IP vehicle/intra-VTA ghrelin injections consumed more food than control rats over a period of 6 hours post infusion. This group ate a majority of this food within the first hour as they consumed on average 1.5- 2 grams more than all other groups. Furthermore, ghrelin continued to elicit increased feeding during the next hour ( 2 hours post microinjection) as the IP vehicle/intra-VTA ghrelin group ate a further 0.5- 1 gram more standard chow than all other treatments. Ghrelin's orexigenic effect tailed off 2 hours post microinjection as increases in food intake between groups and in general 
was minimal ( 4 \& 6 hours after microinjection); however, the cumulative food intake of the IP vehicle/intra-VTA ghrelin group remained significantly higher than controls up to 6 hours after the microinjection. This supports previous findings showing that ghrelin can stimulate food intake when infused into the VTA and that ghrelin increases food intake most substantially within the first 2 hours (Naleid et al., 2005; Abizaid et al., 2006; King et al., 2011). Ghrelin's ability to enhance feeding within this region relies in part on its capacity to increase the firing rate of GHSR-positive dopamine neurons that originate in the VTA (Abizaid et al., 2006). Interestingly, ghrelin has been shown to stimulate these VTA dopamine neurons both directly by binding to GHSR receptors located on their surface and indirectly by increasing the number of excitatory synapses contacting them (Abizaid et al., 2006). Once activated these GHSRpositive VTA dopamine neurons, which project to regions such as the PFC, HIP, \& NA, are thought to increase dopamine turnover in target areas to enhance feeding (Abizaid et al., 2006).

The orexigenic effects induced by intra-VTA ghrelin are dependent on a functional endocannabinoid system as pre-treatment with a sub-anorectic dose of rimonabant before administration of intra-VTA ghrelin completely attenuated feeding to a level indistinguishable from controls at all time points tested. Importantly, rimonabant alone (IP rimonabant/intra-VTA saline) did not diminish feeding beyond controls (IP vehicle/intra-VTA saline) validating that the rimonabant dose used was sub-anorectic (i.e. unable to reduce standard chow intact when administered alone). The fact that a very small dose of rimonabant that did not affect feeding on its own completely eliminated ghrelin's orexigenic effects when infused into the VTA suggests that rimonabant's likely interfered with ghrelin's ability to stimulate VTA dopamine 
neurons. This hypothesis draws support from previous intra-tegmental rimonabant experiments demonstrating that rimonabant dampens dopamine neurotransmission in the nucleus accumbens core and behaviorally reduces food self-administration (Oleson et al., 2012). Consistent with this, it is reasonable to presume that the reduced food intake observed in the rats that were pre-treated with rimonabant (IP rimonabant/intra-VTA ghrelin) relative to those that were only administered intra-VTA ghrelin (IP vehicle/intra-VTA ghrelin) could be the result of an overall suppression of VTA dopamine neuron activity in the former. Mechanistically, one of the ways in which this could be the case is if the inhibitory inputs (i.e. GABA) synapsing on VTA dopamine neurons are in general more numerous than their corresponding excitatory input counterparts (i.e. glutamate afferents). A majority of the non-dopaminergic neurons within the VTA are GABAergic and the abundance of GABA synapses onto VTA dopamine neurons has been reported by a plethora of autonomous research groups (Bayer \& Pickle, 1991; Johnson \& North 1992; Charara et al,. 1996; White 1996; Steffensen et al., 1998; Carr \& Sesack, 2000; Omelchenko \& Sesack, 2009). Consequently, rimonabant pretreatment would mitigate the binding of endocannabinoids to their pre-synaptically located receptors on both GABA and glutamate axons to prevent inhibition of GABA and glutamate release; however, due to the increased prevalence of GABA inputs or stronger GABAergic connections, the main effect would be a heightened inhibitory tone and an overall hyperpolarization of VTA dopamine neurons (Figure 12, panel A). This would effectively counter the ability of ghrelin to stimulate VTA dopamine neurons and could be responsible for the depressed feeding observed in the IP rimonabant/intra-VTA ghrelin group relative to those that were only treated with ghrelin (i.e. IP vehicle/intra-VTA ghrelin). Furthermore, GABAergic neurons within the VTA may send inhibitory 
synapses onto glutamate excitatory inputs that are contacting VTA dopamine neurons

(Omelchenko \& Sesack, 2009; Ciccarelli et al., 2012). Therefore with rimonabant pretreatment, the GABA neurons would become disinhibited (reduced CB-1R activation) and would reduce the overall excitatory tone produced by glutamate neurons (less numerous). This would effectively mitigate the ability of ghrelin to excite VTA dopamine neurons (Figure 12, panel B). Lastly, recent studies have also localized CB-1Rs on astrocytes (Navarrete \& Araque, 2008; Navarrete \& Araque, 2010). When treated with CB-1R agonists, these neurons release glutamate to facilitate excitation and potentiate synaptic plasticity (Navarrete \& Araque, 2008; Navarrete \& Araque, 2010; Castillo et al., 2012). Therefore the interruption of astrocyte CB-1R activation, which normally potentiates synaptic transmission onto VTA dopamine neurons, may be one of the ways in which rimonabant blocks ghrelin's orexigenic effects when ghrelin is infused into the VTA (Figure 12, panel C). A combination of the aforementioned proposed mechanisms may be responsible for the ablation of ghrelin's orexigenic effects following rimonabant pre-treatment. Future electron microscopy studies that allow for the quantification of CB-1R-positive (immunostaining for CB-1R) asymmetric and symmetric synapses onto VTA dopamine neurons, in both GHSR KO and WT rodents, will provide valuable information about how ghrelin and endocannabinoids alter VTA dopamine neuron activation by modifying inputs into the hub of the mesolimbic dopamine system. 


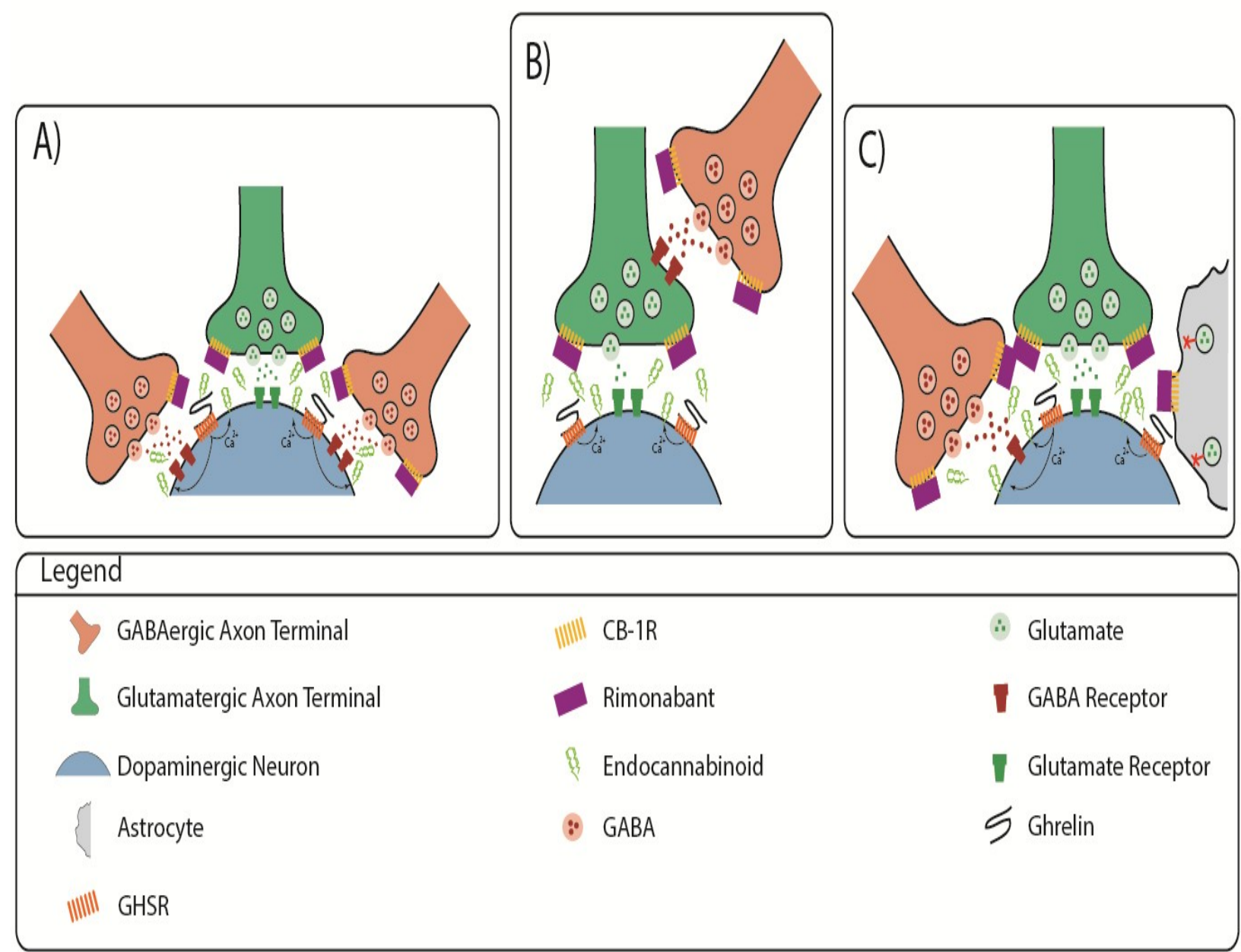

Figure 12: Hypothetical mechanisms in which rimonabant treatment within the VTA could counteract ghrelin's stimulation of VTA dopamine neurons. (A) Higher GABAergic compared to glutamatergic presence. (B) Inhibition of glutamate excitatory release onto VTA dopamine neurons by GABAergic neurons. (C) Blockage of CB-1Rs on astrocytes to prevent glutamate release.

Alternatively, it is plausible that rimonabant blockage of CB-1Rs elsewhere in the brain contributed to the attenuation of the feeding effects induced by intra-VTA ghrelin. Future experiments, in which rimonabant is infused into the VTA before intra-VTA ghrelin, may help elucidate whether blockage of CB-1Rs specifically within the VTA is sufficient to mitigate ghrelin's orexigenic effects within this region. 
Measuring the food intake and locomotor activity of the 4 treatment groups concurrently was an important precautionary measure to rule out the possibility that any feeding effects induced by rimonabant or ghrelin were due to modifications in locomotor activity. The cumulative horizontal activity analysis revealed no significant differences in locomotor activity between the 4 treatment groups at any of the tested time points. It seems clear that ghrelin's ability to increase food intake when infused into the VTA was not a result of an overall increase in locomotor activity as reflected by the normal locomotor activity measured in the IP vehicle/intra-VTA ghrelin group. Similarly rimonabant's ability to ablate ghrelin's appetitive effects was not caused by decreased locomotor activity within the IP rimonabant/intra-VTA ghrelin group.

It is evident from experiment 1 and previous studies that ghrelin and endocannabinoid systems are important and interact to encourage feeding behaviours within multiple important feeding related brain regions (i.e. VTA, HIP, NA, PFC, and HYP); however, the nature of this interaction and whether the mechanism differs between brain regions remain unclear (Tucci et al., 2004; Kola et al., 2008; Isokawa, 2012; Sarvari et al., 2014). For instance, within the hypothalamus, it has been speculated that CB-1Rs and GHSRs may heterodimerize to increase the activation of AMPK signalling cascades, which then leads to the stimulation of feeding (Kola et al., 2008, Lim et al., 2013); whereas, within the VTA, the mechanisms in which endocannabinoid and ghrelin systems interact to stimulate feeding are less clear since CB-1Rs are not found on GHSR positive dopamine neurons, whose activity has been shown to drive food intake (Herkenham et al., 1991; Matsuda et al., 1993; Guan et al., 1997; Abizaid et al., 2006). To this end, we decided to examine CB-1R expression within the VTA, regions that the 
VTA projects to such as the PFC, HIP, \& NA, and other important feeding nuclei such as the HYP, in rats with deletions to the GHSR compared to WT rats. It was hypothesized that if the alleged interaction between these two systems is truly essential to the modulation of feeding in the VTA then a disrupted ghrelin signalling system should induce changes in the endocannabinoid system that ought to be reflected by modifications in CB-1R expression in the aforementioned associated brain regions. Findings from experiment 2 highlighted that CB-1R mRNA is decreased within the VTA, increased within the PFC, and unchanged in the HYP, NA, and HIP of GHSR KO compared to WT rats.

When making inferences about mRNA expression data, particularly with respect to CB$1 \mathrm{R}$ expression, one must take into consideration multiple factors. First, the endocannabinoid system is extremely complex and seems to function diversely in different locations within the body. For example, endocannabinoids are thought to activate AMPK activity in the hypothalamus, decrease AMPK activity in the heart, and although they mostly act as retrograde messengers within the brain they also have been shown to have autocrine capabilities (Kola et al., 2005, Jantti et al., 2013). Second, CB-1Rs are almost exclusively found on axon terminals; whereas, CB-1R mRNA is traditionally found in neuron cell bodies. Therefore one must be careful in interpreting results based on either mRNA or protein expression alone (spatially separated). Third, there have been conflicting results in terms of whether CB-1R agonists (e.g. 2-AG, AEA, \& THC) decrease or increase the transcription of the CB-1R gene (Laprairie et al., 2012). Within numerous brain regions, many studies report that $C B-1 R$ density is inversely related to ligand availability such that chronic $C B-1 R$ agonist treatment (i.e. THC) results in decreased CB-1R mRNA levels (i.e. desensitization) (Harrold et al., 2002; Breivogel et al., 1999; 
Corchero et al., 1999). Intriguingly, many of these studies also found regions in which chronic CB-1R agonist treatment resulted in an upregulation of $C B-1 R$ mRNA; although, these regions often conflicted with those reported from similar studies (Romero et al., 1996; Zhuang et al., 1998; Breivogel et al., 1999; Corchero et al., 1999; Harrold et al., 2002). Conversely, many cell culture conducted studies using neural and non-neural cell types demonstrated a substantial increase in $C B-1 R$ mRNA expression upon endogenous ligand (i.e. 2-AG \& AEA) administration (Mukhopadhyay et al., 2010; Proto et al., 2011; Borner et al., 2007; Laprairie, et al., 2013). It seems as though when CB-1R positive cells are isolated and treated with CB-1R agonist, as is the case with in vitro studies, they respond by upregulating $C B-1$ Rs (i.e. CB-1R mRNA); however, CB-1R positive neurons in vivo may differentially regulate their $\mathrm{CB}-1 \mathrm{Rs}$ depending on the duration of $C B-1 R$ agonist treatment (chronic versus acute) and/or based on external influence (e.g. afferent signals, local neural microenvironments). Future gas chromatography (GC) flame ionization detection and GC-mass spectroscopy studies, that will allow for the quantification of 2-AG and AEA within the aforementioned feeding related regions, in which CB-1R mRNA expression data was collected, will be instrumental in confirming the relationship between endocannabinoid tone and CB-1R mRNA expression.

The lower CB-1R mRNA expression observed within the VTA of GHSR KO rats relative to their WT counterparts is likely a result of a lower local endocannabinoid tone within this region. Consistent with this, ghrelin has an extensive role in activating VTA dopamine neurons (both directly and indirectly) within WT rats; however, within GHSR KOs, ghrelin's ability to excite these neurons would be lost (Abizaid et al., 2006). It follows that the VTA dopamine neurons found in the GHSR KOs would presumably be less excitable (i.e. decreased burst firing 
frequencies) and would have less retrograde endocannabinoid messenger release compared to corresponding WT rats. Consequently, this would reduce the demand of CB-1Rs within this region and may help explain why CB-1R mRNA expression is lower in the GHSR KO relative to the WTs. The downregulation of CB-1R mRNA in response to this chronic lowered endocannabinoid tone cannot be explained by changes in CB-1R expression within a majority of the afferent connections to the VTA as the cell bodies of the neurons that project to this region are found elsewhere (Lupica \& Riegel, 2005). Similarly, it cannot reflect changes in CB-1R mRNA within VTA dopamine neurons themselves as studies using radiolabeled CB-1R agonists have failed to localize CB-1Rs on VTA dopamine neurons (Herkenham et al., 1991). Consequently, the lowered CB-1R mRNA expression observed in the GHSR KOs is likely reflecting a downregulation of $\mathrm{CB}-1 \mathrm{Rs}$ within the other predominant subset of neurons found within the VTA; GABAergic interneurons and efferents that originate in the VTA and which are known to project to the NA, PFC, and the VTA itself. Future studies investigating the excitability of VTA dopamine neurons within GHSR KO rats relative to WT rats, especially after manipulation of endocannabinoid system elements (i.e. CB-1R agonist \& antagonist), will provide a more complete understanding of how these two systems interact within the VTA.

The mechanisms underlying the upregulation of CB-1R mRNA within the PFC of GHSR KO compared to WT rats are unknown as the relationship between ghrelin and endocannabinoid systems within this region is still not well understood; however, recent evidence suggests that these two systems do interact within this region. Functional magnetic resonance imaging blood oxygen level dependant (BOLD) techniques detect a significant alteration (i.e. decrease) in the BOLD response in the PFC of anaesthetized rats in response to ghrelin (Logothetis et al., 2001; 
Sarvari et al., 2014). Interestingly, this decrease is partially attenuated by pre-treating rats with rimonabant; illustrating that the endocannabinoid system either directly or indirectly works in tandem with the ghrelin system to modulate neuronal activity within the PFC (Sarvari et al., 2014). Immunofluoresence studies using antibodies specific for the CB-1R and the GHSR may provide a better anatomical picture of the distribution of these receptors within the PFC and may provide leads as to how these two systems integrate their signals within this region.

Interestingly, the CB-1R mRNA expression profile of the GHSR KOs relative to the WTs (i.e. low VTA expression and high PFC) mimic CB-1R mRNA expression and binding density patterns observed in both human subjects with psychological disorders and in rodents that have been subjected to chronic stress paradigms (Hungund et al., 2004; Dean et al., 2001; Dalton et al., 2011; Hill et al., 2008; Bortolato et al., 2007). For example, CB-1R mRNA is upregulated in the PFC of depressed suicide victims and patients who have been diagnosed with paranoid schizophrenia (Hungund et al., 2004; Dean et al., 2001; Dalton et al., 2011). Moreover, chronic unpredictable stress and chronic mild stress paradigms cause a significant increase in $C B-1 R$ receptor binding site density and $\mathrm{mRNA}$ within the PFC, yet a significant decrease in these measures within the VTA (Hill et al., 2008; Bortolato et al., 2007). There has not been an extensive amount of work done in terms of characterising the genotypic and corresponding functional or behavioural differences of GHSR KO relative to WT rodents. The finding that the GHSR KO rats used have the same dysregulated CB-1R mRNA expression profile (within the PFC and VTA) of chronically stressed mice and human subjects with physiological disorders may help explain the observed predisposition towards anxiety and depressive related 
pathologies reported previously (Lutter et al., 2008; Patterson et al., 2010; Patterson et al., 2013).

The fact that there was no significant difference in CB-1R mRNA expression within the hypothalamus of GHSR KO compared to WT rats was quite surprising given the known interdependence of these two systems within this region (Tucci et al., 2004; Kola et al., 2005; Kola et al., 2008; Lim et al., 2013). One might predict that CB-1R mRNA expression would be upregulated within GHSR KO relative to WT rats due to potential compensatory effects as substantial evidence has demonstrated that both GHSR and CB-1R activation contribute to the stimulation of AMPK signalling cascades within the hypothalamus (see Figure 1). Moreover, it has been predicted that these two receptors (i.e. GHSR \& CB-1R) may form heterodimers to increase their agonistic activity within this region as studies have shown that both CB-1Rs and GHSRs do form heterodimers with other receptors to enhance their agonistic activity (Ellis et al., 2006; Turu \& Hunyady, 2010; Schellekens et al., 2013; Alen et al., 2013; Lim et al., 2013). Accordingly, if the ghrelin receptor is defective then any activity that normally would occur as a result of the GHSR/CB-1R heterodimer would be ablated and presumably elicit changes in CB$1 R$ expression. The fact that there was no detectable difference in hypothalamic CB-1R mRNA levels between the two genotypes could have been the result of many different phenomena. First, the hypothalamus has many small and functionally diverse nuclei that contain numerous different cell types (some of which have antagonistic roles) (e.g. arcuate nucleus) (Abizaid \& Horvath, 2008; Sanchez-Lasheras et al., 2010). Consequently, when the hypothalamus was punched CB-1R mRNA levels within different nuclei and even within opposing cell types could have offset any changes that may have existed within specific subnuclei or even a particular 
subset of neurons within a given nucleus. Laser collection microdissection, a technique that uses a microscope to visualize and software to select a specific nuclei or even single cells of interest before the region of interest is separated and collected from surrounding tissue, via a laser, may prove to be invaluable for analysing CB-1R mRNA expression within distinct nuclei and sub-nuclei of the hypothalamus. The feasibility of this technique for the aforementioned purpose was recently demonstrated when dopamine 2 receptors and G-protein-regulated inward-rectifier potassium channel 2 mRNA were quantified via RTq-PCR after dopamine neurons from mice and human samples were laser dissected and collected for analysis (Dragicevic et al., 2014). Alternatively, it is conceivable that GHSR ablation does significantly affect the endocannabinoid system (i.e. less or more CB-1R protein expression) within the hypothalamus but that it is not reflected in basal CB-1R mRNA expression. There are many processes in between when a gene is transcribed, translated into a protein, and then transported to its active location (e.g. general translation, folding, post-translational modifications, stability, degradation, and membrane localization); many of which could be differentially regulated in the GHSR KO relative to WT rats. Lastly, since we were comparing hypothalamic CB-1R mRNA within a genetic KO model instead of pharmacologically blocking GHSR signalling, it could be that other systems, rather than the endocannabinoid system, compensated for the lack of ghrelin signalling and hence no major observable differences in CB1R mRNA manifested.

Similarly, although there is appreciable expression of GHSR mRNA and CB-1R binding density (as determined using radio labeled CB-1R agonist) within the HIP and NA of rats (Herkenham et al., 1991; Guan et al., 1997), RT qPCR analysis revealed that CB-1R mRNA levels 
were unchanged within these regions in the GHSR KO compared to the WT rats. It was surprising to see no differences within the HIP given the reported importance of the interaction between ghrelin and endocannabinoids in modulating synaptic plasticity and neurogenesis associated with learning and memory (Cuellar \& Isokawa, 2011; Isokawa, 2012; Cahill et al., 2014). Similarly, it was unexpected to see comparable CB-1R expression within the NA of both genotypes as rat fMRI BOLD studies suggest that ghrelin and endocannabinoid systems strongly affect one another within the NA (Sarvari, et al., 2014). The potential reasons listed above for the lack of effect seen in the hypothalamus may be applicable to describe the analogous absence of major changes observed in the HIP and NA; however, other non-discussed mechanisms may also contribute.

Future studies will be needed to elucidate why no significant CB-1R mRNA changes are observed within the HYP, HIP, \& NA of GHSR KOs relative to WTs even though significant evidence suggests that these two systems are intimately interconnected within these regions (Tucci et al., 2004; Kola et al., 2005; Kola et al., 2008; Lim et al., 2013; Cuellar \& Isokawa, 2011; Isokawa, 2012; Sarvari, et al., 2014). Furthermore, figuring out how endocannabinoid levels and other factors modify CB-1R mRNA expression under different conditions (chronic, acute) and how these factors ultimately pertain to functional levels of CB-1Rs on the surface of cells would facilitate the elucidation of molecular circuits and allow for more accurate predictions of the role endocannabinoids play in various nuclei. 


\section{Conclusions}

Here we demonstrated that non-fasted rats will significantly increase their consumption of standard chow following intra-VTA infusions of ghrelin and that this corresponding increase in food intake depends on a functional endocannabinoid system as peripheral pre-treatment with rimonabant completely attenuated the enhanced feeding to control levels. Together, this data suggests that ghrelin targets the VTA to increase food intake through a mechanism that requires a functional endocannabinoid system. Furthermore, we also demonstrated that CB-1R mRNA expression is significantly reduced in the VTA but enhanced in the PFC of GHSR KO relative to WT rats. Interestingly, this may reflect a previously uncharacterized genotypic vulnerability to psychological related disorders as this same CB-1R mRNA expression profile has been commonly observed in subjects with physiological disorders as well as chronically stressed rodents. Lastly, the CB-1R mRNA study also demonstrated that disruption of the ghrelin system induces changes in the endocannabinoid system differentially within distinct brain regions. This highlights the need for the elucidation of the exact nature of the interaction between these two systems, within each specific nucleus, so that future pharmaceuticals can be more appropriately designed and their mechanisms better understood. 


\section{References}

Abizaid, A. (2009). Ghrelin and dopamine: new insights on the peripheral regulation of appetite. Journal of Neuroendocrinology 21:787-793.

Abizaid, A., Liu, Z. W., Andrews, Z. B., Shanabrough, M., Borok, E., Elsworth, J. D., Roth, R. H., Sleeman, M. W., Picciotto, M. R., Tschop, M. H., Gao, X. B., \& Horvath, T. L. (2006). Ghrelin modulates the activity and synaptic input organization of midbrain dopamine neurons while promoting appetite. Journal of Clinical Investigations, 116(12): 32293239.

Abizaid, A., \& Horvath, T. L. (2008). Brain circuits regulating energy homeostasis. Regulatory Peptides, 149: 1-16.

Adan, R. A., Cone, R. D., Burbach, J. P., \& Gispen, W. H. (1994). Differential effects of melanocortin peptides on neural melanocortin receptors. Molecular Pharmacology, 46: 1182-90.

Alen, F., Crespo, I., Ramirez-Lopez, M. T., Jagerovic, N., Goya, P., Rodriguez de Fonseca, F., Gomez de Heras, R., \& Orio, L. Ghrelin-induced orexigenic effect in rats depends on the metabolic status and is counteracted by peripheral CB1 receptor antagonism. PLOS ONE, 8(4): 60918-60924.

Alger, B. E. (2002). Retrograde signaling in the regulation of synaptic transmission: focus on endocannabinoids. Progress in Neurobiology, 68: 247-286.

Anand, B. K., \& Brobeck, J. R. (1951). Localization of a feeding center in the hypothalamus of the rat. Proceedings of the Society for Experimental Biology and Medicine, 77: 323-24.

Andersson, U., Filipsson, K., Abbott, C. R., Woods, A., Smith, K., Bloom, S. R., Carling, D.,\& Small, C. J. (2004). AMP-activated protein kinase plays a role in the control of food intake. Journal of Biological Chemistry, 279: 12005-12008.

Aponte, Y., Atasoy, D., \& Sternson, S. M. (2011). AGRP neurons are sufficient to orchestrate feeding behavior rapidly and without training. Nature Neuroscience, 14: 351-355.

Arnone, M., Maruani, J., Chaperon, F., Thiebot, M., Poncelet, M., Soubrie, P., \& Le Fur, G. (1997). Selective inhibition of sucrose and ethanol intake by SR 141716, an antagonist of central cannabinoid (CB1) receptors. Psychopharmacology, 132: 104-106.

Asakawa, A., Inui, A., Kaga, T., Yuzuriha, H., Nagata, T., Fujimiya, M., Katsuura, G., Makino, S., Fujino, M. A., \& Kasuga, M. (2001). A role of ghrelin in neuroendocrine and behavioral responses to stress in mice. Neuroendocrinology, 74(3): 143-147. 
Baskin, D. G., Breininger, J. F., \& Schwartz, M. W. (1999). Leptin receptor mRNA identifies a subpopulation of neuropeptide $Y$ neurons activated by fasting in rat hypothalamus. Diabetes, 48: 828-33.

Bayer, V. E., \& Pickel, V. M. (1991). GABA-labeled terminals form proportionally more synapses with dopaminergic neurons containing low densities of tyrosine hydroxylaseimmunoreactivity in rat ventral tegmental area. Brain Research, 559: 44-55.

Bednarek, M. A., Feighner, S. D., Pong, S. S., McKee, K. K., Hreniuk, D. L., Silva, M. V., Warren, V. A., Howard, A. D., Van Der Ploeq, L. H., \& Heck, J. V. (2000). Structure-function studies on the new growth hormone-releasing peptide, ghrelin: minimal sequence of ghrelin necessary for activation of growth hormone secretagogue receptor 1a. Journal of Medicinal Chemistry, 43(23): 4370-4376.

Beltramo, M., \& Piomelli, D. (2000). Carrier-mediated transport and enzymatic hydrolysis of the endogenous cannabinoid 2-arachidonylglycerol. Neuroreport, 11: 1231-1235.

Beltramo, M., Stella, N., Calignano, A., Lin, S. Y., Makriyannis, A., \& Piomelli, D. (1997). Functional role of high-affinity anandamide transport, as revealed by selective inhibition. Science, 277: 1094-1097.

Biebermann, H., Castaneda, T. R., van Landeghem, F., von Deimling, A., Escher, F., Brabant, G., Hebebrand, J., Hinney, A., Tschop, M. H., Gruters, A., \& Krude, H. (2006). A role for $\beta$ melanocyte-stimulating hormone in human body-weight regulation. Cell Metabolism, 3 : 141-46.

Borner, C., Holt, V., \& Kraus, J. (2007). Transcriptional regulation of the cannabinoid receptor type 1 gene in T cells by cannabinoids. Journal of Leukocyte Biology, 81: 336-343.

Bortolato, M., Mangieri, R. A., Fu, J., Kim, J. H., Arguello, O., Duranti, A., Tontini, A., Mor, M., Tarzia, G., \& Piomelli, D. (2006). Antidepressant-like activity of the fatty acid amide hydrolase inhibitor URB597 in a rat model of chronic mild stress. Biological Psychiatry, 62: 1103-1110.

Boston, B. A., Blaydon, K. M., Varnerin, J., \& Cone, R .D. (1997). Independent and additive effects of central POMC and leptin pathways on murine obesity. Science, 278: 1641-44.

Breivogel, C., Childers, S. R., Deadwyler, S. A., Hampson, R. E., Vogt, L. J. \& Sim-Selley, L. J. (1990). Chronic $\Delta^{9}$-Tetrahydrocannabinol treatment produces a time-dependent loss of cannabinoid receptors and cannabinoid receptor-activated G Proteins in rat brain. Journal of Neurochemistry, 73(6): 2447-2459. 
Broglio, F., Gottero, C., Benso, A., Prodam, F., Destefanis, S., Gauna, C., Maccario, M., Deghenghi, R., van der Lely, A. J., \& Ghigo, E. (2003). Effects of ghrelin on the insulin and glycemic responses to glucose, arginine, or free fatty acids load in humans. Journal of Clinical Endocrinology Metabolism, 88(9): 4268-4272.

Cahill, S. P., Hatchard, T., Abizaid, A., \& Holahan, M. R. (2014). An examination of early neural and cognitive alterations in hippocampal-spatial function of ghrelin receptor-deficient rats. Behavioral Brain Research, 264: 105-115.

Cameron, D. L. Wessendorf, M. W. \& Williams, J. T. (1997). A subset of ventral tegmental area neurons is inhibited by dopamine, 5-hydroxytryptamine and opiods. Neuroscience, 77: 155-166.

Camina, J. P., Carreira, M. C., El Messari, S., Llorens-Cortes, C., Smith, R. G., \& Casanueva, F. F. (2004). Desensitization and endocytosis mechanisms of ghrelin-activated growth hormone secretagogue receptor 1a. Endocrinology, 145(2): 930-940.

Ciccarelli, A., Calza, A., Panzanelli, P., Concas, A., Giustetto, M., \& Sassoe-Pognetto. (2012). Organization of GABAergic synaptic circuits in the rat ventral tegmental area. PLOS one, 7(10): e46250.

Caminos, J. E., Tena-Sempere, M., Gaytan, F., Sanchez-Criado, J. E., Barreiro, M. L., Nogueiras, R., Casanueva, F. F., Aguilar, E., \& Dieguez, C. (2003). Expression of ghrelin in the cyclic and pregnant rat ovary. Endocrinology, 144: 1594-1602.

Carr, D. B. \& Sesack, S. R. (2000). GABA-containing neurons in the rat ventral tegmental area project to the prefrontal cortex. Synapse, 38, 114-123.

Castillo, P. E., Younts, T. J., Chavez, A. E., \& Hashimotodan, Y. (2012). Endocannabinoid signaling and synaptic function. Neuron, 76: 70-81.

Cawley, J., \& Meyerhoefer, C. (2012). The medical care costs of obesity: An instrumental variables approach. Journal of Health Economics, 31: 219-230.

Charara, A., Smith, Y., \& Parent, A., (1996). Glutamatergic inputs from the pedunculopontine nucleus to midbrain dopaminergic neurons in primates: phaseolus vulgaris leucoagglutinin anterograde labeling combined with postembedding glutamate and GABA immunohistochemistry. Journal of Comparative Neurology, 364: 254-266.

Chen, C. (2000). Growth Hormone secretagogue actions on the pituitary gland: multiple receptors for multiple ligands? Clinical Experimental Pharmacology and Physiology 27:323-329. 
Ciccarelli, A., Calza, A., Panzanelli, P., Concas, A., Giustetto, M., \& Sassoe-Pognetto. (2012). Organization of GABAergic synaptic circuits in the rat ventral tegmental area. PLOS one, 7(10): e46250.

Corchero, J., Romero, J., Berrendero, F., Fernandez-Ruiz, J., Ramos, J. A., Fuentes, J. A. \& Manzanares, J. (1999). Time-dependent differences of repeated administration with Delta9-tetrahydrocannabinol in proenkephalin and cannabinoid receptor gene expression and G-protein activation by mu-opiod and CB1-cannabinoid receptors in the caudate-putamen. Molecular Brain Research, 67(1): 148-157.

Chuang, J. C., Perello, M., Sakata, I., Osborne-Lawrence, S., Savitt, J. M., Lutter, M., \& Zigman, J. M. (2011). Ghrelin mediates stress-induced food-reward behavior in mice. Journal of Clinical Investigations, 121: 2684-2692.

Chuang, J. C., \& Zigman, J. M. (2010). Ghrelin's roles in stress, mood, and anxiety regulation. International Journal of Peptides, 2010: 1-5.

Cowley, M. A., Smart, J. L., Rubinstein, M., Cerdaan, M. G., Diano, S. Horvath, T. L., Cone, R. D., \& Low, M. J. (2001). Leptin activates anorexigenic POMC neurons through a neural network in the arcuate nucleus. Nature, 411: 480-484.

Cowley, M. A., Smith, R. G., Diano, S., Tshop, M., Pronchuk, N., Grove, K. L., Strasburger, C. J., Bidlingmaier, M., Esterman M., Heiman, M. L., Garcia-Segura, L. M., Nillni, E. A., Mendez, P., Low, M. J., Sotonyi, P., Friedman, J. M., Liu, H., Pinto, S., Colmer, W. F., Cone, R. D., \& Horvath, T. L. (2003). The distribution and mechanism of action of ghrelin in the CNS demonstrates a novel hypothalamic circuit regulating energy homeostasis. Neuron, 37: 649-661.

Craft, R. M., Wakley, A. A., Tsutsui, K. T., \& Laggart, J. D. (2011). Sex differences in cannabinoid 1 vs. cannabinoid 2 receptor-selective antagonism of the antinociception produced by $\Delta^{9}$ tetrahydrocannabinol and CP55,940 in the rat. The Journal of Pharmacology and Experimental Therapeutics, 340(3): 787-800.

Cuellar, J. N., \& Isokawa, M. (2011). Ghrelin-induced activation of cAMP signal transduction and its negative regulation by endocannabinoids in the hippocampus. Neuropharmacology, 60(6): 842-851.

Dalton, V. S., Long, L. E., Weickert, C. S., \& Zavitsanou, K. (2011). Paranoid schizophrenia is characterized by increased $\mathrm{CB}_{1}$ receptor binding in the dorsolateral prefrontal cortex. Neuropsychopharmacology, 36: 1620-1630.

Date, Y., Kojima, M., Hosoda, H., Sawaguchi, A., Mondal, M. S., Suganuma, T., Matsukura, S., Kangawa, K., \& Nakazato, M. (2000). Ghrelin, a novel growth hormone-releasing acylated peptide, is synthesized in a distinct endocrine cell type in the gastrointestinal tracts of rats and humans. Endocrinology, 141: 4255-4261. 
Dean, B., Sundram, S., Bradbury, R., Scarr, E., \& Copolov, D. 2001. Studies on [3H]CP-55940 binding in the human central nervous system: regional specific changes in density of cannabinoid-1 receptors associated with schizophrenia and cannabis use. Neuroscience, 103: 9-15.

Demuth, D. G., \& A. Molleman. (2006). Cannabinoid signalling. Life Sciences, 78: 549-563.

Devane, W. A., Dysarz, F. A., Johnson, M. R., Melvin, L. S., \& Howlett, A. C. (1988). Determination and characterization of a cannabinoid receptor in rat brain. Molecular Pharmacology, 34: 605-613.

Devane, W. A., Hanus, L., Breuer, A., Pertwee, R. G., Stevenson, L. A., Griffin, G., Gibson, D., Mandelbaum, A., Etinger, A., \& Mechoulam, R. (1992). Isolation and structure of a brain constituent that binds to the cannabinoid receptor. Science, 258: 1946-1949.

Di Chiara, G.,\& Imperato, A., (1988). Drugs abused by humans preferentially increase synaptic dopamine concentrations in the mesolimbic system of freely moving rats. Proceedings of the National Academy of Sciences, 85: 5274-5278.

Dietrich, M., \& Horvath, T. L. (2013). Hypothalamic control of energy balance: insights into the role of synaptic plasticity. Trends in Neurosciences, 36 (2): 65-73.

Di Marzo, V. (2006). A brief history of cannabinoid and endocannabinoid pharmacology as inspired by the work of British scientists. Trends in Pharmacological Sciences, 1-7.

Di Marzo, V., Bifulco, M., \& De Petrocellis, L. (2004). The endocannabinoid system and its therapeutic exploitation. Nature Reviews, 3: 771-784.

Di Marzo, V., \& Fontana, A. (1995). Anandamide, an endogenous cannabinomimetic eicosanoid: 'killing two birds with one stone'. Prostaglandins, Leukotrienes and Essential Fatty Acids, 53: 1-11.

Di Marzo, V., Goparaju, S. K., Wang, L., Liu, J., Batkai, S., Jarai, Z., Fezza, F., Minura, G. L., Palmiter, R. D., Sungiura, T., \& Kunos, G. (2001). Leptin-regulated endocannabinoids are involved in maintaining food intake. Nature, 410: 822-825.

Di Marzo, V., \& Matias, I. (2005). Endocannabinoid control of food intake and energy balance. Nature Neuroscience, 8(5): 585-589.

Di Marzo, V., Sepe, N., De Petrocellis, L., Berger, A., Crozier, G., Fride, E., \& Mechoulam, R. (1998). Trick or treat from food endocannabinoids? Nature, 396(6712): 636-7. 
Disse, E., Bussier, A. L., Veyrat-Durebex, C., Deblon, N., Pfluger, P. T., Tschop, M. H., Laville, M., Rohner-Jeanrenaud, F. (2010). Peripheral ghrelin enhances sweet taste food consumption and preference, regardless of its caloric content. Physiology \& Behaviour, 101: 277-281.

Dornonville de la Cour, C., Bjorkqvist, M., Sandvik, A. K., Bakke, I., Zhao, C. M., Chen, D., \& Hakanson, R. (2001). A-like cells in the rat stomach contain ghrelin and do not operate under gastrin control. Regulatory Peptides, 99(2-3): 141-150.

Dragicevic, E., Poetschke, C., Duda, J., Schlaudraff, F., Lammel, S., Schiemann, J., Fauler, M., Hetzel, A., Watanabe, M., Lujan, R., Malenka, R. C., Striessnig, J., \& Liss, B. (2014). Cav1.3 channels control D2-autoreceptor responses via NCS-1 in substantia nigra dopamine neurons. Brain, pii: awu131.

Egecioglu, E., Jerlhag, E., Salome, N., Skibicka, K. P., Haage, D., Bohlooly, Y. M., Andersson, D., Bjursell, M., Perrissoud, D., Engel, J. A., \& Dickson, S. L. (2010). Ghrelin increases intake of rewarding food in rodents. Addiction Biology, 15: 304-311.

Ellacott, K.L., \& Cone, R. D. (2004). The central melanocortin system and the integration of short and long-term regulators of energy homeostasis. Recent Progress in Hormonal Research, 59: 395-408.

Ellis, J., Pediani, J. D., Canals, M., Milasta, S., \& Milligan, G. (2006). Orexin-1 receptor cannabinoid CB1 receptor heterodimerization results in both ligand-dependent and independent coordinated alterations of receptor localization and function. Journal of Biological Chemistry, 281: 38812-38824.

Fegley, D., Kathuria, S., Mercier, R., Li, C., Goutopoulos, A., Makriyannis, A., Piomelli D. (2004). Anandamide transport is independent of fatty-acid amide hydrolase activity and is blocked by the hydrolysis-resistant inhibitor AM1172. Proceedings of the National Academy of Science of the USA, 101: 8756-8761.

Ferrini, F., Salio, C., Lossi, L., \& Merighi, A. (2009). Ghrelin in central neurons. Current Neuropharmacology, 7: 37-49.

Fields, H. L., Hjelmstad, G. O., Margolis, E. B., \& Nicola, S. M. (2007). Ventral tegmental area neurons in learned appetitive behavior and positive reinforcement. Annual Reviews in Neuroscience, 30: 289-316.

Finger, B. C., Dinan, T. G., \& Cryan, J. F. (2012). Diet-induced obesity blunts the behavioural effects of ghrelin: studies in a mouse-progressive ratio task. Psychopharmacology, 220(1): 173-181. 
Frago, L. M., Banquedano, E., Argente, J., \& Chowen, J. A. (2011). Neuroprotective actions of ghrelin and growth hormone secretagogues. Frontiers in Molecular Neuroscience, 4(23): 1-11.

French, E. D., Dillon, K., \& Wu, X. F. (1997). Cannabinoids excite dopamine neurons in the ventral tegmentum and substantia nigra. Neuroreport, 8: 649-652.

Gaoni, Y., \& Mechoulam, R. (1964). Isolation, structure, and partial synthesis of an active constituent of hashish. Journal of the American Chemical Society, 86: 1646-1647.

Gessa, G., Melis, M., Muntoni, A., \& Diana, M. (1998). Cannabinoids activate mesolimbic dopamine neurons by an action on cannabinoid CB1 receptors. European Journal of Pharmacology, 341: 39-44.

Glaser, S.T., Abumrad, N, A., Fatade, F., Kaczocha, M., Studholme, K, M., \& Deutsch, D.G. (2003). Evidence against the presence of an anandamide transporter. Proceedings of the National Academy of Science of the USA, 100: 4269-4274.

Grace, A. A., \& Onn, S. (1989). Morphology and electrophysiological properties of immunocytochemically identified rat dopamine neurons recorded in vitro. Journal of Neuroscience, 9: 3463-3481.

Goa, Q., \& Horvath, T. L. (2007). Neurobiology of feeding and energy expenditure. Annual Review of Neuroscience, 30: 367-398.

Gualillo, O., Caminos, J. E., Kojima, M., Kangawa, K., Arvat, E., Ghigo, E., Casanueva, F. F., \& Diéguez, C. (2001). Gender and gonadal influences on ghrelin mRNA levels in rat stomach. European Journal of Endocrinology, 144: 687-690.

Guan, X. M., Yu, H., Palyha, C., McKee, K. K., Feighner, S. D., Sirinathsinghji, D. J. S., Smith, R. G., Van der Ploeg, L. H. T., \& Howard, A. D. (1997). Distribution of mRNA encoding the growth hormone secretagogue receptor in brain and peripheral tissues. Molecular Brain Research, 48: 23-27.

Gulyas, A. I., Cravatt, B. F., Bracey, M. H., Dinh, T. P., Piomelli, D., Boscia, F., \& Freund, T. F. (2004). Segregation of two endocannabinoid-hydrolyzing enzymes into pre- and postsynaptic compartments in the rat hippocampus, cerebellum and amygdala. European Journal of Neuroscience, 20: 441-458.

Gutierrez, J. A., Solenberg, P. J., Perkins, D. R., Willency, J. A., Knierman, M. D., Jin, Z., Witcher, D. R., Luo, S., Onyia, J. E., \& Hale, J. E. (2008). Ghrelin octanoylation mediated by an orphan lipid transferase. Proceedings of the National Academy Sciences, 105(17): 63206325. 
Ha, J., Daniel, S., Broyles, S. S., \& Kim, K. H. (1994). Critical phosphorylation sites for acetyl-CoA carboxylase activity. Journal of Biological Chemistry, 269(35): 22162-22168.

Hahn, T. M., Breininger, J. F., Baskin, D. G., \& Schwartz, M. W. (1998). Coexpression of Agrp and NPY in fasting-activated hypothalamic neurons. Nature, 1: 271-272.

Hao, S., Avraham, Y., Mechoulam, R., \& Berry, E.M. (2000). Low dose anandamide affects food intake, cognitive function, neurotransmitter and corticosterone levels in diet-restricted mice. European Journal of Pharmacology, 392: 147-156.

Hardie, D. G., \& Carling, D. (1997). The AMP-activated protein kinase--fuel gauge of the mammalian cell? European Journal of Biochemistry, 246(2): 259-273.

Hardie, D. G., \& Sakamoto, K. (2006). AMPK: A key sensor of fuel and energy status in skeletal muscle. Physiology, 21: 48-60.

Harrold, J., Elliott, C., King, P., Widowson, P.S., \& Williams, G. (2002). Down-regulation of cannabinoid-1 (CB-1) receptors in specific extrahypothalamic regions of rats with dietary obesity: A role for endogenous cannabinoids in driving appetite for palatable food? Brain Research, 952: 232-238.

Hattori, N., Saito, T., Yagyu, T., Jiang, B. H., Kitagawa, K., \& Inagaki, C. (2001). GH, GH receptor, GH secretagogue receptor, and ghrelin expression in human T cells, B cells, and neutrophils. Journal of Clinical \& Endocrinology Metabolism, 86: 4284-4291.

Hetherington, A. W. (1944). Non-production of hypothalamic obesity in the rat by lesions rostral or dorsal to the ventromedial hypothalamic nuclei. Journal of Comparative Neurology. 80:33.

Hetherington, A.W., \& Ranson, S. W. (1940). Hypothalamic lesions and adipocity in the rat. The Anatomical Record, 78:149.

Herkenham, M., Lynn, A. B., Johnson, M. R., Melvin, L, S., de Costa, B, R., \& Rice, K. C. (1991). Characterization and localization of cannabinoid receptors in rat brain: A quantitative in vitro autoradiographic study. The Journal of Neuroscience, 11(2): 563-583.

Hermann, H., Marsicano, G., \& Lutz, B. (2002). Co-expression of the cannabinoid receptor type 1 with dopamine and serotonin receptors in distinct neuronal subpopulations of the adult mouse forebrain. Neuroscience, 109: 451-460.

Higgs, S., Williams, C. M., \& Kirkham, T. C. (2003). Cannabinoid influences on palatability: microstructural analysis of sucrose drinking after delta(9)-tetrahydrocannabinol, anandamide, 2-arachidonoyl glycerol and SR141716. Psychopharmacology, 165: 370377. 
Hill, M. N., Carrier, E. J., McLaughlin, R. J., Morrish, A. C., Meier, S. E., Hillard, C. J., \& Gorzalka, B. B. (2008). Regional alterations in the endocannabinoid system in an animal model of depression: effects of concurrent antidepressant treatment. Journal of Neurochemistry, 106 (6): 2322-2336.

Holst, B., Cygankiewicz, A., Jensen, T. H., Ankersen, M. \& Schwartz, T. W. (2003). High constitutive signaling of the ghrelin receptor identification of a potent inverse agonist. Molecular Endocrinology, 17: 2201-2210.

Horvath, T. L. (2006). Synaptic plasticity in energy balance regulation. Obesity, 8: 228-233.

Hosoda, H., Kojima, M., Matsuo, H., \& Kangawa, K. (2000) Ghrelin and des-acyl ghrelin: two major forms of rat ghrelin peptide in gastrointestinal tissue. Biochimica et Biophysica Acta, 279: 909-913.

Howard, A. D., Feighner, S. D., Cully, D. F., Arena, J. P., Liberator, P. A., Rosenblum, C. I., Hamelin, M., Hreniuk, D. L., Palyha, O. C., Anderson, J., Paress, P. S., Diaz, C., Chou, M., Liu, K. K., McKee, K. K., Pong, S. S., Chaung, L. Y., Elbrecht, A., Dashkevicz, M., Heavens, R., Rigby, M., Sirinathsinghji, D. J., Dean, D. C., Melillo, D. G., Patchett, A. A., Nargund, R., Griffin, P. R., DeMartino, J. A., Gupta, S. K., Schaeffer, J. M., Smith, R. G., \& Van der Ploeg, L. H. (1996). A receptor in pituitary and hypothalamus that functions in growth hormone release. Science, 273: 974-977.

Howlett, A. C. (2002). The cannabinoid receptors. Prostaglandins \& Other Lipid Mediators, 6869: 619-631.

Hungund, B. L., Vinod, K, Y., Kassir, S. A., Basavarajappa, B. S., Yalamanchili, R., Cooper, T. B., Mann, J. J., \& Arango, V. (2004). Upregulation of CB1 receptors and agonist stimulated [35S]GTPgammaS binding in the prefrontal cortex of depressed suicide victims. Molecular Psychiatry, 9: 184-190.

Isokawa, M. (2012). Cellular signal mechanisms of reward-related plasticity in the hippocampus. Neural Plasticity, 2012: 1-18.

Jamshidi, N., \& Taylor, D. (2001). Anandamide administration into the ventromedial hypothalamus stimulates appetite in rats. British Journal of Pharmacology, 134:11511154.

Jantti, M. H., Putula, J., Turunen, P. M., Nasman, J., Reijonen, S., Lindquist, C., \& Kukkonen, J. P. Autocrine endocannabinoid signaling through CB1 receptors potentiates OX1 orexin receptor signalling. Molecular Pharmacology, 83(3): 621-632. 
Jarrett, M. M., Limebeer, C. L., \& Parker, L. A. (2005). Effect of Delta9-tetrahydrocannabinol on sucrose palatability as measured by the taste reactivity test. Physiology \& Behavior, 86: 475-479.

Jarrett, M. M., Scantlebury, J., \& Parker, L. A. (2007). Effect of delta(9)-tetrahydrocannabinol on quinine palatability and AM251 on sucrose and quinine palatability using the taste reactivity test. Physiology \& Behavior, 90: 425-430.

Johnson, S. W., \& North, R. A. (1992). Two types of neurone in the rat ventral tegmental area and their synaptic inputs. Journal of Physiology, 450:455-468.

Kalivas, P.W., (1993). Neurotransmitter regulation of dopamine neurons in the ventral tegmental area. Brain Research Reviews, 18: 75-113.

Kanehisa, M., Akiyoshi, J., Kitaichi, T., Matsushita, H., Tanaka, E., Kodama, K., Hanada, H., \& Isogawa, K. (2006). Administration of antisense DNA for ghrelin causes an antidepressant and anxiolytic response in rats. Progress in Neuro-Psychopharmacology and Biological Psychiatry, 30(8): 1403-1407.

Kano, M., Ohno-Shosaku, T., Hashimotodani, Y., Uchigashima, M., \& Watanabe, M. (2009). Endocannabinoid-mediated control of synaptic transmission. Physiological Reviews, 89: 309-380.

Kauer, J. A., \& Malenka, R. C. (2007). Synaptic plasticity and addiction. Nature Reviews in Neuroscience, 8: 844-858.

King, S. J., Isaacs, A. M., O'Farrell, E., \& Abizaid, A. (2011). Motivation to obtain preferred foods is enhanced by ghrelin in the ventral tegmental area. Hormones \& Behaviour, 60: 572580.

Kirchner, H., Gutierrez, J. A., Solenberg, P. J., Pfluger, P. T., Czyzyk, T. A., Willency, J. A., Schurmann, A., Joost, H. G., Jandacek, R. J., Hale, J. E., Heimen, M. L., \& Tschop, M. H. (2009). GOAT links dietary lipids with the endocrine control of energy balance. Nature Medicine, 15(7): 741-745.

Kirkham, T. C. (2009). Cannabinoids and appetite: Food craving and food pleasure. International Review of Psychiatry, 21(2): 163-171.

Kirkham, T. C., Williams, C. M., Fezza, F., Di Marzo, V. (2002). Endocannabinoid levels in rat limbic forebrain and hypothalamus in relation to fasting, feeding and satiation: stimulation of eating by 2-arachidonoyl glycerol. British Journal of Pharmacology, 136: 550-557. 
Kohno, D., Gao, H. Z., Muroya, S., Kikuyama, S. \& Yada, T. (2003). Ghrelin directly interacts with neuropeptide-Y-containing neurons in the rat arcuate nucleus: $\mathrm{Ca} 2 \mathrm{p}$ signaling via protein kinase $\mathrm{A}$ and $\mathrm{N}$-type channel-dependent mechanisms and cross-talk with leptin and orexin. Diabetes 52: 948-956.

Kojima, M., Hosoda, H., Date, Y., Nakazato, M., Matsuo, H., \& Kangawa, K. (1999). Ghrelin is a growth-hormone-releasing acylated peptide from stomach. Nature, 402: 656-660.

Kola, B. (2008). Role of AMP-activated protein kinase in the control of appetite. Journal of Neuroendocrinology, 20: 942-951.

Kola, B., Farkas, I., Christ-Crain, M., Wittmann, G., Lolli, F., Amin, F., Harvey-White, J., Liposits, Z., Kunos, G., Grossman, A.B., Fekete, C., \& Korbonits, M. (2008). The orexigenic effect of ghrelin is mediated through central activation of the endogenous cannabinoid system. PLoS One 3(3): 1-8.

Kola, B., Hubina, E., Tucci, S. A., Kirkham, T. C., Garcia, E. A., Mitchell, S. E., Williams, L. M., Hawley, S. A., Hardie, D. G., Grossman, A. B., \& Korbonits, M. (2005). Cannabinoids and ghrelin have both central and peripheral metabolic and cardiac effects via AMPactivated protein kinase. Journal of Biological Chemistry, 280: 25196-25201.

Koleva, D. I., Orbetzova, M. M., Atanassova, P. K. (2013). Adipose tissue hormones and appetite and body weight regulators in insulin resistance. Folia Medica, 55(1):25-32.

Korbonits, M., Bustin, S. A., Kojima, M., Jordan, S., Adams, E. F., Lowe, D. G., Kangawa, K., \& Grossman, A.B. (2001). The expression of the growth hormone secretagogue receptor ligand ghrelin in normal and abnormal human pituitary and other neuroendocrine tumors. Journal of Clinical \& Endocrinology Metabolism, 86: 881-887.

Kortleven, C., Fasano, C., Thibault, D., Lacaille, J. C., \& Trudeau, L. E. (2011). The endocannabinoid 2-arachidonoylgylcerol inhibits long-term potentiation of glutamatergic synapses onto ventral tegmental area dopamine neurons in mice. European Journal of Neuroscience, 33(10): 1751-1760.

Kristenssson, E., Sundqvist, M., Astin, M., Kjerling, M., Mattsson, H., Dornonville De La Cour, C., Hakanson, R., \& Lindstrom, E. (2006). Acute psychological stress raises plasma ghrelin in the rat. Regulatory Peptides, 134: 114-117.

Labouèbe, G., Liu, S., Dias, C., Zou, H., Wong, J. C. Y., Karunakaran, S., Clee, S. M., Phillips, A. G., Boutrel, B., \& Borgland, S. L. (2013). Insulin induces long-term depression of ventral tegmental area dopamine neurons via endocannabinoids. Nature Neuroscience. 16 (3): 300-310. 
Landgren, S., Simms, J. A., Thelle, D. S., Strandhagen, E., Bartlett, S. E., Engel, J. A. \& Jerlhag, E. (2011). The ghrelin signalling system is involved in the consumption of sweets. PLoS One. 6(3):e18170, 1-9.

Laprairie, B. W., Kelly, M., \& Denovan-Wright, E. M. (2012). The dynamic nature of type 1 cannabinoid receptor $\left(\mathrm{CB}_{1}\right)$ gene transcription. British Journal of Pharmacology, 167: 1583-1595.

Laprairie, B. W., Kelly, M., \& Denovan-Wright, E. M. (2013). Cannabinoids increase type 1 cannabinoid receptor expression in a cell culture model of striatal neurons: implications for Huntington's disease. Neuropharmacology, 72: 47-57.

Leibowitz, S. F., \& Wortely, K. E. (2004). Hypothalamic control of energy balance: different peptides, different functions. Peptides, 25: 473-504.

Lim, C. T., Kola, B., Feltrin, D., Perez-Tilve, D., Tschop, M. H., Grossman, A. B., \& Korbonits, M. (2013). Ghrelin and cannabinoids require the ghrelin receptor to affect cellular energy metabolism. Molecular and Cellular Endocrinology, 365(2): 303-308.

Logothetis, N. K., Pauls, J., Augath, M., Trinath, T., \& Oelterman, A. (2001). Neurophysiological investigation of the basis of the fMRI signal. Nature, 412: 150-157.

Lopez, M., Lage, R., Saha, A. K., Perez-Tilve, D., Vazquez, M. J., Varela, L., Sangiao-Alvarellos, S., Tovar, S., Raghay, K., Rodriquez-Cuenca, S., Deoliveira, R. M., Castaneda, T., Datta, R., Dong, J. Z., Culler, M., Sleeman, M. W., Alvarez, C. V.,Gallego, R., Lelliott, C. J., Carling, D., Tschop, M. H., Dieguez, C., \& Vidal-Puig, A. (2008). Hypothalamic fatty acid metabolism mediates the orexigenic action of ghrelin. Cell Metabolism, 7(5): 389-399.

Lu, S., Guan, J.L., Wang, Q.P., Uehara, K., Yamada, S., Goto, N., Date, Y., Nakazato, M., Kojima, M., Kangawa, K., \& Shioda, S. (2002). Immunocytochemical observation of ghrelincontaining neurons in the rat arcuate nucleus. Neuroscience Letters, 321: 157-160.

Lupica, C. R. \& Riegel, A. C. (2005). Endocannabinoid release from midbrain dopamine neurons: a potential substrate for cannabinoid receptor antagonist treatment of addiction. Neuropharmacology, 48: 1105-1116.

Lutter, M., Sakata, I., Osborne-Lawrence, S., Rovinsky, S. A., Anderson, J. G., Jung, S., Birnbaum, S., Yanagisawa, M., Elmquist, J. K., Nestler, E. J., \& Zigman, J. M. (2008). The orexigenic hormone ghrelin defends against depressive symptoms of chronic stress. Nature Neuroscience, 11(7): 752-753.

Malik, S., McGlone, F., Bedrossian, D., \& Dagher, A. (2008). Ghrelin modulates brain activity in areas that control appetitive behavior. Cell Metabolism, 7: 400-409. 
Matsuda, L. A., Bonner, T. I., \& Lolait, S. J. (1993). Localization of cannabinoid receptor mRNA in rat brain. Journal of Comparative Neurology, 327(4): 535-550.

Matsuda, L. A., Lolait, S. J., Brownstein, M. J., Young, A. C., \& Bonner, T. I. (1990). Structure of a cannabinoid receptor and functional expression of the cloned cDNA. Nature, 346: 561564.

Matyas, F., Urban, G. M., Watanabe, M., Mackie, K., Zimmer, A., Freund, T., \& Katona, I. (2008). Identification of the sites of 2-arachidonoylglycerol synthesis and action imply retrograde endocannabinoid signaling at both GABAergic and glutamatergic synapses in the ventral tegmental area. Neuropharmacology, 54(1): 95-107.

McFarland, M. J., Porter, A. C., Rakhshan, F. R., Rawat, D. S., Gibbs, R. A., \& Barker, E. L. (2004). A role for caveolae/lipid rafts in the uptake and recycling of the endogenous cannabinoid anandamide. The Journal of Biological Chemistry, 279: 41991-41997.

McGarry, J. D., Stark, M. J., \& Foster, D. W. (1978). Hepatic malonyl-CoA levels of fed, fasted and diabetic rats as measured using a simple radioisotopic assay. Journal of Biological Chemistry, 253(22): 8291-8293.

Melis, M., Pitis, M., Perra, S., Muntoni, A. L., Pillolla, G., \& Gessa, G. L. (2004). Endocannabinoids mediate presynaptic inhibition of glutamatergic transmission in rat ventral tegmental area dopamine neurons through activation of CB1 receptors. Journal of Neuroscience, 24(1): 53-62.

Melis, T., Succu, S., Sanna, F., Boi, A., Argiolas, A., \& Melis, M. R. (2007). The cannabinoid antagonist SR 141716A (Rimonabant) reduces the increase of extracellular dopamine release in the rat nucleus accumbens induced by a novel high palatable food. Neuroscience Letters, 419: 231-235.

Miller, C. C., Murray, T. F., Freeman, K. G., \& Edwards, G. L. (2004). Cannabinoid agonist, CP 55,940 , facilitates intake of palatable foods when injected into the hindbrain. Physiology \& Behavior, 80: 611-616.

Minokoshi, Y., Alquier, T., Furukawa, N., Kim, Y. B., Lee, A., Xue, B., Mu, J., Foufelle, F., Ferre, P., Birnbaum, M. J., Stuck, B. J., \& Kahn, B. B. (2004). AMP-kinase regulates food intake by responding to hormonal and nutrient signals in the hypothalamus. Nature, 428: 569574.

Minokoshi, Y., Kim, Y. B., Peroni, O. D., Fryer, L. G., Muller, C., Carling, D., \& Kahn, B. B. (2002). Leptin stimulates fatty-acid oxidation by activating AMP-activated protein kinase. Nature, 415: 339-343. 
Mori, K., Yoshimoto, A., Takaya, K., Hosoda, K., Ariyasu, H., Yahata, K., Mukoyama, M., Sugawara, A., Hosoda, H., Kojima, M., Kangawa, K., \& Nakao, K. (2000). Kidney produces a novel acylated peptide, ghrelin. FEBS Letters, 486: 213-216.

Mountjoy, K.G., Mortrud, M. T., Low, M. J., Simerly, R. B., \& Cone, R. D. (1994). Localization of the melanocortin-4 receptor (MC4-R) in neuroendocrine and autonomic control circuits in the brain. Molecular Endocrinology, 8: 1298-308.

Mukhopadhyay, B., Liu, J., Osei-Hyiaman, D., Godlewski, G., Mukhopadhyay, P., Wang, L. Jeong, W. I., Gao, B., Duester, G., Mackie, K., Kojima, S., \& Kunos, G. (2010). Transcriptional regulation of cannabinoid receptor-1 expression in the liver by retinoic acid acting via retinoic acid receptor-gamma. Journal of Biological Chemistry, 285: 19002-19011.

Munro, S., Thomas, K. L., \& Abu-Shaar, M. (1993). Molecular characterization of a peripheral receptor for cannabinoids. Nature, 365: 61-65.

Murphy, K. G., \& Bloom, S. R. (2006). Gut hormones and the regulation of energy homeostasis. Nature, 444: 854-859.

Naleid, A. M., Grace, M. K., Cummings, D. E., \& Levine, A. S. (2005) Ghrelin induces feeding in the mesolimbic reward pathway between the ventral tegmental area and the nucleus accumbens. Peptides, 26: 2274-2279.

Navarrete, M., \& Araque, A. (2008). Endocannabinoids mediate neuronastrocyte communication. Neuron, 57: 883-893.

Navarrete, M., \& Araque, A. (2010). Endocannabinoids potentiate synaptic transmission through stimulation of astrocytes. Neuron, 68: 113-126.

Obici, S., Feng, Z., Arduini, A., Conti, R., \& Rossetti, L. (2003). Inhibition of hypothalamic carnitine palmitoyltransferase-1 decreases food intake and glucose production. Nature Medicine, 9(6): 756-761.

Obici, S., Feng, Z., Morgan, K., Stein, D., Karkanias, G., \& Rossetti, L. (2002). Central administration of oleic acid inhibits glucose production and food intake. Diabetes, 51(2): 271-275.

Ohno-Shosaku, T., Maejima, T., \& Kano, M. (2001). Endogenous cannabinoids mediate retrograde signals from depolarized postsynaptic neurons to presynaptic terminals. Neuron, 29: 729-738.

Oleson, E. B., Beckert, M. V., Morra, J. T., Lansink, C. S., Cachope, R., Abdullah, R. A., Loriaux, A. L., Schetters, D., Pattij, T., Roitman, M. F., Lichtman, A. H., \& Cheer, J. F. (2012). 
Endocannabinoids shape accumbal encoding of cue-motivated behaviour via CB-1 receptor activation in the ventral tegmentum. Neuron, 73(2): 360-373.

Ollmann, M. M., Wilson, B. D., Yang, Y., Kerns, J. A., Chen, Y., Gantz, I., \& Barsh, G. S. (1997). Antagonism of central melanocortin receptors in vitro and in vivo by agouti-related protein. Science, 278: 135-138.

Omelchenko, N., \& Sesack, S. R. (2009). Ultrastructural analysis of local collateral of rat ventral tegmental area neurons: GABA phenotype and synapses onto dopamine and GABA cells. Synapse, 63 (10): 895-906.

Patel, A. D., Stanley, S, A., Murphy, K. G., Frost, G. S., Gardiner, J. V., Kent, A. S., White, N. E., Ghatei, M. A., \& Bloom, S. R. (2006). Ghrelin stimulates insulin-induced glucose uptake in adipocytes. Regulatory Peptides, 134: 17-22.

Patterson, Z., Ducharme, R., Anisman, H., \& Abizaid, A. (2010). Altered metabolic and neurochemical responses to chronic unpredictable stressors in ghrelin receptordeficient mice. European Journal of Neuroscience, 32: 632-639.

Patterson, Z., Khazall, R., Mackay, H., Anisman, H., \& Abizaid, A. Central ghrelin signalling mediates the metabolic reponse of $\mathrm{C} 57 \mathrm{BL} / 6$ male mice to chronic social defeat stress. Endocrinology, 154: 1080-1091.

Patton, D.F., \& Mistlberger, R. E. (2013). Circadian adaptations to meal timing: neuroendocrine mechanisms. Frontiers of Neuroscience, 7(185): 1-14.

Perello, M., Sakata, I., Birnbaum, S., Chuang, J. C., Osborne-Lawrence, S., Rovinsky, S. A., Woloszyn, J., Yanagisawa, M., Lutter, M., \& Zigman, J. M. (2010). Ghrelin increases the rewarding value of high-fat diet in an orexin-dependent manner. Biological Psychiatry, 67: 880-886.

Perello, M., \& Zigman, J. M. (2012). The role of ghrelin in reward-based eating. Biological Psychiatry, 72(5): 347-353.

Perio, A., Barnouin, M. C., Poncelet, M., \& Soubrie, P. (2001). Activity of SR141716 on postreinforcement pauses in operant responding for sucrose reward in rats. Behavioural Pharmacology, 12: 641-645.

Pertwee, R. G. (1997). Pharmacology of cannabinoid $\mathrm{CB}_{1}$ and $\mathrm{CB}_{2}$ receptors. Pharmacological Therapies, 74(2): 129-180.

Phillipson, O. T. (1979). A Golgi study of the ventral tegmental area of Tsai and interfascicular nucleus in the rat. Journal of Comparative Neurology, 187: 99-115. 
Poncelet, M., Maruani, J., Calassi, R., \& Soubrie, P. (2003). Overeating, alcohol and sucrose consumption decrease in CB1 receptor deleted mice. Neuroscience Letters, 343: 216218.

Proto, M. C., Gazzerro, P., Di Croce, L., Santoro, A., Malfitano, A. M., Pisanti, S., Laezza, C., \& Bifulco, M. (2012). Interaction of endocannabinoid system and steroid hormones in the control of colon cancer cell growth. Journal of Cell Physiology, 227(1): 250-258.

Rinaldi-Carmona, M., Barth, F., Heaulme, M., Shire, D., Calandra, B., Congy, C., Martinez, S., Maruani, J., Neliat, G., Caput, D., Ferrara, P., Soubrie, P., Breliere, J. C., \& Le Fur, G. (1994). SR141716A, a potent and selective antagonist of the brain cannabinoid receptor. FEBS Letters, 350: 240-244.

Romero, J., Hillard, C. J., Calero, M., \& Rabano, A. (2002). Fatty acid amide hydrolase localization in the human central nervous system: an immunohistochemical study. Molecular Brain Research, 100: 85-93.

Sahm, U.G., Qarawi, M, A., Olivier, G. W., Ahmed, A. R., Branch, S. K., Moss, S. H., \& Pouton, C. W. (1994). The melanocortin (MC3) receptor from rat hypothalamus: photoaffinity labeling and binding of alanine substituted $\alpha-\mathrm{MSH}$ analogues. FEBS Letters, 350: 29-32.

Sam, A. H., Troke, R. C., Tan, T. M., \& Bewick G. A. (2012). The role of the gut/brain axis in modulating food intake. Neuropharmacology, 63: 46-56.

Sanchez-Lasheras, C., Konner, A. C., \& Bruning, J. C. (2010). Integrative neurobiology of energy homeostasis- neurocircuits, signals and mediators. Frontiers in Neuroendocrinology, 31: 4-15.

Sanchis-Segura, C., Cline, B., Marsicano, G., Lutz, B., \& Spanagel, R. (2004). Reduced sensitivity to reward in CB1 knockout mice. Psychopharmacology, 176: 223-232.

Saper, C. B., Chou, T. C., \& Elmquist, J. K. (2002). The need to feed: homeostatic and hedonic control of eating. Neuron, 36:199-211.

Sarvari, M., Kocsis, P., Deli, L., Gajari, D., David, S., Pozsgay, Z., Hegedus, N., Tihanyi, K., \& Liposits, Z. Ghrelin modulates the fMRI BOLD response of homeostatic and hedonic brain centers regulating energy balance in the rat. PLOS ONE, 9(5): e97651.

Schellekens, H., Dinan, T, G., \& Cryan, J.F. (2013). Taking two to tango: a role for ghrelin receptor heterodimerization in stress and reward. Frontiers in Neuroscience, 148 (7): 118. 
Schellekens, H., Finger, B. C., Dinan, T. G., \& Cryan, J. F. (2012). Ghrelin signalling and obesity: at the interface of stress, mood and food reward. Pharmacology \& Therapeutics, 135: 316326.

Schllcker, E., \& Kathmann, M. (2001). Modulation of transmitter release via presynaptic cannabinoid receptors. Trends in Pharamacological Sciences, 22(11): 565-563.

Shimbara, T., Mondal, M. S., Kawagoe, T., Toshinai, K., Koda, S., Yamaguchi, H., Date, Y., \& Nakazato, M. (2004). Central administration of ghrelin preferentially enhances fat ingestion. Neuroscience Letters, 369:75-79.

Simiand, J., Keane, M., Keane, P., \& Soubrie, P. (1998). SR 141716, a CB1 cannabinoid receptor antagonist, selectively reduces sweet food intake in marmoset. Behavioural Pharmacology, 9: 179-181.

Sinnayah, P., Jobst, E. E., Rathner, J. A., Caldera-Siu, A. D., Tonelli-Lemos, L., Eusterbrock, A. J., Enriori, P. J., Pothos, E. N., Grove, K. L., \& Cowley, M. A. (2008). Feeding induced by cannabinoids is mediated independently of the melanocortin system. PLOS ONE, 3(5): e2202.

Solinas, M., \& Goldberg, S. R. (2005). Motivational effects of cannabinoids and opioids on food reinforcement depend on simultaneous activation of cannabinoid and opioid systems. Neuropsychopharmacology, 30: 2035-2045.

Solinas, M., Justinova, Z., Goldberg, S. R., \& Tanda, G. (2006). Anandamide administration alone and after inhibition of fatty acid amide hydrolase (FAAH) increases dopamine levels in the nuclear accumbens shell in rats. Journal of Neurochemistry, 98: 408-419.

Stanley, B.G., \& Leibowitz, S. F. (1984). Neuropeptide Y: stimulation of feeding and drinking by injection into the paraventricular nucleus. Life Science 35: 2635-2642.

Steffensen, S. C., Svingos, A. L., Pickel, V. M., \& Henriksen, S. J. (1998). Electrophysiological characterization of GABAergic neurons in the ventral tegmental area. Journal of Neuroscience, 18: 8003-8015.

Sugita, S., Johnson, S.W., \& North, R.A. (1992). Synaptic inputs to $G_{A B A}$ and $G_{A B} A_{B}$ receptors originate from discrete afferent neurons. Neuroscience Letters, 134: 207-211.

Sugiura, T., Kondo, S., Sukagawa, A., Nakane, S., Shinoda, A., Itoh, K., Yamashita, A., \& Waku, K. (1995). 2-Arachidonoylglycerol: a possible endogenous cannabinoid receptor ligand in brain. Biochemical and Biophysical Research Communication, 215: 89-97.

Sun, Y., Asnicar, M., \& Smith, R. G. (2007). Central and peripheral roles of ghrelin on glucose homeostasis. Neuroendocrinology, 863: 215-228. 
Suzuki, K., Jayasena, C. N., \& Bloom, S. R. (2012). Obesity and appetite control. Experimental Diabetes Research, SS: 1-19.

Szabo, B., Siemes, S., \& Wallmichrath, I., 2002. Inhibition of GABAergic neurotransmission in the ventral tegmental area by cannabinoids. European Journal of Neuroscience, 15: 20572061.

Tanaka, M., Hayashida, Y., Nakao, N., Nakai, N., \& Nakashima, K. (2001). Testis-specific and developmentally induced expression of a ghrelin gene-derived transcript that encodes a novel polypeptide in the mouse. Biochimica et Biophysica Acta, 1522: 62-65.

Tart, C. (1970). Marijuana intoxication: Common experiences. Nature, 226: 701-704.

Theander-Carrillo, C., Wiedmer, P., Cettour-Rose, P., Nogueiras, R., Perez-Tilve, D., Pfluger, P., Castaneda, T. R., Muzzin, P., Schurmann, A., Szanto, I., Tschop, M. H., \& RohnerJeanrenaud, F. (2006). Ghrelin action in the brain controls adipocyte metabolism. Journal of Clinical Investigations, 116(7): 1983-1993.

Tong, Q., Ye, C. P., Jones, J. E., Elmquist, J. K., \& Lowell, B. B. (2008). Synaptic release of GABA by AgRP neurons is required for normal regulation of energy balance. Nature Neuroscience, 11(9): 998-1000.

Tschop, M., Smiley, D. L., \& Heiman, M. L. (2000). Ghrelin induces adiposity in rodents. Nature, 407(6806): 908-913.

Tucci, S. A., Rogers, E. K., Korbonits, M., \& Kirkham, T. C. (2004). The cannabinoid $\mathrm{CB}_{1}$ receptor antagonist SR141716 blocks the orexigenic effects of intrahypothalamic ghrelin. Pharmacology, 143: 520-523.

Turu, G., \& Hunyady, L. (2010). Signal transduction of the $\mathrm{CB}_{1}$ cannabinoid receptor. Journal of Molecular Endocrinology, 44: 75-85.

Van Brocktaele, E. J. \& Pickle, V. M. (1995). GABA-containing neurons in the ventral tegmental area project to the nucleus accumbens in rat brain. Brain Research, 682: 215-221.

Vandevoorde, S., \& Lambert, D. M. (2007). The multiple pathways of endocannabinoid metabolism: a zoom out. Chemistry and Biodiversity, 4: 1858-1881.

Van Zessen, R., van der Plasse, G., \& Adan, A. H. (2012). Contribution of the mesolimbic dopamine system in mediating the effects of leptin and ghrelin on feeding. Proceedings of the Nutrition Society, 71: 435-445. 
Verhulst, P. J., Janssen, S., Tack, J., \& Depoortere, I. (2012). Role of the AMP-activated protein kinase (AMPK) signaling pathway in the orexigenic effects of endogenous ghrelin. Regulatory Peptides, 173(1-3): 27-35.

Viveros, M. P., Rodriguez de Fonseca, F., Bermudez-Silva, F. J., \& McPartland, J. M. (2008). Critical role of the endocannabinoid system in the regulation of food Intake and energy metabolism, with phylogenetic, developmental, and pathophysiological implications. Endocrine Metabolism Immune Disorder Drug Targets, 8(3): 220-230.

Volante, M., Allia, E., Gugliotta, P., Funaro, A., Broglio, F., Deghenghi, R., Muccioli, G., Ghigo, E., \& Papotti, M. (2002). Expression of ghrelin and of the GH secretagogue receptor by pancreatic islet cells and related endocrine tumors. Journal of Clinical \& Endocrinology Metabolism, 87: 1300-1308.

Walaas, I., \& Fonnum, F., (1980). Biochemical evidence for gammaaminobutyrate containing fibres from the nucleus accumbens to the substantia nigra and ventral tegmental area in the rat. Neuroscience, 5:63-72.

Weinburg, Z. Y., Nicholson, M. L., \& Currie, P. J. (2011). 6-Hydroxydopamine lesions of the ventral tegmental area suppress ghrelin's ability to elicit food-reinforced behavior. Neuroscience Letters, 499 (2): 70-73.

White, F. J. (1996). Synaptic regulation of mesocorticolimbic dopamine neurons. Annual Review of Neuroscience, 19: 405-436.

Williams, C. M., \& Kirkham, T. C. (1999). Anandamide induces overeating: Mediation by central cannabinoid (CB1) receptors. Psychopharmacology, 143: 315-317.

Williams, C. M., \& Kirkham, T. C. (2002a). Observational analysis of feeding induced by $\Delta^{9}$-THC and anandamide. Physiology and Behaviour, 76:241-250.

Williams, C. M., \& Kirkham, T.C. (2002b). Reversal of delta 9-THC hyperphagia by SR141716 and naloxone but not dexfenfluramine. Pharmacology Biochemistry \& Behaviour, 71: 333340.

Wilson, R. I., \& Nicoll, R. A. (2001). Endogenous cannabinoids mediate retrograde signalling at hippocampal synapses. Nature, 410: 588-592.

Wise, R. A. \& Bozarth, M. A. (1984). Brain reward circuitry: four circuit elements 'wired in apparent series. Brain Research Bulletin, 12: 203-208.

World Health Organization. (2013). Obesity and overweight: fact sheet 311. World Health Organization Media Centre. Retrieved on October 18, 2013, from http://www.who.int/mediacentre/factsheets/fs311/en/ 
Wren, A. M., Seal, L. J., Cohen, M. A., Brynes, A. E., Frost, G. S., Murphy, K. G., Dhillo,W. S., Ghatei, M. A., \& Bloom, S. R. (2001a). Ghrelin enhances appetite and increases food intake in humans. Journal of Clinical Endocrinology and Metabolism, 86(12): 5992.

Wren, A. M., Small, C. J., Abbott. C. R., Dhillo, W. S., Seal, L. J., Cohen, M. A., Batterham, R. L., Taheri, S., Stanley, S. A., Ghatei, M. A., \& Bloom, S. R. (2001b). Ghrelin causes hyperphagia and obesity in rats. Diabetes, 50(11): 2542540-2542547.

Zigman, J. M., Jones, J, E., Lee, C, E., Saper, C, B., \& Elmquist, J. K. (2006). Expression of ghrelin receptor mRNA in the rat and the mouse brain. Journal of Comparative Neurology, 494: 528-548.

Zhang, L. Gamo, Y., Sinclair, R., Mitchell, S. E., Morgan, D. G., Clapham, J. C., \& Speakman, J. R. (2012). Effects of chronic oral rimonabant administration on energy budgets of dietinduced obese C57BL/6 mice. Integrative Physiology, (20)5: 954-962.

Zhuang, S., Kittler, J., Grigorenko, E. V., Kirby, M. T., Sim, L. J., \& Hampson, R. E. (1998). Effects of long- term exposure to delta9-THC on expression of cannabinoid receptor (CB1) mRNA in different rat brain regions. Molecular Brain Research, 62: 141-149. 